Florida International University FIU Digital Commons

3-20-1996

\title{
The effects of social skills training on the writing skills of middle school students with learning disabilities
}

Margaret Fahringer

Florida International University

DOI: $10.25148 /$ etd.FI15101333

Follow this and additional works at: https://digitalcommons.fiu.edu/etd

Part of the Special Education and Teaching Commons

\section{Recommended Citation}

Fahringer, Margaret, "The effects of social skills training on the writing skills of middle school students with learning disabilities" (1996). FIU Electronic Theses and Dissertations. 3405.

https://digitalcommons.fiu.edu/etd/3405

This work is brought to you for free and open access by the University Graduate School at FIU Digital Commons. It has been accepted for inclusion in FIU Electronic Theses and Dissertations by an authorized administrator of FIU Digital Commons. For more information, please contact dcc@fiu.edu. 


\section{FLORIDA INTERNATIONAL UNIVERSITY}

Miami, Florida

THE EFFECTS OF SOCIAL SKILLS TRAINING ON THE WRITING SKILLS OF MIDDLE SCHOOL STUDENTS WITH LEARNING DISABILITIES

A dissertation submitted in partial satisfaction of the requirements for the degree

DOCTOR OF EDUCATION

IN

EXCEPTIONAL STUDENT EDUCATION

by

Margaret Fahringer

1996 
To: Dean I. Ira Goldenberg College of Education

This dissertation, written by Margaret Fahringer, and entitled THE EFFECTS OF SOCIAL SKILLS TRAINING ON THE WRITING SKILLS OF MIDDLE SCHOOL STUDENTS WITH LEARNING DISABILITIES, having been approved in respect to style and intellectual content, is referred to you for judgment.

We have read this dissertation and recommend that it be approved.

Patricia M. Barbetta

Marisal Reyłs-Gaviłąn

Michael P. Brady, Major Professor

Date of Defense: March 20, 1996

This dissertation of Margaret Fahringer is approved.

Dean If Ira Goldenberg

College of Education

Dr. Kichard L. Campbell

Dean of Graduate Studies

Florida International University, 1996 
COPYRIGHT 으 Margaret Fahringer 1996

All Rights Reserved 


\section{DEDICATION}

This dissertation is dedicated to my husband, Glenn and our sons, Alan and Justin. They gave me the support and inspiration that were necessary to complete this work.

This dissertation is also dedicated to my parents, Carmen Reyes Triana and Juan Ramon Triana. They supported me in my academic endeavors. They instilled in me the value of hard work and a good education. 


\section{ACKNOWLEDGMENTS}

Many people helped me with the completion of this dissertation. My major professor, Michael P. Brady, provided the impetus I needed throughout this work. The other members of my dissertation committee, Patricia M. Barbetta and Marisal ReyesGavilan provided me with focus and direction.

Paulette Johnson provided ongoing support for the statistical aspects of the study. Rosanne Gmuer provided invaluable assistance in the statistical aspects of the study and provided the necessary guidance in the analysis of data. Lorraine Gay helped me with the design.

Karen Fishman and Silvia Balsinde assisted me with data collection and provided me with the opportunity to use their classrooms in this dissertation. They most graciously allowed me to guide their lessons for an entire academic year. C. Melanie Green contributed her editorial expertise. I am grateful for everyone's support and guidance throughout this scholarly process. 


\author{
ABSTRACT OF THE DISSERTATION \\ The Effects Of Social Skills Training On The Writing Skills Of \\ Middle School Students With Learning Disabilities \\ by \\ Margaret Fahringer \\ Florida International University, 1996 \\ Miami, Florida \\ Professor Michael P. Brady, Major Professor
}

The purpose of the study was to determine if training in social skills in a classroom setting would lead to greater achievement in writing. Fifty-seven children in grades six through eight (ages 11-14) from a predominantly middle-class school in a largely urban school district in South Florida participated in this study. Participation in the study was limited to students who had been evaluated, met diagnostic criteria for learning disabilities and were placed in a learning disabilities language arts class.

Seven dependent variables were measured to evaluate the effects of social skills training (independent variable) on the writing skills of children with learning disabilities. The four writing variables were thematic maturity, syntactic maturity, fluency, and quality of expression. Three social skills measures were parent rating, student rating, and teacher rating of social skills behavior in the classroom. Three tests designed to measure changes in written language development and social skills acquisition and performance were used for pre-testing and post-testing. To assess the writing skills, two assessment instruments were selected: Test of Written Language-2 (TOWL-2) (Hammill \& Larsen, 1988) and the Woodcock Psychoeducational Battery Achievement and Supplemental Tests (Woodcock \& 
Johnson, 1990). To assess social skills, Social Skills Rating System (Gresham \& Elliott, 1990) was selected.

Areas of significant improvement in the writing measures were syntactic maturity and quality of expression in the experimental group. In the control group, syntactic maturity improved significantly more than in the experimental group. When pre and post test differences were examined for both groups, only syntactic maturity was significant. However, the gain score was greater for the control group than for the experimental group. The students' home language had a significant effect on syntactic maturity but not on any other variable. Thematic maturity approached significance and should be considered when practical applications are discussed.

Examination of the results of the social skills measures revealed that no significant differences were evident in any area. There were no significant effects on the parent, student or teacher rating measures either by the social skills training or the writing instruction. The home language of the students had no effect on the social skills measures. 


\section{TABLE OF CONTENTS}

CHAPTER

PAGE

I. INTRODUCTION $\ldots \ldots \ldots \ldots \ldots \ldots \ldots \ldots \ldots \ldots \ldots$

Statement of the Problem $\ldots \ldots \ldots \ldots \ldots \ldots \ldots \ldots$

Significance of the Study $\ldots \ldots \ldots \ldots \ldots \ldots \ldots \ldots$

Assumptions and Limitations $\ldots \ldots \ldots \ldots \ldots \ldots \ldots$

Definitions of Terms ........................ 9

II. REVIEW OF THE RELEVANT LITERATURE $\ldots \ldots \ldots \ldots \ldots \ldots$

The Writing Skills of Students with Learning Disabilities . . . . . . . 11

Instructional Strategies for Writing Skills $\ldots \ldots \ldots \ldots \ldots \ldots$

Social Competence of Children with Learning Disabilities $\ldots \ldots \ldots .18$

Acquisition Deficit or Performance Deficit $\ldots \ldots \ldots \ldots \ldots \ldots$

Social Skills Training $\ldots \ldots \ldots \ldots \ldots \ldots \ldots \ldots \ldots \ldots$

Social Skills and the Writing Process $\ldots \ldots \ldots \ldots \ldots \ldots \ldots$

Purpose of the Study $\ldots \ldots \ldots \ldots \ldots \ldots \ldots \ldots \ldots \ldots$

Research Questions . . . . . . . . . . . . . . . 28

Hypotheses . . . . . . . . . . . . . . . . . . . 29

III. METHODOLOGY . . . . . . . . . . . . . . . 30

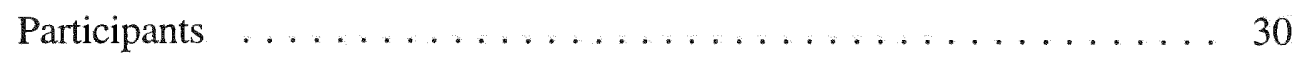

Instruments $\ldots \ldots \ldots \ldots \ldots \ldots \ldots \ldots \ldots \ldots \ldots \ldots \ldots \ldots \ldots$

Data Collection ...................... 37

Experimental Procedure $\ldots \ldots \ldots \ldots \ldots \ldots \ldots \ldots \ldots \ldots \ldots$

Treatment Integrity $\ldots \ldots \ldots \ldots \ldots \ldots \ldots \ldots \ldots . . . \ldots \ldots$

Writing Instruction Program $\ldots \ldots \ldots \ldots \ldots \ldots . \ldots . \ldots$ 
Social Skills Training Instructional Program . . . . . . . . . . . 46

Experimental Design and Analysis $\ldots \ldots \ldots \ldots \ldots \ldots \ldots$

IV. $\quad$ RESULTS . . . . . . . . . . . . . . . . . . . . . . . . . 48

Characteristics of the Sample $\ldots \ldots \ldots \ldots \ldots \ldots \ldots \ldots$

Writing Results $\ldots \ldots \ldots \ldots \ldots \ldots \ldots \ldots \ldots \ldots \ldots \ldots$

Social Skills Results . . . . . . . . . . . . . . . 58

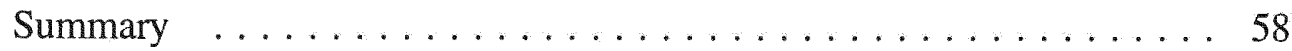

V. DISCUSSION ........................ 62

Summary of Findings $\ldots \ldots \ldots \ldots \ldots \ldots \ldots \ldots \ldots \ldots$

Practical Applications $\ldots \ldots \ldots \ldots \ldots \ldots \ldots \ldots \ldots \ldots \ldots \ldots$

Future Research $\ldots \ldots \ldots \ldots \ldots \ldots \ldots \ldots \ldots \ldots \ldots \ldots$

LIST OF REFERENCES . . . . . . . . . . . . . . . . . . . . 75

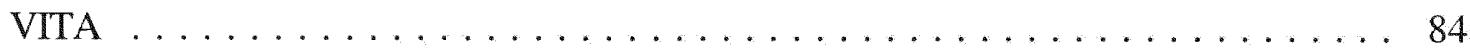

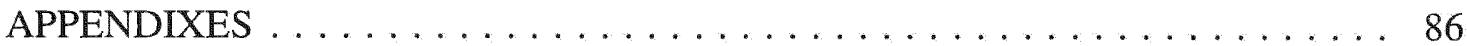




\section{LIST OF TABLES}

TABLE

PAGE

1 Summary of Writing Activities and Lesson Plans . . . . . . . . . . . 41

2 Race, Language, Gender, Grade and Lunch (SES) . . . . . . . . . . . . . . 49

3 T-tests for Age, IQ, Reading Level and Reading Percentile ............ 51

4 T-tests for Pre-test and Post-test Differences on Writing Measures . . . . . . . . . 54

5 T-test of Gain Scores on Writing Measures $\ldots \ldots \ldots \ldots \ldots \ldots$

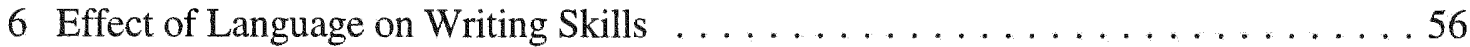

7 Test for Independent Social Skills Measures $\ldots \ldots \ldots \ldots \ldots \ldots$

8 Pre-test and Post-test Differences on Social Skills Measures . . . . . . . . . . . . . 59

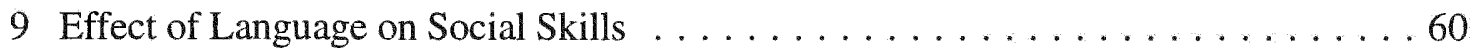




\section{LIST OF APPENDIXES}

APPENDIX

PAGE

A Dade County Approval Letter $\ldots \ldots \ldots \ldots \ldots \ldots \ldots \ldots \ldots \ldots \ldots \ldots$

B Parent Letter and Permission (English) $\ldots \ldots \ldots \ldots \ldots . \ldots \ldots$

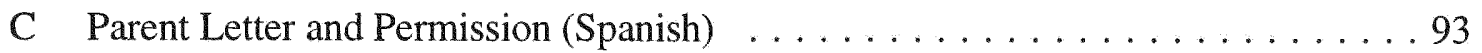

D Writing Prompts ................................ 97

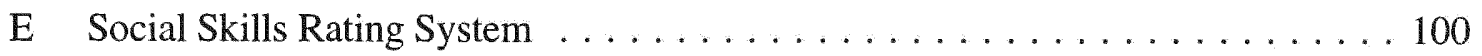

F Data Entry Sheet .......................... 111

G Process Writing Approach and Lesson Plan Topics $\ldots \ldots \ldots \ldots \ldots$

H Scope and Sequence of Writing Topics . . . . . . . . . . 115

I Sample of Student Tests . . . . . . . . . . . . . . . . . 117

J Instructional Model for Social Skills Instruction and Lesson Topics . . . . . . . 124

K Strategies for Social Skills Training $\ldots \ldots \ldots \ldots \ldots \ldots \ldots \ldots \ldots \ldots \ldots$ 


\section{CHAPTER I}

Introduction

A growing concern about the level of literacy in this country has prompted an increased emphasis on reading and writing skills in the curriculum (Franklin, 1992). This concern has been an important part of a larger movement directed at improving students performance on all basic skills, but it also reflects the importance of writing in contemporary society (Graham \& Harris, 1988). Writing serves many purposes. First, writing is a powerful tool for recording ideas and exploring thought. Second, it is also used as a common means of personal communication and as a way to fulfill emotional needs. Third, writing is a source of enjoyment and entertainment. Subsequently, the time allotted to writing instruction has increased within the general school curriculum and the quantity of writing expected of students has also increased (Graham, Harris, MacArthur, \& Schwartz, 1991).

Writing performance is increasingly included in state assessments of student academic performance such as the Florida Writes exam given in the fourth, eighth and eleventh grades. The importance attributed to writing is also evident at a national level. The Department of Education, through the National Center for Educational Statistics, prepared a 1990 portfolio study to explore new methods for collecting students' school-based writing (Gentile, 1992). The 1990 study revealed the types of writing used by students in grades four and eight. Of the total writing produced by children in grades four and eight, informative writing in grade four comprised $51 \%$ of the total writing and in grade eight $59 \%$. Thirty-six percent of the total writing in grade four, and $30 \%$ of the total writing in grade eight was narrative. The majority of writing in grades four and eight were either informative or narrative in style. The 1990 study also looked for evidence of process writing strategies in students' writing and it was evident in $38 \%$ of the writing of children in grade four and $43 \%$ of the writing of children in grade eight. In 1992, further interest in 
student writing was followed by the publication of Windows into the Classroom, A Writing Portfolio Study, which examined the writing of students across the country (Gentile, Martin-Rehrman, \& Kennedy, 1995).

Students receiving high school diplomas must be able to write clearly and in an organized manner. Experts in the field of writing recommend that students write frequently for authentic audiences and for real purposes (Graham \& Harris, 1988). Students need to write in supportive and collaborative environments. There has also been an increased emphasis on the processes of effective writing, the importance of the message over form, and the contribution of writing across the curriculum. Additionally, writing has become a critical occupational skill, as success in many occupations requires the ability to write clearly and understandably (Graham \& Harris, 1988).

In addition to the significance of written language in academic areas, writing skills have been recognized as critical elements in facilitating the communication of social and emotional feelings and needs by students with learning difficulties (Thomas, 1996). Writing skills can serve as an avenue for the communication of thoughts and ideas that some students with learning disabilities may otherwise be unwilling or unable to express.

As expected, these developments in writing in the curriculum have important implications for students with learning disabilities and their teachers (Newcomer \& Barenbaum, 1991). First, many students with learning disabilities spend part of their day in a mainstream school environment where they are asked to write coherently. This inclusion in regular classrooms demands that these students be equipped with specific skills so that they can independently use these strategies (Schumaker \& Deshler, 1995). Second, it is important that regular and special education teachers work collaboratively to insure that students with learning disabilities receive an effective writing program. Many special educators are only minimally involved in their students' writing program. Since many teachers focus primarily on skills in reading and math, writing instruction often does not receive the time and attention it merits. When special educators do include instruction in 
writing, they often concentrate on practicing skills in form or usage, such as grammar, handwriting and spelling (Graham, Harris, MacArthur, \& Schwartz, 1991). Since students with learning disabilities typically display poor writing performance, effective programs and strategies for improving writing performance are needed.

Research has shown that students with learning disabilities spend less than ten minutes a day engaged in composing (Graham \& Harris, 1988). Development of writing skills is accomplished by writing and ten minutes a day is an inadequate amount of time for many students. However, just having students write is inadequate and will not necessarily lead to improved writing performance (Graham, 1982). The development of good writing skills is promoted by motivation, a carefully and well-designed sequence of instruction, and practice and guidance in developing skills and strategies (Graham \& Harris, 1988). A well-designed writing program provides an atmosphere for building and shaping a writing community (Bos, 1988).

One aspect of fostering a writing community is creating an environment that facilitates listening, questioning, observing, and writing. Students need opportunities to listen to good writing if they are to understand the writing process. They need to ask questions related to their writing and others' writing and watch and think with others as they compose and write (Bos, 1988).

Another aspect of fostering a writing community is establishing an environment where students can take risks (Bos, 1988). Students read their work to get comments and responses by sharing their written work with peers and adults. Often, students with learning disabilities lack the social skills needed to benefit from peer and adult feedback (Graves, 1983). They may require instruction in social skills to participate effectively in the sharing element of the writing process.

Social skills training for students with learning disabilities may help their ability to function within a group. The ability to provide and receive responses from others successfully may encourage participation in the sharing and peer revision component of the 
writing process (Olson, 1990). In a study by Wong, Butler, Ficzere and Kuperis (1996) adolescents with learning disabilities were divided into pairs to collaboratively select topics or generate topics of their own. They were encouraged to negotiate with each other to reach a mutually acceptable topic. The students were taught to collaboratively use interactive dialogues to plan and revise essays. The quality of student writing improved and topic generation increased through the use of negotiation and peer revision.

Research has established that there is a significant difference between children with learning disabilities, non-learning disabled children and delinquent children in their level of ability of giving positive feedback to peers among adolescents (Schumaker, Bragg, Stephen, Sherman, \& Sheldon, 1982). Schumaker et al., (1982) found that students with learning disabilities were slightly better at supplying positive responses to peers than juvenile delinquents but significantly poorer at the task than students without learning disabilities. Students with learning disabilities who exhibit social skills deficits could be trained in social skills to prepare them for successful participation in classroom activities. A study by Campbell, Brady and Linehan (1991) explored the effects of peer-mediated instruction on the acquisition and generalization of written capitalization skills. Although this study targeted the mechanics of writing, it concluded that peers were effective in improving capitalization skills. For the intervention to be efficacious, however, it was necessary for those peers to interact well together showing appropriate use of pro-social skills to accomplish the task. Effective peer mediation helped students to produce a better piece of writing through the use of the writing process. By participating in the activities of the writing process, the writing skills of students with learning disabilities should improve. Training in social skills should help students with learning disabilities take part in those writing activities.

\section{Statement of the Problem}

Students with learning disabilities need to engage in writing activities to increase their writing skills. Skills needed to participate in those writing activities include the ability 
to share in the writing group and give responses to peers (Graves, 1983). Giving feedback is a component of social skills that many students with learning disabilities lack. This skill may be lacking in their behavioral repertoire because of a deficit in a nonverbal skill such as looking at the listener while talking or while engaged in the verbal behavior that typifies conversation (Nowacek, 1988). The focus of this study was to improve the social skills performance of students with learning disabilities in writing activities. By enhancing their social skills during writing activities, students might become motivated and reinforced to engage positively in those activities. Active and successful participation in writing activities could lead to greater achievement in writing skills.

The present investigation builds on writing skills and social skills literature about students with learning disabilities (Swanson \& Malone, 1992). A rationale for a social skills approach to teaching writing is developed from the literature on social skills deficits and the writing process approach (Nowacek, 1988; Bos, 1988). The interaction between pro-social skills and effective writing process activities will be explored to see if facilitating the social interaction skills of students in writing group activities will result in greater achievements in writing.

Significance of the Study

The importance of this study is twofold. First, interest in writing skills instruction and writing assessment in regular education has also influenced special education (Calkins, 1986). Procedures need to be developed that are designed to move assessment from simple summation statements into procedures for planning and evaluating instruction for special education students (Tindal \& Parker, 1991). Trends in the literature illustrate this focus on writing as shown by entire journals being devoted to writing instruction. A recent survey of the last ten years of academic intervention research with students with learning disabilities highly recommends a need for more research (Lessen, 1989). Further, it is recommended that this research focus on academic interventions for adolescents with learning disabilities 
and address the issues of generalization of new skills, maintenance of new skills, and length of intervention and follow-up (Lessen, 1989).

Second, interest and a focus on social skills training of children has been evident in the literature for the past twenty-five years. In the past ten years, there has been a focus on different approaches and research has revisited social skills acquisition and performance (Cartledge \& Milburn, 1986). Many programs and curricula have been developed to teach social skills to children (Conte, Andrews, Loomer, \& Hutton, 1995). A classroom intervention consisting of coaching, modeling, role-playing and information sharing was implemented over a six month period by a clinical psychologist in collaboration with classroom teachers. Participants in the experimental group demonstrated greater social acceptance and social skills when compared to the control group (Conte et al., 1995). However, the gap between social skills deficits of children with and without learning disabilities persists (Swanson \& Malone, 1992).

Cartledge and Milburn (1986) addressed specific social skills that predict achievement from one academic area to another. Training in these specific skills could produce an increase in academic achievement (Cartledge \& Milburn, 1986). There is some controversy in research circles about whether the most efficient focus for classroom behavior change efforts may be academic responses instead of social behavior. For some populations, improvement in academic achievement appears to lead to improved social skills, and improved social skills appear to lead to improvement in academic achievement (Cartledge \& Milburn, 1986). A reciprocal relationship appears to exist between curriculum, reinforcement of academic responses, and the development of relevant social behavior.

This study sought to address the need for intervention with adolescents with learning disabilities and analyzed the result of strategies for teaching social skills during academic instruction in the classroom. Social skills taught during academic instruction in the classroom were reinforced in the classroom. Since most of the child's day is spent in 
the classroom, generalization may occur in other classrooms and academic settings. Social skills taught in isolation as discrete skills or as part of a cluster of skills generally fades through lack of reinforcement. According to Hersen and Bellak (1977), the effectiveness of children's social interactions depends on the context and parameters of a situation. An individual possessing interaction skills, an accurate perception of a situation, and an awareness of when a particular set of behaviors will lead to positive outcomes will use this information to guide his social interactions (Cartledge \& Milburn, 1986). Through practice in a classroom setting during academic instruction, behavioral skills and the individual's perceptual abilities are trained and reinforced, and thus becomes part of a child's social repertoire.

A teaching strategy that can include social skills training in an academic program may promote generalization and maintenance. Social skills training may take place as direct instruction, but it must be reinforced during academic activities. A teacher may directly reinforce appropriate social skills as they are observed in the classroom. This is precisely the approach taken by educators who build writing instruction into children's social environments. This can strengthen an educator's ability to mainstream students because, while regular educators may not teach social skills, they will teach writing. Currently, in the area of writing, the focus is on the process. The whole language process approach focuses on the collaboration between writers and on writers and their audiences (Bos, 1988). Activities such as brainstorming, peer revision, and publishing employ the social skills of children as they interact in the writing process (Bos, 1988). By enhancing the social interaction skills of children in the writing activities, it is hoped that they will be motivated and reinforced to write, and to write more effectively (Stipek, 1988). A teaching strategy that will increase social skills and enhance writing achievement in adolescents with learning disabilities will be a worthwhile contribution to the field of learning disabilities (Pernia, 1987). 


\section{Assumptions and Limitations}

This study rests on at least six assumptions about the students who participated and the experimental procedures used.

\section{Assumptions}

1. All raters, students, parents and teachers can report their perceptions of social skills accurately (Gresham, Noell, \& Elliott, 1996).

2. The time allotted for this study is adequate to record changes both in social behaviors and writing skills (Boehnlein, 1995).

3. All important variables influencing the dependent variables have been controlled (Gay, 1996).

4. Social behavior is characterized by some degree of consistency (Ciechalski \& Schmidt, 1995).

5. Social skills can contribute to positive social interaction of adolescents (Ciechalski \& Schmidt, 1995).

6. Positive social interactions between adolescent peers during writing instruction and activities increase writing achievement (Hillocks, 1984).

This study also rests on at least three limitations of the students who participate in it and the experimental procedures used.

\section{$\underline{\text { Limitations }}$}

1. Due to practical restraints and the availability of youngsters who meet criteria for participation, students will not be randomly assigned to treatment groups.

2. Students already have some experience in the writing process.

3. Students are already assigned to a language arts class for children with learning disabilities through computer scheduling. 


\section{Definition of Terms}

social skills: socially accepted learned behaviors that enable the person to interact with others in a way that elicits positive responses and assists in avoiding negative responses from them

social skills training: a systematic method to improve social skills through observation, modeling, rehearsal, and feedback

writing: the comprehension and expression of thought through characters, letters or words writing skills: the skills needed to place thoughts on paper, including, but not limited to, preparation, organization, selection of vocabulary, development of sentences, use of punctuation and grammar, editing and revision

thematic maturity: the ability to write in a logical and organized fashion that will convey meaning

theme: topic or subject

fluency: writing for both speed and accuracy that requires use of syntax and automaticity syntax: the way words, word groups, phrases, and clauses are put together and connected to one another in sentences

quality of expression: written expression that requires generation of ideas, organization, task adherence and reasoning

writing process: a writing instruction strategy that focuses on planning, drafting, revising, editing, sharing and publication, and that stresses student-centered instruction modeling: providing small groups of trainees with a demonstration of the skills and behaviors we wish them to learn

role playing: behavioral rehearsal or practice for eventual real life use of the skill transfer of training: a variety of procedures used to encourage transfer of the newly learned behavior from the training setting to a real-life situation coaching: verbal instructions given to the child by an adult, followed by opportunity to practice, and, finally, a post-play review with the same adult 
cooperative learning interventions: small groups of students are rewarded for working together on a common task

prompting: an event happening before a target behavior that helps a child initiate a response reinforcing behavior: a consequence that results in an increase in frequency of another behavior or response. The behavior consequence can represent either the presentation of a positive reinforcer or the removal of a negative reinforcer. 


\section{CHAPTER II}

\section{Review Of The Relevant Literature}

This review will examine research on the writing skills and social skills of children with learning disabilities. Approaches to writing instruction with these children and social skills interventions will also be presented.

For this review, thematic maturity, syntactic maturity, fluency, and quality of expression in writing will be examined. These areas effect the writing skills of children. Consequently, these writing skills effect the general competency of writers and are the foundation of good writing.

Research on the social skills of children with learning disabilities is relatively recent, although early conceptualizations of learning disabilities did address this issue. In the study of social skills, it is necessary to review basic concepts and definitions of social skills. It is also important to discuss social competence, maintenance, and generalization of social skills.

This chapter is divided into four sections:

1. Writing skills of children with learning disabilities;

2. Writing programs that are effective with children who have learning disabilities;

3. Social competence of children with learning disabilities and;

4. Social skills training as a method of improving the writing skills of children with learning disabilities.

The Writing Skills of Students with Learning Disabilities

Research on the writing skills of children with learning disabilities. Students identified as learning disabled differ from low-achieving and high achieving students in their knowledge of strategies related to writing. They are less aware of steps in the writing process and ideas and procedures for organizing their written text (Grinnell, 1988).

Students with learning disabilities are also more dependent upon external clues, such as 
how much to write, teacher feedback, and mechanical presentation of the paper (Englert \& Raphael, 1988).

Children with problems in oral expressive language may also have disturbances in writing (Johnson \& Myklebust, 1967). Although Myklebust (1973) said that children with learning disabilities must be able to read before they can write, it is suggested that writing has a schema all its own. A child who is reading has to process a schema someone else has developed, whereas a child who is writing develops his own schema (Beach \& Bridwell, 1984). This is not to suggest that children with learning disabilities do not bring their reading difficulties to writing tasks. However, it is unrealistic to expect mastery of reading before attempting to write as both reading and writing should be parallel in their development.

When compared to children without disabilities, children classified as learning disabled write much shorter stories. Usually, these children write one-third to one-half fewer words in their stories. For both non-disabled children and children with learning disabilities, the greatest growth in writing occurs from nine to thirteen years, with a decline or plateau at fifteen years (Myklebust, 1973). A study by Nodine, Barenbaum, and Newcomer (1985) documented the lower productivity rates of students with learning disabilities compared with normally achieving peers. In a later study, they used the modes of writing and dictation to contrast student writing performance across three grade levels (third, fifth, and seventh). They also found that the mode used did not effect story production and that children with learning disabilities produced fewer stories (Newcomer, Barenbaum, Nodine, 1988).

Children with learning disabilities also write shorter stories as measured by total sentences and total words per sentence (Graham \& Harris, 1988). Although these children make gains in total sentence production at the same rate as average children from the age of nine, they performed at a level below average and never catch up. In words per sentence, 
however, children with learning disabilities, performing below average rates, are commensurate with average children on this factor of written language.

Children with learning disabilities are seriously deficient in language "structure" (Myklebust, 1973). These children often produce many errors in the correct use of tense, punctuation, word order, and other aspects of syntax. Myklebust suggested that deficiencies in syntax can be remediated, and that the ages of 11 through 15 , are the optimum for remediation.

Learning disabilities that express themselves in written form can be classified into three main types. One type is a disorder in visual-motor integration. Children with visualmotor integration problems can speak and read but cannot execute the motor patterns for writing. This problem is known as dysgraphia. The second main type is a deficit in revisualization. Children with revisualization problems recognize words and can read, however, they cannot revisualize words and thus are unable to write spontaneously or from dictation. The third main type is a deficiency in formulation and syntax. The child can copy and revisualize but cannot organize thoughts into the correct form for written communication. This child does not write the way he or she speaks, making errors in written formulation that are not made in speaking (Johnson \& Myklebust, 1967).

In the area of written formulation children with learning disabilities can have superior auditory language, adequate reading comprehension, and the ability to copy the printed word, yet often they cannot express ideas in writing (Espin \& Sindelar, 1988). One explanation for this phenomenon is found in the theories of Vygotsky. Vygotsky (1978) suggests that pure thought cannot be expressed because of what is lost in the translation from thought to symbol. It is possible that the expressive difficulties found in many students with learning disabilities represents a problem, from Vygotsky's perspective, in translation.

Disorders of formulation and syntax vary in severity and nature among children with learning disabilities. These children often have the greatest problems in ideation, 
productivity, and syntax. Children with a disturbance in ideation and production are limited in their output and use more concrete language (Englert \& Raphael, 1988). A problem with fluency, or the ability to translate ideas into sentences, is shown by children's inability to get started on a writing assignment (Reid, 1988). A child might say that there is nothing to say or that he or she does not know how to start the writing. These children usually can tell stories but cannot translate thoughts into written language.

A disturbance of written syntax may occur with problems in ideation or in isolation. The most frequent errors in syntax are word omissions, distorted word order, incorrect verb and pronoun usage, incorrect word endings, and lack of punctuation (Espin \& Sindelar, 1988).

A metacognitive problem area in writing is that students with learning disabilities have difficulty activating prior knowledge and sustaining their thinking about various topics. This results in early termination and redundancies when asked to complete comparison and contrast and descriptive writing tasks (Thomas, 1996). The compositions of students with learning disabilities also tended to be less organized and to contain fewer ideas than the compositions of nondisabled peers (Thomas, 1996).

Some children may have greater deficiencies in writing skills development than others (Grinnell, 1988). The most critical areas should be remediated first (Wansor, 1986). Using Gaskin's and Elliott's objectives, a hierarchy emerges: content, organization, effectiveness, and mechanics. Writing activities should be structured to address these deficiencies within the context of social writing (Wansor, 1986).

For this study, the Gaskin's and Elliott hierarchy is adapted to include four elements:

1. Thematic maturity;

2. Syntactic maturity;

3. Fluency and;

4. Quality of expression. 
Thematic maturity. Thematic maturity refers to the ability to write logically, coherently, and sequentially to produce a written product. The actual writing may be of different types, however, despite its content, the passage must be understood by a reader. The maturity of the product is usually evident if the writer uses definite introductions and endings, well-structured paragraphs, character development, dialogue, humor, or expresses some moral or philosophic theme or defends a position.

A product that is immature in its development of expression is often viewed as "sloppy" in the presentation of ideas, disjointed in thought sequence, lacking in theme, or simply difficult to understand. If a person does not write conceptually, effective written communication will be difficult.

Syntactic maturity. Syntax refers to the complexity of sentences. Skilled writers write longer and more complex sentences than unskilled writers. Children with learning disabilities show a markedly slower syntactic developmental trend than children without learning disabilities (Campbell, Brady, \& Linehan, 1991). While children experience periods of rapid growth in syntactic maturity, children with learning disabilities exhibit gradual control of syntax.

Fluency. Fluency is the number of words written. Fluency measures skill in formulating and writing sentences quickly and accurately. Fluency is also a measure of cognitive processing speed (Woodcock \& Mather, 1990). Fluency is influenced by the nature of the writer. As writing skills develop, the student can write more words in gradually longer sentences. Across different age levels and among both exceptional and average-achieving groups, studies have shown a significant correlation between fluency and other measures of writing skills. Many students with learning disabilities are deficient in fluency when compared with average achieving peers.

Quality of expression. Writing for quality of expression requires generation of ideas, organization, adherence to task, and reasoning. Beginning writers frequently lack strategies for generating or discarding ideas according to the constraints of the writing task 
and for constructing discourse that conforms to accepted text structure (Isaacson, 1988).

The degree of success which writers manage these cognitive processes are evidenced by the unity, coherence, and clarity of the final written product. Writers with learning disabilities have many of these same problems and lack the ability to generate ideas appropriate to the written task.

\section{Instructional Strategies for Writing Skills}

Disorders of written language may be remediated through various writing instruction approaches. First, children should be made aware of their errors in writing. Second, the child should write sentences and then listen as the teacher reads them aloud. Corrections should be made on paper, so that the child can see the exact position of the omitted word or the transposition of words within a sentence. Next, a child should monitor his or her own written material by reading it aloud. Finally, proofing exercises also help the child in recognizing written language errors (Johnson \& Myklebust, 1967).

Strategies to help in ideation and productivity include creating an atmosphere of freedom and acceptance. This environment will lend itself to spontaneous expression. Opportunities to brainstorm and freewrite will enhance the productivity of children with learning disabilities. Teachers should be accepting of a child's attempts to get ideas down on paper. Care should be taken to avoid the "red pencil" syndrome, and teachers should not be overly critical. Children should have an opportunity to complete their ideas before revision occurs. A strategy employed to increase fluency is oral discussion of experiences, ideas, and feelings. These auditory verbal expressions are then translated into written language.

The writing difficulties of children with learning disabilities has been presented with a focus on four areas of writing that have an impact on the quality of writing: thematic maturity, syntactic maturity, fluency and quality of expression.

Current literature applauds writing as a tool for learning and this understanding has inspired an approach that focuses on the process of putting one's thoughts on paper 
(Lucas, 1993). The process approach to writing involves many phases. Graves (1978) supports this process approach in composition and suggests three phases: (a) preparation, (b) implementation and (c) review. The preparation phase involves the writer's initial motivation to write, the selection of a topic and the formulation of an organizational strategy. The implementation phase is characterized by the selection of vocabulary, the development of sentences, and the use of punctuation and grammar rules. The physical act of writing or typing is included in this phase. The third phase involves editing and revision. This phase is most critical to the essence of the writing process. It is in this phase that the written product evolves and is refined (Graves, 1983).

The characteristics of the process approach in writing, as evidenced in the classroom, include: daily writing, student-selected topics, focus on what students know about their topics, group-sharing and peer editing sessions, opportunities to revise work, publication of student work, and writing conferences that target the skills and content reflected in students' paper (Englert \& Raphael, 1988).

Although many of these characteristics of writing activities parallel those of the product approach, the basic focus is different. When writing is viewed as a product, the major focus is on the results and less emphasis is placed on the process or development. When a process approach to writing is used, there is less fear of the mechanics of writing because the students are aware of writing as a way to convey ideas, not just as an exercise of rules and punctuation marks (Lucas, 1993).

The cooperative learning approach is not so much an approach to the writing process as it is a "framework" in which to place an instructional strategy for teaching writing. Cooperative learning strategies can raise the perceived value of academic achievement of students and encourage students to help and support classmates in their group (Slavin, 1990). Students working in groups to complete specified writing tasks create a positive climate for a good writing environment. Initial brainstorming activities can be carried out in groups to aid in the pre-writing phase in generation of ideas. Cooperative 
learning can be combined with the process approach as an effective strategy for writing instruction. Many writing activities can be implemented using cooperative strategies that enhance the social aspect of writing (Johnson \& Johnson, 1986). Factors such as determination of an audience and the purpose of the writing can be established with the assistance of group members (Hillocks, 1984). Also, students participating in cooperative learning activities during writing plan, revise, and edit written compositions in close collaboration with their peers ( Wood, Algozzine, \& Avett, 1993). However, it might be necessary to train peers to give constructive and specific feedback, and writers will need training and guidance in accepting feedback constructively (Whittaker \& Salend, 1991).

Cooperative learning strategies can also help in peer revision and writing conferences as students share their writing with their group and accept their ideas and revisions (Johnson, Johnson, \& Holubec, 1986). These activities also increase the ability to understand someone's perspective, help students develop trust and motivate them to complete assignments, so that they can share them with their group (Slavin, 1990; Espin \& Sindelar, 1988).

The next area to be examined is the social competence of children with learning disabilities and the issues that may contribute to poor academic performance. Studies will be presented in support of social skills training with children with learning disabilities. Social Competence of Children with Learning Disabilities

The social skills deficits of children with learning disabilities have been regarded as part of the general syndrome of learning disabilities (McIntosh, Vaughn, \& Zaragoza, 1991). There is disagreement on specific social skills deficits in this population, but there is considerably less disagreement about the presence of these deficits in children or adolescents with learning disabilities (Forness \& Kavale, 1991). There is strong empirical support for these social skills deficits (Farmer \& Farmer, 1996). Studies in this area have used direct observation, sociometric measures, videotaped interactions, teacher or parent questionnaires and self-concept measures. More recent research studies have investigated 
the social skills of this population partly because Public Law 94-142, and its reauthorizations in more recent years, emphasized educating handicapped children in the least restrictive environment (Gresham, 1982). Empirical studies suggest that children with learning disabilities act similarly to juvenile delinquents in role play situations, are generally less liked than their peers, participate in school activities at a low rate, and exhibit social problems that continue into adulthood (Schumaker \& Hazel, 1984). Higher dropout rates, mental health problems, and delinquency are related to these social problems of children with learning disabilities.

A study of the social interactions of adolescents with learning disabilities reported significantly higher frequencies of involvement in three social activities than normally achieving students: hanging around the neighborhood, hanging around with friends, and having friends over to their house (Schumaker, 1992). These findings suggest that the children with learning disabilities have a similar frequency of informal interactions with peers and spend more time "hanging out." In an observational study, Schumaker, Sherman and Sheldon-Wildgen documented the social behavior of adolescents with learning disabilities in a classroom setting (as cited in Schumaker, 1992). The finding was that students with learning disabilities talked to many different peers and spent $5 \%$ more time in interaction with their peers in the classroom. This finding may suggest the inability of children with learning disabilities to determine appropriate times and settings for their social interaction. This inability may demonstrate itself in inappropriate talking and classroom disruptions.

Results of a study conducted by the University of Kansas indicate that the quality of social performance by students with learning disabilities is different from their nonhandicapped peers (Schumaker et al., 1982). Students with learning disabilities perform fewer appropriate behaviors in complex social situations (Schumaker, 1992). Also, these students are less involved in formal social activities than their peers such as organized sports or school clubs. 
Research reveals that employment supervisors consider social competencies to be more important than specific job skills in obtaining and maintaining a job (Schloss, Schloss, Wood, \& Kiehl, 1986). Social skills affect work experiences and home and community environments. Incompetence in social skills results in job firings and unsatisfactory relationships in daily living activities (Mithaug, Martin, \& Agran, 1987).

Definition of social competence. The need for clarification of appropriate strategy training has been expressed as educators attempt to integrate theory and practice (de Bettencourt, 1987). Those in the field of exceptional education are currently evaluating the different theoretical perspectives as related to social skills competencies or social learning processes.

Social competence is demonstrated by socially acceptable learned behavior that enables a person to interact effectively with others and to avoid socially unacceptable responses (Gresham \& Elliott, 1990). Difficulties with social competence manifest themselves in an inability to judge one's impact on others, generalize from one situation to another, and interpret others' moods and communication, both verbal and nonverbal (Hazel, Schumaker, Sherman, \& Sheldon, 1984). Social competence is also seen as a composite of skills that includes: discriminating situations in which social behavior is appropriate, deciding which verbal and nonverbal social skills are appropriate for a given situation, performing those social skills fluently in appropriate combinations according to social mores, accurately perceiving the other person's verbal and nonverbal cues, and flexibly adjusting to this feedback (Schumaker \& Hazel, 1984). Deficits in social skills in children with learning disabilities seem to produce a considerable disability in an individual who is already hindered academically.

Children with learning disabilities often have difficulties with social-problem solving strategies. Social problem-solving is not normally the object of direct instruction in children (Kuhn \& Phelps, 1982). Instead, these strategies develop incidentally in many 
children, often because of general experience. These strategies may include metacognitive awareness of social situations and responses (Wellman, 1985).

A study conducted at the University of Kansas suggests that in children with learning disabilities, social competence may be more related to cognitive processing deficits than to general social skills deficits (Hazel et al., 1984). Thus, training programs which target children with learning disabilities may not need to be different from children without learning disabilities. Instruction in social skills in children with learning disabilities however, may need to be more intensive and deliberate (Mcintosh et al., 1991).

\section{Acquisition Deficit or Performance Deficit}

Social skills deficiencies can be delineated into four basic types. The type depends on the child's ability to perform the social skills in question, and the presence or absence of interfering cognitive, emotional, or behavioral responses (Gresham, 1988). This conceptualization is a modification and extension of Bandura's distinction between acquisition versus performance deficits.

The four types of social skills deficiencies are: (a) skill deficits, (b) performance deficits, (c) self-control skill deficits, and (d) self-control performance deficits. This classification system is a heuristic framework from which to understand social skills deficits.

Social behavior includes the response systems or response modes of cognitiveverbal behavior, physiological-emotional behavior, and overt-motoric behavior. One or a combination of these response systems can block the acquisition or performance of a social skill. For example, anxiety (emotional response) can prevent the learning or performance of a social skill. Aggressive behavior (overt-motoric) can prevent the acquisition or performance of a social skill. The identification of these interfering behaviors is important in the assessment of social skills deficiencies because competing responses must be controlled or eliminated before social behaviors can be taught (Walker, McConell, Holmes, Todis, Walker, \& Golden, 1983). 
Children with social skills deficits may not have the social skills in their repertoires or they may lack a critical step in the performance of a behavioral sequence. A child may not know how to cooperate with peers, work in groups, give a compliment, accept negative feedback or initiate a conversation. If the child has seldom been observed performing the behavior, it is likely a skill deficit. Social skills deficits often are the result of an absence of opportunities to learn the skill or of deficits in attentional or retentional processes involved in learning social behaviors through vicarious means (Bos \& Vaughn, 1991).

The idea of interfering responses is important to understanding self-control skill and performance deficits because it is assumed that these responses interfere with the acquisition and/or performance of social skills. Self-control is used here to refer to the higher probability of an interfering response than a socially skilled response.

A social performance deficit describes a child who can perform a given behavior, but does not perform the behavior at an acceptable level. Performance deficits can be a deficiency in the number of times a behavior is performed and may be related to lack of motivation, an absence of opportunities to perform behavior, or a miscue in social perception.

The self-control skill deficit applies to individuals who have not learned a social skill because of an interfering response that has prevented the acquisition of the skill. Interfering responses such as anxiety and aggression may prevent social skills acquisition. Anxiety prevents social approach behaviors to the extent that the child avoids social situations and, by that, reinforces social withdrawal or isolation. Children who are aggressive may be rejected and avoided by the peer group. This may result in the child not being exposed to models of appropriate social behavior.

Children with self-control performance deficits have specific social skills in their repertoires, but do not perform these skills at acceptable levels because of the presence of interfering responses. Two criteria are used to detect a self-control performance deficit: (a) presence of interfering response, and (b) the inconsistent performance of the skill. 
An example of a self-control performance deficit would be a child who is extremely impulsive. Impulsivity can be considered interfering behavior. An impulsive child may know how to interact appropriately with peers and teachers, but may do so infrequently because his or her impulsive style of responding is typically inappropriate.

\section{Social Skills Training}

Social skills training (SST) may be an effective strategy for changing the behavior of children with learning disabilities. A study by Ferre and Ferre (1991) showed the effectiveness of SST with third grade students with learning disabilities. After five weeks of SST all students showed improvements in peer acceptance, social skills, and general self-esteem. Social skills training is a strategy that may be implemented in various ways. A structured learning approach is presented by Goldstein as a method of skillstreaming the adolescent (Goldstein, Sprafkin, Gershaw, \& Klein, 1980). The skillstreaming provides guided practice in pro-social behaviors.

A study by Ciechalski and Schmidt (1995) involving fourth grade students resulted in promising effects of social skills training. The social skills component was taught once a week by the school counselor and included a social skills assessment to identify deficient skills. Skill deficits were addressed through individual and group counseling and social skills training sessions. The skills were taught through modeling, role-playing, and specific performance feedback. The students kept a people skill notebook that contained the steps needed to perform each social skill. The skills were also practiced as homework. The results indicated that the use of social skills training with students with learning disabilities positively affected their social interactions.

Researchers Rudolph and Luckner (1991) studied the effect of social skills training on college students with learning disabilities. The purpose of the study was to develop a social skills training support that would increase students' awareness of social situations and help them develop a behavioral repertoire of socially appropriate responses. The results of the study were positive. The students developed skills for interacting with their 
instructors and peers. The students reported that they felt they had a safe environment in which to practice their social skills and that they had learned to communicate more effectively with others and were more comfortable in handling social situations. The significance of this study is the value of social skills training at a higher education level demonstrating that social skills are skills that are not learned easily by students with learning disabilities through normal development.

Since social skills are not always developed by children with learning disabilities through normal development, social skills may need to be taught. These skills may be taught through social skills training (SST). Social skills training may be understood as a four-step process: (a) promoting skills acquisition, (b) enhancing skills performance, (c) removing interfering behavior, and (d) simplifying generalization. These steps are related to the type of social skills deficit, the presence or absence of interfering behavior, and the functional control of social behavior in specific situations (Gresham, 1988).

Modeling and coaching are two common ways in which social skills are acquired. These procedures are used to remediate social skills deficits that refer to the child not having the social skill or the child not knowing a particular step in the performance of a behavioral sequence.

For many children, modeling is one of the most effective and efficient ways of teaching social behavior (Gresham, 1988). Modeling is efficient because the component behavior of a particular social skill does not have to be taught using a time-consuming, shaping process. Modeling instruction presents the entire sequence of behavior involved in a particular social skill and teaches how specific behavior can be integrated into composite behavior.

Modeling may be in the form of videotape, live models, and verbal modeling (books, stories etc.). The most important aspects of learning through modeling are the observer's attention to the modeling stimulus, the observer's behavioral reproduction of the modeling sequence, and the environment of the modeled behavior. 
Coaching is direct verbal instruction that consists of three steps: (a) presentation of rules or standards for behavior, (b) behavioral rehearsal of the social skill, and (c) feedback on the behavioral performance (Gresham, 1988). The two techniques of coaching and modeling also lend themselves well to group instruction and are techniques that may be used in the classroom with success. Many commercial intervention programs for the remediation of social skills deficits employ these two techniques.

Maintenance of acquired skills. Once social skills behavior has been acquired and is readily performed it is necessary to maintain these skills and to generalize these skills to other settings and people. Social skills that do not occur outside the training setting or do not maintain over time are not functional in obtaining environmental reinforcers for individuals. To maximize the generalization of social skills it is necessary to take advantage of natural contingencies of reinforcement. By teaching behavior that is relevant and functional, maintenance is more readily achieved. For example, training social skills that enable a child to participate in small groups in a classroom can be reinforced each time small group activity takes place. Also, this positive peer group behavior will also be reinforced in other classrooms where the social skills training has not taken place. The generalization across settings will be useful for the child as he adapts to different peer groups and different teachers.

For generalization and maintenance to take place, it is also advisable to train loosely, use sufficient stimulus exemplars (vary ways of teaching the same response), and reinforce unprompted, generalized social behavior. It is also important to use common physical, social, and self-mediated stimuli to promote generalization.

Social Skills and the Writing Process

Social skills needed for positive peer interaction. As discussed, children with learning disabilities lack social competence. The resulting social interaction problems may exacerbate their academic problems (Reid, 1988). If children with learning disabilities are 
unable to interact effectively with their classmates and teachers, their school experiences may become quite negative (Ogilvy, 1994).

The framework for social competence used in this study identifies two factors that contribute to social competence: social cognition and social tactics. Social cognition is the ability to understand social interaction processes. Social cognition may involve a variety of cognitive processes such as perspective taking, empathy, and knowledge of social conventions of behavior. This knowledge base helps direct children's social behavior. Thus, there is an intimate relationship between social cognition and social behavior.

Problems interacting with classmates may result in classroom disruptions that lead to a negative and hostile classroom climate. During both individual and group activities, a variety of social interaction skills are needed. Students must learn to initiate and respond to social exchanges, cooperate with peers, take turns, listen to others, handle materials appropriately, share ideas, respect others' feelings and be receptive to negative and positive feedback from others. Clearly, problems in task-related peer interactions can significantly limit production.

When confronted with students who exhibit social interaction problems, teachers need to consider four potential sources of student social behavior. First, opportunities for peer interaction may be infrequent or inappropriately structured. Students may not have received adequate instruction or guided practice in social behavior. For students with social skills deficits, teachers need to provide opportunities for peer interaction rather than limit peer interaction opportunities. Planning for short, well-structured and motivating learning activities that include productive peer interactions will provide opportunities for students to practice positive peer interactions.

Social skills practice in the writing group. Social skills are needed if the child with learning disabilities is to participate appropriately in writing groups that include such activities as giving feedback to others on their writing, sharing their ideas in brainstorming exercises, conferencing with teachers and peers, and having empathy for others (Dale, 
1994). Appropriate skills such as taking turns, receiving negative feedback, and reacting to criticism and self-control is necessary if a risk-free and trusting writing climate is to be established.

Children with learning disabilities need to engage in writing activities to increase their writing skills. Social interaction skills are needed to participate in those writing activities. By enhancing the social skills of these students in writing activities, the students will be motivated and reinforced to engage positively in those activities.

Since writing ability is related to social cognitive ability, or the ability to make inferences about the characteristics and qualities of others, it is important to focus on this skill in addressing the audience (Rubin, 1984). Since writing is a social act involving communication between writer and reader and audience, one way to increase the ability to read one's writing from another's perspective is to interact with responding readers. This activity also helps students increase their ability to put themselves in another's place. Other writing activities that require good social skills include peer revision activities, sharing the writing, and publishing their written work. Many of these activities can be found in the process approach to writing.

\section{Purpose of the Study}

The purpose of the study was to determine if training in social skills would lead to greater achievement in writing. A major goal of the intervention was to improve writing achievement through pro-social skills training. This study explored the effects of social skills training on the writing skills of middle school students with learning disabilities. The focus in writing skills was on thematic maturity, syntactic maturity, fluency, and quality of expression.

Thematic maturity is related to the ability to organize and develop ideas. Children with learning disabilities have difficulties separating irrelevant information from relevant information when composing their writing to a theme or central idea. 
Children with learning disabilities also show a serious deficiency in language structure or syntax. They typically lack facility in correct use of tense, word order, and other aspects of syntax. There is a serious delay in acquiring basic knowledge of the syntactical relations among words in children with learning disabilities (Myklebust, 1973). Syntactic maturity was chosen as a focus because of this deficiency.

Fluency was selected as an area of focus because students with learning disabilities typically write shorter sentences and shorter stories than children without learning disabilities (Myklebust, 1973). Children with learning disabilities are markedly deficient in output of written language, suggesting a lack of fluency, and a laboriousness in the use of the written word (Myklebust, 1973).

Quality of expression in writing requires that a child generate ideas, organize, reason, and adhere to task. Since children with learning disabilities may be limited in their use of abstract meaning and have difficulties with organization and adherence to task, the area of quality of expression was selected for this study (Myklebust, 1973).

In this study, social skills training is the independent variable. The dependent variables are writing achievement in (a) thematic maturity, (b) syntactic maturity, (c) fluency, and (d) quality of expression. The second area is social skills acquisition and performance in a classroom setting. A control group received writing instruction but not the social skills training.

\section{$\underline{\text { Research Questions }}$}

Research questions that were developed from this review of literature are posed below.

1. What is the effect of social skills training on the thematic maturity, syntactic maturity, fluency, and quality of expression in the writing of middle school children with learning disabilities?

2. What is the effect of social skills training on the acquisition and performance of social behavior of middle school children with learning disabilities in a classroom setting? 


\section{Hypotheses}

Given these general research questions, two specific hypotheses were proposed.

1. Middle school students with learning disabilities who are instructed in social skills will show greater achievement in the writing areas of thematic maturity, syntactic maturity, fluency, and quality of expression than a control group receiving no instruction in pro-social skills.

2. Middle school students with learning disabilities who are instructed in social skills will demonstrate greater acquisition and performance of pro-social skills in a classroom setting than a control group receiving no instruction in pro-social skills. 


\section{CHAPTER III}

\section{Methodology}

\section{Participants}

Fifty-seven children in grades six through eight (ages 11-14) from a predominantly middle-class school in a largely urban school district in South Florida participated in this study. Participation in the study was limited to students who have been evaluated for and met diagnostic criteria for learning disabilities, and received language arts instruction in a class for students with learning disabilities. The district's criteria for identification and placement into services are consistent with state law and federal law. Parent permission slips and parent rating scales were sent to 125 students. Fifty-seven of the students returned parent permission and parent rating scales (both pre-test and post-test). Two groups of students were formed from the pool of students who received parental permission to participate in the study. Data were obtained from school records for each group regarding race, language, gender and grade. Other data on age, intellectual ability (IQ), reading level, and reading percentile were also obtained from school records (see Table 3 in the Results section). Socioeconomic data were obtained through qualification for the free and reduced lunch program.

There were 41 boys and 16 girls in the study. Twenty-eight students were white, 19 students were Hispanic, and nine students were African-American. The primary language of the Hispanic students was Spanish. All 19 Hispanic students were ESOL level five which indicates that the child is oral English proficient. Students were assigned to learning disabilities language arts classes by random computer scheduling. There were six language arts classes in the school, and students in all six language arts classes in the school participated in the study. Each class was assigned randomly to one of two groups: Group A (experimental group $=28$ ) received social skills training along with writing instruction. Group B (control group $=29$ ) received only writing instruction. There were three classes in each condition. 
There were two teachers in the study. Teacher A had five classes involved in the study. Three classes of Teacher A were in the experimental group and two classes were in the control group. Teacher B had one class in the control group.

An evaluation was made to determine whether the random assignment resulted in an equivalent distribution of students' IQ and reading scores. For this evaluation, intelligence scores (WISC-R) and reading scores were compared using an analysis of variance (ANOVA) to determine if there were any significant differences between the experimental and control groups. There were no significant differences in these measures (see Table 3 in the Results section).

Students whose first language was not English were included in the study but their scores were also analyzed separately to note differences between them and children whose first language was English. Results are reported separately.

In conclusion, the students participating in the study were middle school students in grades six, seven, and eight and identified as learning disabled. Educational programming of these students consisted of two components: special education classes and mainstreamed regular classes.

This study was reviewed by Dade County Public Schools to determine feasibility of study in a school setting and value of study to educational research. Permission was given to conduct study through the office of Educational Accountability Research Review Committee (Appendix A). All students had signed permission forms approved by Florida International University and Dade County Public Schools (Appendix B \& C). Instruments

Seven dependent variables were used to measure the effect of social skills training on the writing skills of children with learning disabilities. The four writing variables were thematic maturity, syntactic maturity, fluency, and quality of expression. To assess the writing skills, two assessment instruments were selected: the Test of Written Language-2 (TOWL-2) (Hammill \& Larsen, 1988) and the Woodcock Psychoeducational Battery 
Achievement and Supplemental Tests (Woodcock \& Johnson, 1990). Three social skills measures used were parent rating, student rating, and teacher rating of social skills behaviors in the classroom (Hauger \& Vaughn, 1995). To assess social skills, Social Skills Rating System (Gresham \& Elliott, 1990) was selected.

Test of Written Language- 2 . The Test of Written Language was administered as a measure of written language development. The administration time is 20 minutes. The TOWL-2 consists of ten subtest but only two subtests were used in this study. These are thematic maturity and syntactic maturity. These two subtests are in a spontaneous format that measures the product of a 15 minute writing sample with a visual prompt (Appendix D).

A description of the subtests of the TOWL-2 follows:

Subtest 6. Thematic maturity: Student writes a story in response to one of two stimulus pictures. Points are earned for each instance in which a student mentions a predetermined element in the story's content (for example, paragraph usage, naming objects depicted in the stimulus, definite story ending, presence of a moral or philosophic theme, and so forth).

Subtest 8 . Syntactic maturity: The syntactic maturity score is computed by tallying the number of grammatically correct words in the composition. Spelling and punctuation are not counted as grammatical errors.

The TOWL-2 norms provide both percentile ranks and standard scores for students in grades two through 12. The TOWL- 2 was administered between March and December of 1987 to a sample of 2,216 students living in nineteen states. The TOWL-2 is available as a measure of internal consistency and test-retest stability. The internal consistency estimates depend on the average correlation among items.

The internal consistency coefficients, standard error of measurement and test-retest stability reliability for the TOWL-2 subtests are reported as: 

1). thematic maturity: .78 and 2 SEM
$r=.90$
2). syntactic maturity: .95 and 1 SEM
$r=.77$

Thematic maturity has adequate stability reliability and syntactic maturity has borderline stability. The test is found to have a sound theoretical basis and is said to offer the most structurally sound and instructionally relevant instrument currently available in the area of written language.

Construct validity of the TOWL-2 is available as eight basic constructs:

1. Abilities of writing are developmental in nature; therefore, performance on subtests should be related to age.

2. The abilities measured by the TOWL-2 subtests and composite are related to each other because they all measure some type of writing.

3. The TOWL-2 measures written language, so its results should differentiate between groups of people know to be average writers and groups of people known to be poor or good writers.

4. The contents of the TOWL-2 are taught in school, so test performance should correlate with grade level.

5. The items of each subtest measure similar traits so they should relate highly to the total score.

6. Since the TOWL-2 measures school performance, students who do well in writing should do well in other academic areas. The TOWL-2 should correlate with performance in reading, math, and total achievement.

7. Since writing is an intellectual activity, the scores on the test should relate to the IQ of the students.

8. The abilities measured by the TOWL-2 subtests relate to the theoretical basis for their development and will load on factors consistent with the underlying model. Criterion- referenced validity of the TOWL-2 (effectiveness of a test in predicting an individual's behavior in a specific situation) indicate $r=.62$. Criterion referenced validity 
coefficients among written language instruments rarely exceed .60 and are commonly in the .30 to .50 range. Therefore, the coefficient of the TOWL-2 $(r=.62)$ is considered acceptable.

The N (sample number) and SRA score for the two subtests are:

1. thematic maturity: $\quad \mathrm{N}=68 \quad \mathrm{SRA}=.49$

2. syntactic maturity: $\quad \mathrm{N}=68 \quad \mathrm{SRA}=.30$

Content validity (whether the test covers a representative sample of the behavior domain to be measured) is reported for the two TOWL-2 subtests as:

1. thematic maturity: $\quad r=.90$

2. syntactic maturity: $\quad \mathrm{r}=.77$

The Woodcock-Johnson Psychoeducational Battery-Revised (WJPB-R). The Woodcock-Johnson Psychoeducational Battery-Revised (WJPB-R) is a wide range comprehensive set of individually administered tests for measuring cognitive abilities, scholastic aptitudes, and achievement. Normative data are based on a single sample that was administered both cognitive and achievement tests. These tests were nationally standardized on 6,359 subjects, aged 24 months to 95 years of age.

Written expression on the WJPB-Revised is a combination of Writing Samples and Writing Fluency and provides a measure of written expression skills including the production of simple sentences with easy and increasingly complex sentences. The subtests used for this study include Writing Samples and Writing Fluency. Quality of expression was evaluated through the subtest Writing Samples. Fluency was evaluated through the subtest Writing Fluency.

Administration time for the Writing Samples subtest requires about 15 minutes. There is no time limit for this subtest. Writing Fluency requires seven minutes for administration and five minutes for instruction.

Writing Samples measures the student's skill in writing responses to a variety of demands. The student must phrase and present written sentences that are evaluated with 
respect to the quality of expression. The student is not penalized for errors in the basic mechanics of writing, such as spelling or punctuation.

Writing Fluency measures the student's skill in formulating simple sentences quickly. Each set must relate to a given stimulus picture and use a set of three words.

Since Writing Fluency is a timed test, the reported reliabilities for this section of the WJPB-Revised are test-retest correlations (which provide an underestimate of the test's internal consistency reliability). The test reliabilities and standard error of measurement for Writing Samples is $r=.93$ with a SEM of 5.80 . Writing Fluency has $r=.75$ and a SEM of 7.1

The concurrent validity correlation of the WJPB-R Achievement clusters with other commonly used measures of achievement in writing and reading at the approximate age of nine years old are reported as:

\begin{tabular}{|c|c|c|c|c|c|}
\hline 1. & K-TEA Reading & $N=70$ & WJP/WL= & .66 & WJP/Read= \\
\hline 2. & K-TEA Spelling & $\mathrm{N}=70$ & WJP/WL = & .68 & WJP/Read= \\
\hline 3. & PIAT-Reading & $N=70$ & WJP/WL= & .62 & WJP/Read= \\
\hline 4. & PIAT-Spelling & $N=70$ & WJP/WL = & .53 & WJP/Read $=$ \\
\hline 5. & WRAT-Reading & $N=70$ & WJP/WL = & .70 & WJP/Read= \\
\hline 6. & WRAT-Spelling & $\mathrm{N}=70$ & $\mathrm{WJP} / \mathrm{WL}=$ & .68 & WJP/Read $=$ \\
\hline
\end{tabular}

Social Skills Rating System. Social Skills Rating System (SSRS) (Gresham \& Elliott, 1990) provides a broad, multi-rater assessment of student social behaviors that can effect teacher-student relationships, peer acceptance, and academic performance. These standardized, norm-referenced scales may be used with pre-school, elementary, and secondary students. The SSRS documents the perceived frequency and importance of behaviors influencing the student's development of social competence and adaptive functioning at school and at home.

SSRS forms take a rater approximately 25 minutes to complete. Each component of the SSRS may be used separately or in combination. The SSRS components include three 
assessment forms (teacher, parent, and student versions) which elicit information about a student from the viewpoint of the respondent (Appendix E). All three respondents were used.

Features of the SSRS distinguish it from most other behavior rating scales and was an important factor in its selection for this study. First, the SSRS emphasizes positive social skills and includes a brief assessment of potential problem behaviors and academic competence. Second, national norms have been compiled on a diverse sample (multiracial, handicapped, male and female) of more than 4,000 children. Third, a coordinated, multirater approach may involve teachers, parents, and students. Fourth, an importance rating scale facilitates the selection of appropriate and valued target behaviors for intervention. Fifth, an integrative record form links assessment results and intervention planning which is useful in educational programming.

The SSRS teacher, parent, and student rating scales all include three social components: cooperation, assertion, and self-control. The SSRS parent version also assesses responsibility and the SSRS student version also measures empathy. Five subscales were developed to measure these components. These subscales are represented by the acronym CARES (cooperation, assertion, responsibility, empathy, and self-control).

The cooperation subscale includes behaviors, such as helping others, sharing materials, and complying with rules and directions. The assertion subscale includes initiating behaviors, such as asking others for information, introducing oneself, and responding to the actions of others. The responsibility subscale includes behaviors that demonstrate ability to communicate with adults and regard for property or work. The empathy subscale includes behaviors that show concern and respect for others' feelings and viewpoints. Finally, the self-control subscale includes behaviors that emerge in conflict situations, such as responding appropriately to teasing, and in non-conflict situations that require taking turns and compromising. 
The SSRS uses two types of ratings based on frequency and importance.

Frequency ratings reflect how often the events on a subscale occur. Importance ratings are defined as the importance of each behavior for classroom success.

Three methods were used to estimate the reliability of the SSRS: internal consistency (coefficient alpha), test-re-test, and inter-rater. The internal consistency total scale has .93 for the teacher, .90 for the parent and .83 for the student. The reliability of the inter-rater for test-retest for the total scale was teacher $\mathrm{r}=.88$, parent $\mathrm{r}=.87$ and student $\mathrm{r}=$ .68 .

Three criterion referenced validity studies investigated the relationship between the SSRS teacher form and other social rating scales.

1. Comparison to Social Behavior Assessment

- cooperation $r=-.72$

- assertion $r=-.48$

- self-control $r=-.51$

- total $r=-.68$

2. Comparison to Child Behavior Checklist

- assertion $\mathrm{r}=.37$

- responsibility $\mathrm{r}=.48$

- self-control $\mathrm{r}=.51$

- total $\mathrm{r}=.58$

3. Comparison to Piers-Harris Childrens' Self-Concept

- assertion $r=.25$

- self-control $\mathrm{r}=.12$

- empathy $r=.34$

- total $\mathrm{r}=.30$

\section{Data Collection}

All students were pre-tested in September 1993 and post-tested in May 1994 with the instruments described in the preceding section. All pre-test and post-test scores were documented on a data entry sheet for each student (Appendix F). Both groups were tested in a group classroom situation by their classroom teacher. Students were given the Writing 
Fluency and Writing Samples on one day, the TOWL-2 on the next day and the Social Skills Rating Form (Student) on the third day. For the Social Skills Rating Scale and the Woodcock-Johnson subtests (Writing Fluency and Writing Samples) the same test was both pre-test and post-test. The TOWL-2 has a Form A and Form B. Form A was administered as the pre-test and Form B as the post-test (Appendix I). Teachers were trained to administer the tests by following the script in the manuals of each test. Tests were collected by the teacher. Results were scored, evaluated, and recorded in a table form to indicate individual performance. Post-tests were given in May 1994 and the results were compared with the pre-test scores.

Information on each child's IQ level, age, ethnicity, and standardized test scores was taken from the child's school cumulative record. Reading level was taken from the Individualized Educational Plan for each child.

\section{Experimental Procedures}

Notification and parental permission. The students attended an introductory session during which the purpose of the study and expectations were explained. The study was presented as a motivating and unique learning opportunity and the students were encouraged to participate. Students were given an opportunity to decline if they felt hesitant or uninterested. None of the students declined. Since the writing instruction is a regular part of the ongoing instructional program, students who were not part of the study continued to receive instruction in language arts, but their test data is not included in this study.

The parents of the students were notified by letter of their child's willingness to participate in the study. Written parent permission was required to participate in the study. Parent ratings of social skills were obtained using the Social Skills Rating Scale for Parents (Gresham \& Elliott, 1990). Mothers completed parent forms in all but a few cases.

Plan of instruction and group differentiation. All students (Group A \& B) received writing instruction using the process method with the two language arts teachers. Both 
teachers (Teacher A and Teacher B ) followed the master lesson plans which use the process writing approach with small writing activity groups. Lessons followed specific topics and writing activities (Table 1).

Students in both groups received identical writing instruction. Lesson plans were used by both Teacher A and Teacher B to ensure that all students (Group A \& Group B) received an identical writing program. Assignment to experimental and control groups determined whether or not students received the experimental social skills training procedures. Specifically, Group A (experimental) received social skills instruction and writing instruction. The social skills training occurred immediately before the writing instruction three times a week and consisted of a formal social skill presented for the first ten minutes of that class period (Appendix J).

Group B (control) received no social skills instruction. This group received writing instruction only for the class period.

The control group, which consisted of three classes, received instruction from the same two teachers. Teacher A taught two classes and Teacher B taught one class. The experimental group, which consisted of three classes, received instruction only from Teacher A.

\section{Treatment Integrity}

An integral principle of intervention research, especially behaviorally based interventions, is the demonstration that changes in behavior are related to the manipulated change in the environment (Gresham, Gansle, Noell, Cohen, \& Rosenblum, 1993). Unless it can be demonstrated that changes in the dependent variable are a function of changes in the independent variable, the results of a given intervention may suffer from threats to internal and external validity.

Two strategies were used to increase the probability that the changes were a function of the independent variable (social skills training). Social skills training was implemented through a series of scripted lessons from The Social Skills Intervention Guide 
(Gresham, 1992). The script presented the steps that were to be followed. Prior to implementation of the study, Teacher A was trained to use the script. Lesson plans were provided to establish a scope and sequence of the skill topics. This researcher modeled three lessons for the first week. Teacher A implemented the remainder of the lessons by adhering to the script for the duration of the study (30 weeks).

The social skills lessons were monitored by this investigator through direct observation of Teacher A three times a week. Since Teacher A had three classes as the experimental group, this researcher varied the class observed. This direct observation was at random intervals to ensure that Teacher A implemented the lessons as prescribed to avoid "schedule compliance."

Treatment integrity was encouraged in two ways, but was not measured directly. First, the integrity of each social skills lesson (treatment component) across all the days of intervention was observed to establish that the teacher actually implemented the entire set of scripted lessons (component integrity). Second, to establish that a scripted lesson was followed each time it was delivered, this investigator observed Teacher A presenting the same lesson at different times. Direct observation consisted of this investigator's observation of Teacher A in her classroom conducting the prescribed social skills lessons.

Although the writing program was not the independent variable, an additional action was taken to increase the probability that the writing lessons would be conducted as prescribed. This investigator observed Teacher A conducting the writing lessons. On a weekly basis, Teacher A and this researcher reviewed the writing lesson plans. Teacher B was provided with the lesson plan topics and lesson plans. Observation of Teacher B was concerned with the implementation of the writing lesson plans on a random basis and occurred twice weekly.

\section{Writing Instructional Program}

This study adapts an approach that employs the process method of teaching writing with cooperative learning strategies as the basis for a holistic writing program. This 
approach provides students with the opportunity to use their experiences to write, uses a specific organization on which to base their writing (process phases), and provides an environment in which to share their writing. The general sequence of the writing instructional program consisted of three days per week of instruction in writing. This writing instruction consisted of a whole language process approach to the teaching of writing and specific skill instruction. The first topics included the introduction of the writing process and its component steps: prewriting, drafting, revision, editing and publishing.

Writing tasks included autobiographies, biographies, a how to article, fairy tales, poetry (limericks, haiku, free verse, cinquains and nursery rhymes) and short stories. The students also kept portfolios of their writing (Table 1).

Instruction in specific skills was contained in lessons on brainstorming, idea listing, mechanics of revision, editing exercises, capitalization, punctuation, and sequencing. Other skill lessons covered research skills, outlining, effective leads to a story, components of a fairy tale, adjectives, verbs, history of nursery rhymes, and focusing on a theme.

Both teachers shared lesson plans to increase the probability that all teachers would present the same material in the same manner to both groups of students. Master lesson plans were developed to ensure that all groups followed the same lesson plans for the writing instruction. Both teachers were coached in class, observed the other teacher, and also presented the same materials and topics. Teachers attended initial meetings to discuss how the writing units would be presented. The process writing approach was outlined and consisted of three phases: prewriting, composing and post writing. All writing activities followed this process (Appendix G). The scope and sequence was developed to outline the topics to be addressed. Activities for each scope were chosen (Appendix $\mathrm{H}$ ) for implementation (Table 1). 


\section{Table 1}

\section{Summary of Writing Activities and Lesson Plans}

Lesson \# Topic

1

Introduction of writing clustering, freewriting

3 Introduction of writing idea listing, brainstorming prewriting

$4 \quad$ Introduction of writing

5 Journal writing/guide

$6 \quad$ Intro-drafting

7 Intro-revision

8 Intro-revision

9 Intro- revision

10 Intro- editing

11 Intro- editing

12 Proofreading prewriting phase

oral composing, story prewriting

Skill

capitalization

personal experiences narration (storytelling)

questions to ask

mechanics of revision

peer conferences, role playing

teacher conferences portfolio**

editing exercises

using dictionary/thesaurus

editor's marks/editor checklist

author's chair/class magazine
Activity

prewrite: how you feel about writing (Brainstorming)

cluster: ideas on how you feel about writing

describe:how you feel about writing

present: Oral composition

idea list: future topics

freewrite

revise: given story

revise: a given story

decorate portfolios

computer editing*

share: idea listing

cluster: idea listing

computer editing* 


\begin{tabular}{|c|c|c|c|}
\hline Lesson \# & Topic & Skill & Activity \\
\hline 14 & $\begin{array}{l}\text { Narrative writing/ } \\
\text { autobiography }\end{array}$ & capitalization & prewrite: fact sheet \\
\hline 15 & Narrative writing/ & editing exercises/portfolio** & $\begin{array}{l}\text { first draft } \\
\text { autobiography }\end{array}$ \\
\hline 16 & $\begin{array}{l}\text { Narrative writing/ } \\
\text { autobiography }\end{array}$ & editing exercises & $\begin{array}{l}\text { revise, edit } \\
\text { peer conference }\end{array}$ \\
\hline 17 & $\begin{array}{l}\text { Narrative writing/ } \\
\text { autobiography }\end{array}$ & famous person study & publish \\
\hline 18 & Narrative writing/ & speaking in public & publish/presentation \\
\hline 19 & Narrative writing/ & creating a book & publish \& print \\
\hline 20 & $\begin{array}{l}\text { Narrative writing/ } \\
\text { biography }\end{array}$ & components of a biography & prewrite/fact sheet \\
\hline 21 & Narrative writing/ & how to research a biography & library research \\
\hline 22 & Narrative writing/ & subject-verb agreement & draft of biography \\
\hline 23 & Narrative writing/ & sequencing & revision of biography \\
\hline 24 & Narrative writing/ & outlining for non-fiction & $\begin{array}{l}\text { publish \& share } \\
\text { biography }\end{array}$ \\
\hline 25 & Giving directions & syntax & freewrite activity \\
\hline 26 & Giving directions & how to write how-to article & draft \\
\hline 27 & Giving directions & effective leads to stories & edit/revise/conference \\
\hline 28 & Giving directions & review of how-to article & publish/share \\
\hline
\end{tabular}

(table continues) 
Table 1 (continued)

\begin{tabular}{|c|c|c|c|}
\hline Lesson \# & Topic & Skill & Activity \\
\hline 29 & $\begin{array}{l}\text { Pattern stories } \\
\text { fairy tales }\end{array}$ & components of a fairy tale & brainstorm \\
\hline 30 & Pattern stories & $\begin{array}{l}\text { settings and adjectives } \\
\text { /portfolio** }\end{array}$ & draft, edit \\
\hline 31 & Pattern stories & plot & revise, conference \\
\hline 32 & Pattern & development of characters & publish/share \\
\hline 33 & Pattern stories & illustrations & publish/share \\
\hline 34 & Sharing opinions & what is a movie review? & prewrite \\
\hline 35 & $\begin{array}{l}\text { Sharing opinions } \\
\text { movie review }\end{array}$ & outlining for movie review & draft \\
\hline 36 & Sharing opinions & subject-verb agreement & $\begin{array}{l}\text { Edit, revise, } \\
\text { conference }\end{array}$ \\
\hline 37 & Sharing opinions & writing a conclusion & publish/share \\
\hline 38 & $\begin{array}{l}\text { Giving information } \\
\text { news report }\end{array}$ & components of a news report & prewrite \\
\hline 39 & Giving information & plagiarism & draft/revise \\
\hline 40 & Giving information & fiction/non-fiction & edit/publish \\
\hline 41 & Writing poetry & limericks & prewrite/draft \\
\hline 42 & Writing poetry & choosing titles & revise, edit, publish \\
\hline 43 & Writing poetry & Haiku formats & prewrite/draft \\
\hline 44 & Writing poetry & Japanese culture/poetry & revise, edit, publish \\
\hline
\end{tabular}

(table continues) 
Table 1 (continued)

Lesson \# Topic

45

46

$47 \quad$ Writing poetry

$48 \quad$ Writing poetry

$49 \quad$ Writing poetry

$50 \quad$ Writing poetry nursery rhymes

51 Writing poetry nursery rhymes

52. Writing poetry nursery rhymes

53 Creating stories science fiction

$54 \quad$ Creating stories

55 Creating stories

$56 \quad$ Creating stories

57 Creating stories

$58 \quad$ Creating stories

59. Creating stories

60
Skill

Activity

prewrite/draft

advertising and jingles

revise/edit/publish

free verse

prewrite/draft

free verse/choosing strong verbs revise/edit/publish

Cinquains

prewrite

history of nursery thymes

prewrite/draft

choosing colorful adjectives

revise/edit/publish

illustrating

publish

characteristics of stories

prewrite

cartooning

draft, revise

choosing titles

edit/publish

idioms

publish

myths \& legends:Greek

prewrite

myths/Native Am.

draft/ revise

settings

edit/publish

publish

Note. $* *$ review of portfolios * computer editing program 


\section{Social Skills Training Instructional Program}

The general sequence of the social skills training consisted of lessons from

Social Skills Intervention Guide (Gresham, 1992). Teacher A used these lessons to teach the identified social skills. The skills were:

- $\quad$ receiving criticism well

- $\quad$ making transitions from one activity to another

- $\quad$ paying attention to and following teacher instructions

- $\quad$ making positive self-statements

- $\quad$ volunteering to help peers with classroom tasks

- $\quad$ paying attention to a speaker

- $\quad$ responding to a compliment from a peer

- $\quad$ compromising in situations with peers and adults to reach agreement

- $\quad$ giving compliments to a peer

- $\quad$ saying nice things to others when they have done something nice

- $\quad$ accepting peers' suggestions for group activities

- $\quad$ joining ongoing groups or activities without prompting

- $\quad$ cooperating with others without prompting

These skills were chosen for their contribution to enabling students to participate in their group activities as part of their writing instruction. Lessons in social skills were presented before each day's lesson on writing. Social skills lessons were conducted for approximately ten minutes, three times a week. One skill per day was introduced until all skills were presented. After all 13 skills were presented, the teacher began to repeat the skills. Teacher A followed the guidelines for presenting social skills materials according to the Intervention Guide (Appendix J). These guidelines included using modeling, using behavior rehearsal, coaching and social problem solving (Appendix K). Teacher A also referred to the Intervention Guide for using peer-initiation strategies, reinforcement based 
strategies, group oriented contingency systems and positive practice. The instructional model for teaching the skills was also followed (Appendix J).

Teacher A was trained to use the Social Skills Intervention Guide and was given a sequence of topics from which scripted lessons plans were followed. Teacher $\mathrm{A}$ and Teacher B were also trained to use the social skills assessment instrument and completed questionnaires for all of their students.

\section{Experimental Design and Analysis}

The design used in this study was quasi-experimental, specifically nonequivalent control group design since it was not possible to assign students to random groups. Existing classrooms were randomly assigned to groups.

$\begin{array}{ccc}\mathrm{O} & \mathrm{X}_{1} & \mathrm{O} \\ \mathrm{O} & \mathrm{X}_{2} & \mathrm{O}\end{array}$

This representation indicates that both groups are being exposed to the independent variable; one group is receiving the treatment, and one group is receiving the usual treatment.

A chi square analysis was used to compare group frequencies in the sample populations. Before analyzing pre-test and post-test differences an evaluation was made to detect whether the random assignment resulted in an equivalent distribution of students' IQ and reading scores.

An ANOVA (analysis of variance) was used to examine significant differences by group and by interaction. Subtest standard scores and relationships were evaluated to determine the results, establish patterns, and make conclusions. The rationale for using ANOVA is that with several criterion measures we could obtain a complete and detailed description of the phenomenon under study (Gay, 1996). 


\section{CHAPTER IV}

Results

In this chapter, the statistical analyses of the data are presented according to the procedures outlined in Chapter III. As discussed earlier, this study sought to explore the effect of social skills training on the writing skills of children with learning disabilities at the middle school level. The results of the writing assessments of thematic maturity, syntactic maturity, fluency and quality of expression were examined. The pre-test and posttest scores for thematic maturity and syntactic maturity were derived from a writing sample from the TOWL-2. The Woodcock-Johnson Achievement -R supplied the pre-test and post-test scores for fluency and quality of expression. The parent, teacher and student pretest and post-test scores for social skills were based on responses to a social skills rating instrument, the Social Skills Rating System.

The data analyzed were based on the pre-test and post-test scores of 57 (control $\mathrm{n}=28$ and experimental $\mathrm{n}=29$ ) children with learning disabilities in grades six through eight (ages 11-14) in a middle school. Additional data were based on responses from parents of the 57 children and two teachers on the parent and teacher rating scales.

Cross-tabulations were conducted on subject demographic variables of race, language, gender, grade, SES (based on free lunch), age, IQ (Full scale), reading level, and reading percentile to detect if there were any significant differences between the two groups in their characteristics. T-tests were conducted on the writing and social skills scores for each group separately to decide if there were any gains from pre-test to post-test scores in the experimental and control groups. An ANOVA was applied to each of the seven dependent variables (syntactic maturity, thematic maturity, fluency, quality of expression, parent, student and teacher social skills) to detect changes in scores for each group. An ANOVA was also applied to each of the seven dependent variables to explore the effect of language and culture on the scores. 


\section{Characteristics of the Sample}

The distributions of the variables race, language, gender, grade, socioeconomic status based on free lunch eligibility, age, full scale IQ, reading level and reading percentile were compared across the two groups to check for differences. In Table 2 the results of a chi square analysis comparing the two groups are presented. Alpha level was set at .05 . As indicated by Table 2, a chi square analysis found a significant effect at the $p<.05$ level $(p=.01)$ for grade. In the experimental group $55.17 \%$ were sixth graders but only $25 \%$ of the control group were sixth graders. The experimental and control groups were comprised of about the same percentage of seventh graders (experimental group $=34.49 \%$ control group $=32.15 \%$ ). The experimental group had only $10.34 \%$ eighth graders compared to $42.85 \%$ eighth graders in the control group. A two way ANOVA on post-test to pre-test main effect to take out the effect of grade revealed no significant effect of grade on either writing measures or social skills measures.

There were no other significant effects for the other variables of race, language, or gender. Table 3 displays $t$ tests for age, IQ, reading level and reading percentile. There were no significant differences between the two groups on these variables. 
Table 2

Race, Language, Gender, Grade, and Lunch (SES)

\begin{tabular}{|c|c|c|c|c|c|}
\hline \multirow[t]{2}{*}{ Variable } & Experimental & \multicolumn{2}{|c|}{ Control } & \multicolumn{2}{|c|}{ Total } \\
\hline & $\underline{\%}$ & $\underline{\mathrm{n}}$ & $\%$ & $\underline{N}$ & $\underline{\%}$ \\
\hline
\end{tabular}

Race

$\begin{array}{lrrrrrr}\text { white } & 14 & 48.28 & 15 & 53.58 & 29 & 50.90 \\ \text { black } & 11 & 37.93 & 8 & 32.14 & 19 & 33.30 \\ \text { Hispanic } & 4 & 13.79 & 4 & 10.71 & 8 & 14.00 \\ \text { other } & & & 1 & 3.57 & 1 & 1.80 \\ \text { nguage } & 19 & 65.51 & 21 & 75.00 & 40 & 70.20 \\ \text { English } & 10 & 34.49 & 7 & 25.00 & 17 & 29.80 \\ \text { Spanish } & & & & & & \end{array}$

Gender

$\begin{array}{lrrrrrr}\text { Male } & 21 & 72.41 & 18 & 64.29 & 39 & 68.40 \\ \text { Female } & 8 & 27.59 & 10 & 35.71 & 18 & 31.60\end{array}$

(table continues) 
Table 2 (continued)

\begin{tabular}{|c|c|c|c|c|c|c|}
\hline \multirow[t]{2}{*}{ Variable } & \multicolumn{2}{|c|}{ Experimental } & \multicolumn{2}{|c|}{ Control } & \multicolumn{2}{|c|}{ Total } \\
\hline & $\underline{\mathrm{n}}$ & $\underline{\%}$ & $\underline{\mathrm{n}}$ & $\underline{\%}$ & $\underline{\mathrm{N}}$ & $\underline{\%}$ \\
\hline \multicolumn{7}{|l|}{ Grade** } \\
\hline 6 & 16 & 55.17 & 7 & 25.00 & 23 & 40.40 \\
\hline 7 & 10 & 34.49 & 9 & 32.15 & 19 & 33.30 \\
\hline 8 & 3 & 10.34 & 12 & 42.85 & 15 & 26.30 \\
\hline \multicolumn{7}{|l|}{ Lunch } \\
\hline Free & 10 & 34.48 & 7 & 25.00 & 17 & 29.80 \\
\hline Reduced & 6 & 20.69 & 1 & 3.57 & 7 & 12.30 \\
\hline Not free & 13 & 44.83 & 20 & 71.43 & 33 & 57.90 \\
\hline
\end{tabular}

${ }^{*} \mathrm{p}<.05 \quad * * \mathrm{p}<.01$ 
Table 3

T-tests for Age, IQ, Reading Level and Reading Percentile

Experimental $(n=29) \quad$ Control $(n=28)$

$\underline{M} \quad \underline{S D} \quad \underline{M} \quad \underline{S D} \quad \underline{\text { Mean difference }} \underline{\mathrm{t}}$-value $\mathrm{p}$-value

$\begin{array}{llllllll}\text { Age } & 12.50 & .92 & 12.98 & 1.03 & -.48 & -1.85 & .07\end{array}$

$\begin{array}{llllllll}\text { IQ } & 111.10 & 21.19 & 107.20 & 21.75 & 3.85 & .68 & .50\end{array}$

Reading

level

$3.47 \quad 2.26$

4.43

$1.94-.95$

$-1.71 .09$

Reading

percentile

$23.27 \quad 24.07$

$32.92 \quad 28.02$

$-9.65$

$-1.40 \quad .17$

$\mathrm{p}<.05$ 
To address the hypotheses of this study, the data were analyzed in two ways. Results were generated from the data to study the strength of interrelation between the writing measures and social skills measures and any relationships with race, language, gender, grade, SES, age, IQ, and reading achievement scores. An analysis of variance (ANOVA) procedure and $t$ tests for each of the four writing skills measures and three social skills measures were used to study the effect of group placement.

The study attempted to answer the following research questions:

1. What is the effect of social skills training on the thematic maturity, syntactic maturity, fluency, and quality of expression in the writing of middle school children with learning disabilities?

2. What is the effect of social skills training on the acquisition and performance of social behavior of middle school children with learning disabilities in a classroom setting?

Writing Results

$\mathrm{T}$ - tests were conducted to detect if there were any differences between the experimental and control groups on the writing variables of thematic maturity, syntactic maturity, fluency and quality of expression. The significance level for the $t$ test was set at the .05 alpha level.

Table 4 presents the results of $t$ tests on writing variables. As illustrated by this table, there were significant differences in syntactic maturity $(\mathrm{p}=.03)$ and in quality of expression $(\mathrm{p}=.00)$ in the experimental group from pre-test to post-test. Significant differences in the control group were found in syntactic maturity $(\mathrm{p}=.00)$.

Table 5 illustrates the differences between the pre-test and post-test difference scores (gain scores) on the writing measures. The alpha level was set at $\mathrm{p}<.05$. Only syntactic maturity was significantly different between the two groups. However, the control group scored significantly better than the experimental group on this variable. 
Table 6 illustrates the effect of language (English and Spanish) on writing measures. There is no significant effect of language on any of the writing measures. However, an examination of the means in the experimental group demonstrated that in syntactic maturity, thematic maturity, and fluency the means were higher for students whose primary language was English than for students whose primary language was Spanish. In the area of quality of expression, Spanish speaking students scored higher than English speaking students.

A review of the control group results (Table 6) revealed no significant differences in any area of writing by language. However, the means of English speaking students were higher than the means of Spanish speaking students in the areas of syntactic maturity, thematic maturity, and fluency. 
Table 4

T tests for Pre-test to Post-Test Differences on Writing Measures

$\underline{\text { Pre-test }}$

Post-test

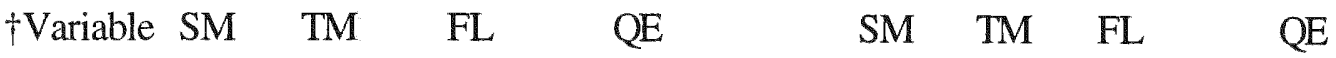

\begin{tabular}{|c|c|c|c|c|c|c|c|c|}
\hline & & & & Experimental & $n=29$ & & & \\
\hline$\underline{M}$ & 4.58 & 5.55 & 77.75 & 72.65 & 5.72 & 4.86 & 80.55 & 83.79 \\
\hline $\mathrm{SD}$ & 2.07 & 2.44 & 15.21 & 17.57 & 2.91 & 2.32 & 15.34 & 18.1 \\
\hline
\end{tabular}

$\begin{array}{lllll}\text { M dif. } & 1.13 & -.69 & 2.79 & 11.13\end{array}$

t-value $\quad \begin{array}{llll}2.36 & -1.21 & 1.11 & 4.91\end{array}$

$\begin{array}{lllll}\text { p-value } & .03 * & .24 & .28 & .00^{* *}\end{array}$

\begin{tabular}{llllllllll} 
& \multicolumn{8}{c}{ Control } & $\mathrm{n}=28$ \\
M & 4.21 & 6.35 & 81.75 & 69.60 & 7.46 & 6.60 & 88.03 & 75.10 \\
SD & 2.25 & 3.82 & 16.74 & 20.57 & 3.50 & 4.29 & 20.06 & 19.29
\end{tabular}

$\begin{array}{lllll}\text { M dif. } & 3.25 & .25 & 6.28 & 5.50\end{array}$

$\begin{array}{lllll}\text { t-value } & 4.00 & .31 & 1.75 & 1.71\end{array}$

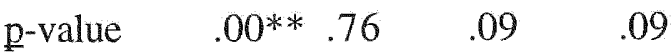

$* \mathrm{p}<.05 \quad \dagger \mathrm{TM}=$ Thematic Maturity

$\uparrow \mathrm{SM}=$ Syntactic Maturity

$* * \mathrm{p}<.01 \quad \dagger \mathrm{FL}=$ Fluency

$\mathrm{tQE}=$ Quality of Expression 
Table 5

T test of Gain Scores on Writing Measures

$\underline{\mathrm{S}} \underline{\mathrm{SD}} \quad \underline{\mathrm{MD}} \quad \underline{\mathrm{t}}$-value p-value

Syntactic Maturity

$\begin{array}{llll}\text { experimental } & 1.13 & 2.60 & .48 \\ \text { control } & 3.25 & 4.30 & .81\end{array}$

$2.11 \quad-2.23 \quad .03 *$

Thematic Maturity

$\begin{array}{lrrr}\text { experimental } & -.68 & 3.06 & .56 \\ \text { control } & .25 & 4.28 & .81\end{array}$

$.94 \quad-.95 \quad .34$

Fluency

$\begin{array}{llll}\text { experimental } & 2.79 & 13.61 & 2.52 \\ \text { control } & 6.28 & 18.99 & 3.58\end{array}$

$-3.49 \quad-.80$

Quality of Expression

$\begin{array}{lrrr}\text { experimental } & 11.13 & 12.22 & 2.27 \\ \text { control } & 5.50 & 17.07 & 3.21\end{array}$

$5.63 \quad 1.43 \quad .16$

$* \mathrm{p}<.05$ 
Table 6

Effects of Language on Writing Measures

English

Spanish

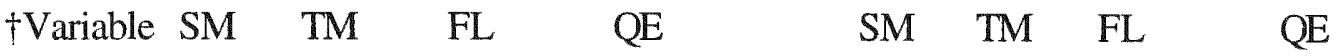

Experimental $\mathrm{n}=29$

$\begin{array}{lrrrrrrrr}\text { M } & 6.26 & 5.26 & 81.05 & 83.36 & 4.7 & 3.80 & 79.60 & 84.50 \\ \text { SD } & 2.94 & 2.30 & 18.41 & 19.83 & 2.71 & 1.60 & 7.27 & 15.35 \\ & & & & & & & & \\ \text { M dif. } & 1.90 & 1.46 & 1.45 & 1.14 & & & & \\ \text { t-value } & 1.39 & 1.76 & .23 & .16 & & & & \\ \text { p-value } & .17 & .08 & .81 & .87 & & & & \end{array}$

\begin{tabular}{lrrrrrrrr}
\multicolumn{10}{c}{ Control } & $\mathrm{n}=28$ \\
M & 8.29 & 6.90 & 89.90 & 75.04 & 5.00 & 5.71 & 82.42 & 75.28 \\
SD & 2.94 & 3.03 & 6.90 & 20.57 & 4.40 & 3.70 & 2.27 & 19.29
\end{tabular}

$\begin{array}{lllll}\text { M dif. } & 3.29 & 1.19 & 7.50 & .24\end{array}$

$\begin{array}{lllll}\text { t-value } & 1.82 & .77 & .84 & .02\end{array}$

$\begin{array}{llllll}\text { p-value } & .07 & .44 & .40 & .97\end{array}$

$* \mathrm{p}<.05 \quad \dagger \mathrm{TM}=$ Thematic Maturity

$* * \mathrm{p}<.01 \quad \dagger \mathrm{FL}=$ Fluency
$\lceil\mathrm{SM}=$ Syntactic Maturity

$\nmid \mathrm{QE}=$ Quality of Expression 


\section{$\underline{\text { Social Skills Results }}$}

Table 7 displays the results of $t$ tests on the social skills variable of parent, student, and teacher ratings for both groups. There were no significant differences in any of the interactions between group and social skills measures. However, the teacher rating $(\mathrm{p}=.09)$ and student rating $(\mathrm{p}=.13)$ approached significance. Table 8 shows the pre-test and post-test differences (gain scores) on the social skills measures. At the $\mathrm{p}<.05$ level, there were no significant differences between experimental and control groups on the parent, student or teacher ratings.

Table 9 displays the results of differences based on students' home language. Results compared children whose home language was Spanish and English. There were no significant main effects of language on the parent, student or teacher ratings.

Summary

In conclusion, areas of pre-test and post-test significance in the writing measures were syntactic maturity and quality of expression in the experimental group. In the control group, syntactic maturity was significant. When pre-test and post-test differences were examined for both groups only syntactic maturity was significant. However, the gain score was greater for the control group than for the experimental group. The students' home language had significant effect on syntactic maturity but not on any other variable.

Examination of the results of the analysis of social skills measures revealed that no significant outcomes were evident in any area. There were no significant effects on the parent, student or teacher rating measures by either social skills training or the writing instruction. The home language of the students had no effect on the social skills measures. 
Table 7

Test for Independent Social Skills Measures

Pre-test

Parent Student Teacher

Post-test

Parent Student

Teacher

Experimental $n=29$

$\begin{array}{lllllll}\text { M } & 90.17 & 97.62 & 83.62 & 92.93 & 94.41 & 79.48 \\ \text { SD } & 16.37 & 16.72 & 24.45 & 16.32 & 14.47 & 20.52\end{array}$

$\begin{array}{llll}\text { M dif } & 2.75 & -3.20 & -4.13\end{array}$

t-value $1.22 \quad-1.56 \quad-1.71$

$\begin{array}{lll}\text { P-value. } 23 & .13 & .09\end{array}$

Control $\mathrm{n}=28$

$\begin{array}{lrrrrrr}\text { M } & 96.92 & 101.07 & 96.85 & 98.60 & 98.07 & 93.96 \\ \text { SD } & 13.19 & 13.98 & 16.90 & 12.58 & 16.34 & 15.90\end{array}$

$\begin{array}{llll}\text { M dif } & 1.67 & -3.00 & -2.89\end{array}$

$\begin{array}{llll}\text { t-value } & .83 & -.97 & -.89\end{array}$

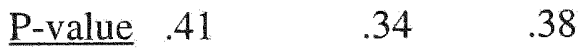

$\mathrm{p}<.05$ 
Table 8

Pre-test and Post-test Differences on Social Skills Measures Samples

$\underline{\mathrm{S}} \underline{\mathrm{SE}} \quad \underline{\mathrm{MD}} \quad \underline{\mathrm{t}}$-value p-value

Parent Rating

$\begin{array}{llll}\text { experimental } & 2.75 & 12.135 & 2.25 \\ \text { control } & 1.67 & 10.646 & 2.01\end{array}$

$\begin{array}{lll}1.08 & .36 \quad .72\end{array}$

Student Rating

$\begin{array}{llll}\text { experimental } & -3.20 & 11.07 & 2.05 \\ \text { control } & -3.00 & 16.39 & 3.09\end{array}$

$-.21 \quad .06 \quad .96$

Teacher Rating

$\begin{array}{llll}\text { experimental } & -4.13 & 13.04 & 2.42 \\ \text { control } & -2.89 & 17.20 & 3.25\end{array}$

$\begin{array}{lll}-1.24 & -.31 \quad .76\end{array}$

$\mathrm{p}<.05$ 
Table 9

Effect of Language on Social Skills

Variable

$\underline{\mathrm{N}} \quad \underline{\mathrm{M}}$

$\underline{S D}$

$\underline{\mathrm{MD}}$

p-value

Parent Rating

$\begin{array}{llll}\text { English } & 40 & 94.37 & 12.07 \\ \text { Spanish } & 17 & 98.88 & 19.80\end{array}$

$\begin{array}{ll}-4.5 & .29\end{array}$

Student Rating

$\begin{array}{llll}\text { English } & 40 & 97.02 & 16.14 \\ \text { Spanish } & 17 & 94.29 & 13.71\end{array}$

$2.73 \quad .54$

Teacher Rating

$\begin{array}{llll}\text { English } & 40 & 86.40 & 21.40 \\ \text { Spanish } & 17 & 87.05 & 15.27\end{array}$




\section{CHAPTER V}

\section{Discussion}

A growing concern about the level of literacy in this country has prompted an increased emphasis on writing skills in the curriculum that reflects the importance of writing in contemporary society (Graham \& Harris, 1988). Writing has many purposes; it is a powerful tool for recording ideas and for exploring thought, is a means of personal communication and a way to fulfill emotional needs, and writing can also be a source of enjoyment and entertainment. Given this multidimensional importance, it is no surprise that writing assessments and the quantity of time allotted to writing instruction have increased (Graham, Harris, MacArthur, \& Schwartz, 1991).

As expected, this emphasis on writing in the curriculum introduces important implications for students with learning disabilities and their teachers (Newcomer \& Barenbaum, 1991). Students with learning disabilities typically display poor writing performance, particularly in the areas of syntactic maturity, thematic maturity, fluency and quality of expression (Manganello, 1994). These student writing weaknesses must be remediated to produce good writing. It is important that regular and special education teachers work collaboratively to insure that students with learning disabilities receive an effective writing program.

The remediation of writing inadequacies may be accomplished through participation in a well-designed writing program (Graham, 1982). A well-designed writing program provides an atmosphere for building and shaping a writing community (Bos, 1988). A strong writing program can create an environment that helps students in the areas of listening, questioning, observing, and writing. It is especially important that students ask questions and collaborate with others as they compose and write. Students also need a writing environment where they can take risks. Children need the opportunity to read their work to an audience of peers and adults to recruit comments and responses. Unfortunately, students with learning disabilities often lack the pro-social skills needed to participate in 
effective programs and to benefit from peer and adult feedback (Graves, 1983). There is some indication that social skills training for students with learning disabilities may heighten their ability to function within a group setting and participate more effectively in the sharing component of the writing process. In a study by Olson (1990), sixth grade students revised their work with and without peer feedback. Students who were provided with peer feedback could revise their work more effectively, resulting in a better piece of writing.

This study was designed to determine whether training in social skills in a classroom setting would lead to greater achievement in writing. The intervention was formulated to improve writing achievement through pro-social skills training. The students targeted in this study were middle school students with learning disabilities. The time line for this study was an academic year from September to May.

The results of this study are discussed in this chapter as they relate to the purpose of this study. The discussion is organized around the areas posed in the two research questions regarding writing skills and social skills. Additionally, implications for future research are considered.

\section{Summary of Findings}

Two areas of improvement in writing were evident: syntactic maturity and quality of expression. Both the experimental and control groups made significant improvement in syntactic maturity. The experimental group showed a significant improvement in quality of expression. Thematic maturity and fluency showed no significant improvements for either group. A more detailed analysis of the writing variables follows.

Deficiencies in thematic maturity, syntactic maturity, fluency, and quality of expression may be remediated, and attention should be given to the discrete skills in these areas. Thematic maturity is the ability to organize and develop ideas. These children often have difficulties separating irrelevant information from relevant information when composing their writing using a theme or central idea. Thematic maturity also refers to the 
ability to write logically, coherently, and sequentially to produce a written product. The actual writing may be of different types; however, despite its content, the passage must be understood by a reader. The maturity of the product is usually evident if the writer uses definite introductions and endings, well-structured paragraphs, character development, dialogue, humor, or expresses some moral or philosophic theme or defends a position. Writing instruction, although not the intervention in this study, did not have an effect on thematic maturity in either group. Social skills training also did not have any effect on thematic maturity in either the experimental or control group. Previous research suggests that deficiencies in the area of thematic maturity are difficult to differentiate among learners who are learning disabled/gifted, gifted, and learning disabled. This area of writing appears to be difficult for most children (Sherman, 1991).

However, when looking at the difference in thematic maturity between children whose first language is Spanish and children whose first language is English, a difference in writing outcomes was observed. While this effect was not statistically significant, it did approach significance $(p=.06)$. This suggests that primary language has an effect on the ability of children to write well thematically. It may be that children whose primary language is not English may have to translate ideas into English before those ideas are written down. This may pose a problem for many children with learning disabilities.

A second area of language problems common to children with learning disabilities involves language structure or syntax. These children often lack facility in correct use of tense, word order, and other aspects of syntax. There is a serious delay in acquiring basic knowledge of the syntactical relations among words (Manganello, 1994). In this study, writing instruction had significant effects on syntactic maturity in both groups of children who participated. This includes students in both the experimental and control groups. However, the control group made greater positive gains in syntactic maturity than the experimental group implying that social skills training did not have a notable effect on syntactic maturity. 
Examination of the differences in syntactic maturity when home language is considered revealed a difference $(\mathrm{p}=.07)$. One might expect these differences, considering that the syntax of Spanish differs from the syntax of English. The tenses and word order differ in the two languages. Children with learning disabilities, whose home language is English, wrote better than students whose home language was Spanish.

Fluency, the third dependent measure, was examined in this study because students with learning disabilities typically write shorter sentences and shorter stories than children without learning disabilities (Zaragoza \& Vaughn, 1992). Children with learning disabilities usually lack fluency in their writing. Fluency is the ability to put words down on paper quickly and accurately. Children with problems in fluency typically cannot get started in their writing and frequently turn in assignments either blank or with very little writing (Newcomer \& Barenbaum, 1991). Given the amount of writing practice and timed writing built into the intervention, it is surprising that the writing exercises did not improve fluency in either group. Neither writing instruction nor social skills training had any effect on fluency in this study. This contrasts with the results of a study involving elementary students with learning disabilities in which a significant growth in fluency was observed when process writing strategies were used (Zaragoza \& Vaughn, 1992). Since process writing strategies were used in this study, it was surprising to find no improvements in fluency in either the experimental or control group. Perhaps, results would have differed if more timed writing could had been utilized or more writing activities stressing fluency could had been used.

The fourth outcome measured was quality of expression. Quality of expression in writing requires that a child generate ideas, organize, reason, and adhere to task. Children with learning disabilities may be limited in their use of abstract meaning and have difficulties with organization and adherence to task (DeBeer, 1993). A significant increase was seen in the experimental group in quality of expression when comparing pre-test to post-test. However, when comparing the increase in scores between experimental group 
and control group there was no significant difference. Consequently, social skills training did not have an effect on quality of expression in writing for either group.

The other area examined in this study is social skills. Specifically, the study examined whether children who are taught pro-social skills in a classroom setting would generalize social behaviors in an academic setting. Examination of the results of the social skills measures revealed that no significant outcomes were evident in any area. There were no significant effects on the parent, student or teacher rating measures either by the social skills training or the writing instruction. The home language of the students had no effect on the social skills measures.

Overall, the results of this study do not provide support for the two research hypotheses. The following discussion addresses these implications from the findings.

Hypothesis one. Hypothesis one predicted that children with learning disabilities would show greater achievement in the writing areas of thematic maturity, syntactic maturity, fluency, and quality of expression when they were first trained in social skills. The logic of the two research questions is that social skills training would provide the children with greater ability to function in group settings, thus helping them to participate in writing process activities. However, the findings of this study show that this did not occur. It appears that only syntactic maturity improved and only in the control group. Therefore, social skills training did not have any effect on writing skills.

Hypothesis two. Hypothesis two anticipated that social skills training would improve the pro-social behavior (e.g., peer interactions) of the students in the classroom as they participated in the writing activities. This did not happen. Social skills training had no effect on pro-social behavior in the classroom as rated by the parent, the student, or the teacher. In fact, the teacher ratings of children's social behaviors decreased. Formal presentations of pro-social skills did not make a difference in how the students conducted themselves in a classroom setting. While the students could verbally explain both the steps and intent of the training to their teacher, they did not appear to generalize their training to 
the classroom setting. When cued by the teacher, the students were able to display the trained behavior but reverted to their former behavior when not cued. Since they did not perform the skills unless coached or prompted, it is possible that the students exhibited a performance deficit not a skill deficit (Gresham, 1988). A performance deficit could be remediated by incorporating social skills training in the context of teaching writing instead of being taught as isolated discrete skills. Perhaps in future studies, social skills should be taught indirectly instead of through direct instruction.

In conclusion, areas of significant improvement in the writing measures were syntactic maturity and quality of expression in the experimental group. This gain may be attributed to the writing process instruction. The activities of the writing process encourage revision that might increase the likelihood that a student in the process of revision will detect errors in syntax. In the control group, syntactic maturity was significantly improved over the experimental group. When pre-test and post-test differences were examined for both groups, only syntactic maturity was significant. However, the gain score was greater for the control group than for the experimental group. This may be attributed to a greater amount of time spent on writing in the control group.

The students' home language had a significant effect on syntactic maturity but not on any other variable. Thematic maturity approached significance and should be considered when practical applications are discussed.

Analysis of the results of the social skills measures revealed that no significant outcomes were evident in any area. There were no significant effects on the parent, student or teacher rating measures either by the social skills training or the writing instruction. Based on the home language of the students, social skill training had no effect on the social skills measures.

The expected outcome of social skills training on the various areas of writing was an increase in writing achievement scores. Some studies have identified specific social skills that predict achievement in various academic areas. Other studies have shown that 
training in these skills could produce an increase in academic achievement (Cartledge \& Milburn, 1986). For some students, improvement in academic achievement appears to lead to improved social skills; increases in social skills also increases academic achievement (Cartledge \& Milburn, 1986). Reciprocal relationships appear to exist among curriculum, reinforcement of academic responses, and the development of relevant social behavior. Since children with learning disabilities typically lack social competence, their social interaction problems may exacerbate their academic problems (Reid, 1988). Based on these studies, it was anticipated that writing scores would increase as the social skills training was introduced. Why this did not occur remains a topic of speculation. Perhaps, the students were not aware enough of the social skills training or did not recognize the training as skills they needed to master in a classroom setting. Perhaps, they did not learn the appropriate social skills.

The delivery method of the social skills training may need to be altered so that it would be more effective. It might be that social skills training would need to be taught in the context of writing instruction to be generalized to writing situations. The teaching of social skills may need to be embedded across the curriculum. Embedding social skills training across the curriculum may increase generalization and maintenance.

The findings show that both groups increased in syntactic maturity when comparing pre-test and post-test scores. Increased time spent on writing ( three times a week for 55 minutes) has an impact on a child's syntactic maturity. This finding, however, negates the impact of social skills training on syntactic maturity. In this study, writing instruction alone had a positive impact on syntactic maturity. An increase in achievement scores in the area of quality of expression was displayed by the experimental group. However, gain score comparisons did not support that social skills training had any effect on this area of writing. Perhaps only writing instruction, and implementation of specific strategies, are necessary for improvement in quality of expression. 
It would be expected that training in social skills would increase the performance of pro-social skills in the experimental group receiving such training. Social skills training for children with learning disabilities in this study had no effect on the performance of prosocial skills in the classroom. This information is based on the ecological report of the teacher's daily observation of the child in the classroom and the child's self-report. The teacher's expectation of appropriate classroom behavior, and what was actually observed, served as the basis for comparison of social skills competency. The teacher's daily observation of classroom behaviors affected what programming was established.

Ecological assessment of a child's skills within the context of the classroom environment is considered best practice (Linehan \& Brady, 1995). Since students are taught ageappropriate skills in natural environments, it follows that ecological assessments are appropriate (Linehan, Brady \& Hwang, 1991).

The parents' ratings were based on observations of their communications with their child and their child's teacher. The parents were also asked how important was the specific behavior and whether they had observed that behavior in their child (Appendix E). The parents did not actually observe the specific behavior in the classroom.

One possible explanation for the greater achievement of the control group in syntactic maturity is the effect of grade. A two way ANOVA controlling for grade did not show a statistically significant effect of grade on the dependent variables. However, the effect of grade may still be a minor factor. Students who are a little older are usually easier to keep on task and have more experience with the routine of the classroom. The control group had significantly more eighth graders than the experimental group (control group = 12 , the experimental $=3$ ) . Eighth graders had two more years of exposure to a curriculum than sixth graders. Perhaps eighth graders have greater experience in the writing process than sixth graders coming from an elementary school.

Another aspect which bears examination is the fact that the experimental treatment group received 45 minutes of writing instruction and ten minutes of social skills instruction 
three times a week. The control group received 55 minutes of writing instruction three times a week. In effect, the control group received more writing instruction than the experimental group. This may be a factor in the greater writing achievement of the control group since time-on-task methods are the most direct means by which students improve skill levels (Boehnlein, 1995).

The lack of difference between experimental and control groups in social skills might be a function of improvement in all social skills areas due to the nature of the process approach to writing. The process approach to writing encourages students to interact in order to complete writing tasks. By interacting in the process approach to writing, students in both groups practiced their social skills. Although not statistically significant, the parent ratings of the social skills area improved. The process approach may act as a factor in understanding the parent ratings of the social skills pre-test to post-test difference.

Since children with learning disabilities experience difficulties in areas of language, it is reasonable to extrapolate that these deficits manifest themselves in deficiencies in writing skills and social skills. Vygotsky (1978) increasingly focused on the role of social interaction in spoken language, and this focus has been extended to look at the social interaction roots of written language development. Writing is a cultural and social process which emphasizes communication (Englert, 1992). As written language is a form of communication and often is produced to ease social interaction, written language should be examined as a part of a child's cognitive development.

Vygotsky was not only concerned with the way in which children develop speech, but also addressed the antecedents to the development of writing (Garton \& Pratt, 1989). Language and thought are considered to originate from separate roots, but come together in later development. By language, Vygotsky referred to both speech and the child's social and cultural experience. Language is the means through which thought is transmitted and created. There is an intimate relationship between language, thought, an individual's social context, and the spoken and written word. 


\section{Practical Applications}

The practical applications of the findings of this study support writing instruction using the process approach for children with learning disabilities. Greater time spent on writing in the middle school results in greater achievement. As little as ten minutes a day three times a week may be sufficient to increase writing achievement. Subsequently, the time allotted to writing instruction has increased within the general school curriculum and the quantity of writing assigned to students has also increased (Graham, Harris, MacArthur, \& Schwartz, 1991). Development of writing skills is accomplished by writing. However, just having students write is inadequate and will not necessarily lead to improved writing performance (Graham, 1982). The development of good writing skills is eased by proper motivation, a carefully and well-designed sequence of instruction, and practice and guidance in developing skills and strategies (Graham \& Harris, 1988). A well-designed writing program provides an atmosphere for building and shaping a writing community (Bos, 1988). In this study, a well-designed writing program at a middle school level included thematic writing and writing for various purposes. Peer assisted revision and student and teacher conferences provided opportunities for students to share their work and to view writing as process driven, not product driven. Since children with learning disabilities often do not experience sufficient time spent writing in the classroom, their teachers should provide more time for the writing process. Students need to spend more time on writing in order to revise their work, reformulate goals, and collaborate with peers when completing a piece. An interwoven approach to reading and writing, taught concurrently, yields the best outcome in the classroom.

\section{Future Research}

Conducting research in a school setting has its obstacles. Time to conduct the lessons, maturation, drop out, and teacher cooperation are factors to consider when doing research in a school. Time to conduct lessons was hindered because other language arts 
activities had to be presented. In conducting this research, it would have been valuable to conduct these writing and social skills lessons on a daily basis.

The effects of maturation could not be avoided given the length of time of the study (nine months). Students did not participate in the study because (a) they did not return permission slips, (b) their parents did not return the social skills rating instrument, (c) they were absent when a test was given and, (d) they came after the pre-test was given. From an original sample population of 125 children, only 57 children completed all requirements to be included in the study. All group administrations of the tests were conducted in the classroom.

The cooperation of the teachers involved in this study was an important factor in the success of the study. The two teachers who consented to being part of this study had to be trained in the administration of the tests. The teacher who conducted the social skills training had to be willing to reliably present the lessons as instructed. The teacher needed to present the social skills lessons according to a script to preserve the reliability of the lessons. The willingness of teachers to conduct their writing lessons in concert with the study's themes and objectives was a major concern. For example, teachers expect the flexibility to lengthen or shorten a lesson or reschedule the lesson if students are not responding. All things considered, the two teachers involved in the study were extremely cooperative and creative in meeting the demands of this researcher.

Random assignment to groups, a caveat in many studies, was not possible. The sampling was dictated by clusters (i.e., already established classrooms). Children could not be randomly assigned to groups because of scheduling issues. Time was needed to conduct extensive assessments in a school setting. These comprehensive assessments were not part of the normal beginning or ending of the year assessments. This additional assessment time resulted in a loss of instructional time. Activities such as assemblies, special lessons, and the presence of substitute teachers sometimes hindered the orderly progression of lessons. 
The effect of the study on the students was also an area of concern. When polled, the children responded in a positive manner to the increased time and different method of writing instruction. The children stated that they enjoyed the activities they had experienced. Many children expressed that they had never had never been previously exposed to these writing activities. Both teachers and students communicated that their writing experiences had been very gratifying. The teachers were so excited about the ambiance of the classroom that teachers are continuing to provide their students with an intensive writing program. They also report a great improvement in their students' writing skills.

With regard to writing skills, more research is needed to determine what specific areas of writing may be remediated through increased time and instruction in the classroom. Research should also focus on the difference between children with learning disabilities and children without learning disabilities in regards to written language acquisition skills. What instructional methods are most effective in the remediation of writing skills deficits?

Should writing be taught as a process, as part of whole language, or through more traditional levels? How important is spelling and grammar in writing instruction and what is its effect upon encouraging children to write?

Additional research is necessary to determine whether lengthier or more comprehensive social skills training interventions in a classroom setting would affect the writing skills and social skills of children with learning disabilities. In consideration of social skills training and its effect on children with learning disabilities, strategies and interventions need to be closely examined. What is the best method to deliver social skills instruction? Is direct instruction more effective than modeling? How often should children be instructed in social skills? How does a teacher introduce and reinforce appropriate prosocial skills? 
An interesting research study would examine what kinds of social skills can be remediated. Is it easier to teach pro-social skills or to extinguish inappropriate behavior in the classroom?

In conclusion, the writing of children with learning disabilities, with respect to syntactic maturity and quality of expression, can be remediated through the implementation of a writing program which is developmental in nature. The writing program should stress the process approach and children should be encouraged to view writing as process directed, not product directed. Writing activities should be conducted at least three times a week to be effective and teachers should support the formation of a good writing community.

The writing skills of children with learning disabilities is an area that demands reform in curriculum and instructional methodology. To underestimate the importance of writing in our society is a grievous error. Competence in the language arts should be a priority in the classroom and the primary focus of curriculum and pedagogy. To view reading and writing as discrete skills is folly.

To delay the teaching of writing to students with learning disabilities until competence in reading is exhibited is a further disservice. Inattention to difficulties these students experience with the writing process only exacerbates the problem and gives rise to frustrations that can easily evolve into social skills deficits. By offering children the means to express themselves and the social skills to accept responses to their expression, we open the door to new opportunities that transcend the academic arena. 


\section{References}

Beach, R. , \& Bridwell, L. (1984). Learning through writing: A rationale for writing across the curriculum. In A. Pellegrini \& T. D. Yawkey (Eds.), The development of oral and written language in social contexts. Norwood, $\mathrm{NJ}$ : Ablex.

Boehnlein, J. M. (1995). Explicit teaching and the developmental writing course. University Microfiche (ERIC ED384902).

Bos, C. S. (1988). Process oriented writing: Instructional implications for mildly handicapped students. Exceptional Children, 54, 521-527.

Bos, C. S., \& Vaughn, S. (1991). Strategies for teaching students with learning and behavior problems. Boston: Allyn and Bacon.

Calkins, L. M. (1986). The art of teaching writing. Portsmouth, NH: Heinemann.

Campbell, P. , Brady, M. , \& Linehan, S. (1991). Effects of peer-mediated instruction on the acquisition and generalization of written capitalization skills. Journal of Learning Disabilities, 24, 6-14.

Cartledge, G. , \& Milburn, J. F. (1986). Teaching social skills to children. New York: Pergamon Press.

Ciechalski, J. C., \& Schmidt, M. W. (1995). The effects of social skills training on students with exceptionalities. Elementary School Guidance and Counseling, 29 (3), 21722.

Conte, R., Andrews, J. J., Loomer, M. , \& Hutton, G. (1995). A classroombased social skills intervention for children with learning disabilities. The Alberta Journal of Educational Research, 12 (1), 84-102.

Dale, H. (1994). Collaborative writing: Interactions in one ninth grade classroom. Journal of Educational Research, 87 (6), 334-344.

De Bettencourt, L. U. (1987). Strategy training: A need for clarification. Exceptional Children, 54, 24-30. 
Debeer, L. (1993, April) Tutoring strategies for LD college students's common writing errors. Paper presented to a meeting of "Quill", Lincroft, NJ.

Englert, C. S. (1992). Writing instruction from a sociocultural perspective: The holistic, dialogic, and social enterprise of writing. Journal of Learning Disabilities, 25 (3), 153-172.

Englert, C. S., \& Raphael, T. E. (1988). Constructing well-formed prose: Process, structure and metacognitive knowledge. Exceptional Children, 54 (6), 513-520.

Espin, C. A. , \& Sindelar, P. T. (1988). Auditory feedback and writing: Learning disabled and non-disabled students. Exceptional Children, 55 (1), 45-51.

Farmer, T. W. , \& Farmer, E. M. (1996). Social relationships of students with exceptionalities in mainstream classes: Social networks and homophily. Exceptional Children, 62 (5), 431-450.

Ferre, L. , \& Ferre, V. (1991), The results of individualized social skills training sessions with rural elementary learning disabled students. Rural Special Education Quarterly, 10 (4), 35-41.

Forness, S. , \& Kavale, K. (1991). Social skills deficits as primary learning disabilities. Learning Disabilities Research and Practice, 6 (1), 44-49.

Franklin, A. E. (1992). Learning to read and write the natural way. Teaching Exceptional Children, 24, 45-48.

Gay, L. R. (1996). Educational research: Competencies for analysis and application. Englewood Cliffs, NJ: Prentice Hall.

Garton, A. , \& Pratt, C. (1989). Learning to be literate: The development of spoken and written language. New York: Basil Blackwell.

Gentile, C. A. (1992). Exploring new methods for collecting students' schoolbased writing. National Center for Education Statistics. Washington, DC: U.S. Government Printing Office. 
Gentile, C. A. , Martin-Rehrman, J. , \& Kennedy, J. H. (1995). Windows into the Classroom ( Report number 23-FR-06). National Center for Education Statistics. Washington, DC: U.S. Government Printing Office.

Goldstein, A. P., Sprafkin, R. P., Gershaw, N. J. , \& Klein, P. (1980). Skillstreaming the adolescent: A structured learning approach to teaching prosocial skills. Champaign, IL: Research Press.

Graham, S. (1982). Composition research and practice: A unified approach. Focus on Exceptional Children, 14, 1-16.

Graham, S. , \& Harris, K. R. (1988). Instructional recommendations for teaching writing to exceptional students. Exceptional Children, 54 (6), 506-512.

Graham, S. , \& Harris, K. R. (1988). Research and instruction in written language: Introduction to the Special Issue. Exceptional Children, 54 (6), 495-496.

Graham, S. , Harris, K. R. , MacArthur, C. A. , \& Schwartz, S. (1991). Writing and writing instruction for students with learning disabilities. Learning Disability Quarterly, 14. 89-114.

Graves, D. H. (1978). Balance the basics: Let them write. New York: Ford Foundation.

Graves, D. H. (1983). Writing: Teachers and children at work. Exeter, NH: Heinemann Educational Books.

Gresham, F. M. (1982). Misguided mainstreaming: The case for social skills training with handicapped children: A review. Review of Educational Research, 51, 139 176.

Gresham, F. M. (1988). Social skills: Conceptual and applied aspects of assessment, training, and social validation. In J. C. Witt, S. N. Elliott, \& F. M. Gresham (Eds.), Handbook of Behavior Therapy in Education (p. 523-546). New York: Plenum Press. 
Gresham, F. M. (1992). Social Skills Intervention Guide. Circle Pines, MN: American Guidance Service.

Gresham, F. M., \& Elliott, S. N. (1990). Social Skills Rating System. Examiners Manual. In F. M. Gresham \& S. N. Elliott, Social Skills Rating System. Circle Pines, MN: American Guidance Service.

Gresham, F. M., \& Elliott, S. N. (1990). Social Skills Rating System. Circle Pines, MN: American Guidance Service.

Gresham, F. M. , Gansle, K. A., Noell, G. H., Cohen, S., \& Rosenblum, S. (1993). Treatment integrity of school based behavioral intervention studies: 1989-1990. School Psychology Review, 22 (2), 254-272.

Gresham, F. M. , Noell, G. H. , \& Elliott, S. N. (1996). Teachers as judges of social competence: A conditional probablity analysis. School Psychology Review, 25 (1), $108-117$.

Grinnell, P. C. (1988). Instruction in composition. In D. K. Reid's Teaching the learning disabled: A cognitive developmental approach. Needham, MA : Allyn \& Bacon.

Hammill, D. , \& Larsen, S. (1988). Test of Written Language-2. Austin, TX: ProEd.

Hauger, D. , \& Vaughn, S. (1995). Parent, teacher and self-reports of the social competence of students with learning disabilities. Journal of Learning Disabilities, 28, 205$215,231$.

Hazel, J. , Schumaker, J. B. , Sherman, J. A. , \& Sheldon, J. (1984). Application of a group training program in social skills and problem solving to learning disabled and non-learning youth. (Research Report \#30) Lawrence, KS: The University of Kansas Research in Learning Disabilities.

Hersen, M. , \& Bellak, A. S. (1977). Assessment of social skills. In A. R. Ciminero, K. S. Calhoun, \& H. D. Adams (Eds.), Handbook for behavior assessment. New York: Wiley. 
Hillocks, G. (1984). What works in teaching composition: A meta-analysis of experimental treatment studies. American Journal of Education, 93, 133-170.

Isaacson, S. (1988). Assessing the writing product: Qualitative and quanitative measures. Exceptional Children, 54 (6), 528-534.

Johnson, D. W. , \& Johnson, R. T. (1986). Mainstreaming and cooperating learning strategies. Exceptional Children, 52 (6), 553-561.

Johnson, D. W. , Johnson, R. T. , \& Holubec, E. J. (1986). Circles of learning: Cooperation in the classroom. Edina, MN: Interaction Book Company.

Johnson, D. J., \& Myklebust, H. R. (1967). Learning disabilities: Educational principles and practices. New York: Grune \& Stratton.

Kuhn, D. , \& Phelps, E. (1982). The development of problem solving strategies. In H. Reese (Ed.), Advances in child development and behavior vol. 17 (pp. 2-44). New York: Academic Press.

Lessen, E. (1989). A survey of ten years of academic intervention research with learning disabled students: Implications for research and practice. Learning Disabilities Focus, 4 (2), 106-122.

Linehan, S., Brady, M., \& Hwang, C. (1991). Ecological versus developmental assessment: Influences on instructional expectations. Journal of the Association for Persons with Severe Handicaps, 16(3), 146-153.

Linehan, S. , \& Brady, M. (1995). Functional versus developmental assessment: Influences on instructional planning decisions. The Journal of Special Education, 29 (3), 295-309.

Lucas, J. (1993). Teaching writing: Emphasis swings to process, writing as tool for learning. Curriculum Update, January 1993 1- 7. Association for Supervision and Curriculum Development. Alexandria, VA.

Manganello, R. E. (1994). Writing and the LD student. Journal of Teaching Writing, 12 (2), 235-45. 
McIntosh, R. , Vaughn, S. , \& Zaragoza, N. (1991). A review of social interventions for students with learning disabilities. Journal of Learning Disabilities, 24 (8), 451-458.

Mithaug, D. E. , Martin, J. E. , \& Agran, M. (1987). Adaptability instruction: The goal of transitional programming. Exceptional Children, 53, 5-505.

Myklebust, H. R. (1973). Development and disorders of written language: vol. two. New York: Grune \& Stratton.

Newcomer, P. , \& Barenbaum, E. (1991). The written composing ability of children with learning disabilities. Journal of Learning Disabilities, 24 (10), 578-593.

Newcomer, P. , Barenbaum, E. , \& Nodine, B. F. (1988). Comparison of the story production of $\mathrm{LD}$, normal achieving, and low-achieving children under two modes of production. Learning Disabilities Quarterly . 11, 82-96.

Nodine, B. F., Barenbaum, E., \& Newcomer, P. (1985). Story composition by learning disabled, reading disabled, and normal children. Learning Disabilities Quarterly, 8. 167-179.

Nowacek, E. J., (1988). Teaching social skills in school. Academic Therapy. 24. $137-141$.

Ogilvy, C. (1994). Social skills training with children and adolescents: A review of the evidence of effectiveness. Educational Psychology: An International Journal of Experimental Educational Psychology, 14 (1), 73-83.

Olson, V. L. (1990). The revising processes of sixth grade writers with and without peer feedback. Journal of Educational Research, 84, 22-29.

Pernia, S. S. (1987). Effects of microcomputer use and word processing on the writing skills of learning disabled middle school students. Unpublished doctoral dissertation. University of Michigan, Anne Arbor.

Reid, D. K. (1988). Teaching the learning disabled: A cognitive developmental approach. Needham, MA: Allyn \& Bacon. 
Rubin, D. L. (1984). Social cognition and written communication. Written Communication, 1, 211-245.

Rudolph, S. M. , \& Luckner, J. L. (1991). Social skills training for students with learning disabilities. Journal of Humanistic Education and Development, 29, 163-171.

Schloss, P. J. , Schloss, C. N. , Wood, C. E. , \& Kiehl, W. S. (1986). A critical review of social skills research with behaviorally disordered students. Behavioral Disorders, 12 (1), 1-14.

Schumaker, J. B. (1992). Social performance of individuals with learning disabilities:through the looking glass of KU-IRLD Research. School Psychology Review, 21 (3), 387-399.

Schumaker, J. B. \& Deshler, D. D. (1995). Secondary classes can be inclusive, too. Educational Leadership, 52, 50-51.

Schumaker, J. B. , \& Hazel, J. S. (1984). Social skills assessment and training for the learning disabled: Who's on first and what's on second? Part I. Journal of Learning Disabilities, 17 (7), 422-430.

Schumaker, J. , Bragg, H. , Stephen, J., Sherman, J. A. , \& Sheldon, J. (1982). Social skills performances of learning disabled, non-learning disabled and delinquent adolescents. Learning Disability Quarterly, 5, 388-396.

Sherman, L. (1991). Written language in exceptional male elementary school children: A comparative analysis of the learning disabled/gifted. Paper presented at the Annual Convention of the Council for Exceptional Children.Indianapolis, IN (ERIC ED341187).

Slavin, R. E. (1990). Cooperative learning: Theory, research \& practice. Englewood Cliff, NJ: Prentice Hall.

Stipek, D. J. (1988). Motivation to learn: From theory to practice. Englewood Cliffs, NJ: Prentice Hall. 
Swanson, H. L. , \& Malone, S. (1992). Social skills and learning disabilities. School Psychology Review, 21 (3), 427-443.

Thomas, C. C. (1996). Helping students with learning difficulties develop expressive writing skills. Reading \& Writing Quarterly, 12, 59-75.

Tindal, G. , \& Parker, R. (1991). Identifying measures for evaluating expression. Learning Disabilities Research and Practice, 6 (4) 211-218.

Vygotsky, L. S. (1978). Mind in society. Cambridge, MA : Harvard University Press.

Walker, H. M. , McConnell, S. , Holmes, D. , Todis, B. , Walker, J. , \& Golden, N. (1983). The Walker Social Skills Curriculum. Austin, TX: Pro-Ed.

Wansor, C. T. (1986). Assessing writing ability: What are the issues, approaches? National Association of Secondary School Principals Bulletin, 69 (486), 67-73.

Wellman, H. M. (1985). The child's theory of mind: The development of conceptions of cognition. In S. R. Yussen (Ed.), The growth of reflection in children, 162-206. New York: Academic Press.

Whittaker, C. R., \& Salend, S. J. (1991). Collaborative peer writing groups. Reading, Writing and Learning Disabilities, 7, 125-136.

Wong, B. Y. , Butler, D. L. , Ficzere, S. A., \& Kuperis, S. (1996). Teaching low achievers and students with learning disabilities to plan, write, and revise opinion essays. Journal of Learning Disabilities, 29 (2), 197-212.

Wood, K. D. , Algozzine, B. , \& Avett, S. (1993). Promoting cooperative learning experiences for students with reading, writing, and learning disabilities. Reading and Writing Quarterly, 9. 369-376.

Woodcock, R. W. , \& Mather, N. (1989, 1990). WJ-R Tests of Achievement: Examiners Manual. In R. W. Woodcock \& M. B. Johnson, Woodcock-Johnson Psychoeducational Battery-Revised. Allen, TX: DLM Teaching Resources. 
Woodcock, R. W., \& Johnson, M. B. $(1989,1990)$. Woodcock-Johnson Psychoeducational Battery- Revised. Allen, TX: DLM Teaching Resources.

Zaragoza, N. , \& Vaughn, S. (1992). Effects of process writing instruction on three 2nd grade students with different achievement profiles. Learning Disabilities Research and Practice, 7 (4), 184-93. 
VITA

Margaret Fahringer

March 7, 1952

1972

1974

1974-1980

1981-1990

1983

1990-1996
Born New York City, NY

A.A. Education

Miami-Dade Community

College

Miami, Florida

B.S. Special Education

Florida International

University

Miami, Florida

Teacher of the Mentally Handicapped

South Miami Jr. High

Miami, Florida

Teacher of the Severely Emotionally Disturbed Special Teenage Resource System (STARS)

Centennial Middle School

Miami, Florida

M.S., Diagnostic Teaching Florida International University

Miami, Florida

Exceptional Student Education Program Specialist Centennial Middle School Miami, Florida

\section{PRESENTATIONS}

Council for Behavior Disorders (April 1990). Miami, FL Creative writing and response journals with severely emotionally disturbed children. 
Appendixes 
Appendix A

Dade County Approval Letter 
JFFICE OF EDUCATIONAL ACCOUNTABILITY • 1444 BISCAYNE BOULEVARD, SUITE $100 \bullet$ MIAMI, FLORIDA 33132

AVIO J. VISIEDO

. RINTENOENT OF SCHOOLS

IERBERT F. WEINFELD

XECUTIVE DIRECTOR

IFFICE OF EDUCATIONAL ACCOUNTABILITY

305) $995-7501$
DADE COUNTY SCHOOL BOARD

MS. JANET A. MCALILEY, CHAIRPERSON MS. BETSY KAPLAN, VICE-CHAIRPERSON MR. G. HOLMES BRADDOCK DR. ROSA CASTRO FEINBERG DA. MICHAEL KAOP MA. ROEERT RENICK

MR. WILLIAM H. TURNER

Ms. Margaret Fahringer

Centennial Middle School

8601 S. W. 212 Street

Miami, Florida 33189

October 12, 1992

Dear Ms. Fahringer:

The Research Review Committee has approved your request to conduct the study, "Effects of Social Skills Training on the Writing Skills of Learning Disabled Middle School Students," with the following provisions:

1. The agreement to participate (or not) in the study is at the discretion of the school principal(s).

2. Participation of all subjects is voluntary.

3. Parent release forms must be modified to list the specific student records which will be accessed by the researcher. The revised form must be submitted to this office prior to beginning the study. Additionally, the Spanish translation of the parent releast forms must be approved by the Division of Information Services. As soon as we receive your revised forms we will forward them to this Division, and mail them to you when they are approved.

4. Parent release forms must be secured for participating students prior to the beginning of the study.

5. Confidentiality and anonymity of all responses must be assured.

6. Data collection efforts of the study will commence September 20, 1993, and will be completed (in DCPS) by June 15, 1994, and must not interfere with countywide testing.

7. The study will involve no more than 138 DCPS students who are learning disabled, in grades 6, 7 and 8; their participation will not exceed one hour testing/assessment and 48 hours of teaching/instruction.

8. The instructional phase of the study (social skills training during writing instruction) will be carried out in cooperation with Ms. Terri Kanov, Assistant Superintendent, Exceptional Student Education, or her designee, and under the supervision of the principal(s) of the participating school(s).

9. Teacher participation must be completely voluntary. Training/inservice activities must occur during planning or other non-teaching time, and will not exceed 56 hours. 
10. A copy of the approval letter must be shown to each principal from whose school participation is requested.

11. The DCPS internal school mail system cannot be used in conducting re-
search.

Please note that it is the responsibility of the researcher to ensure that data are collected in an appropriate manner, and that any documents or instruments distributed within DCPS will be carefully edited and proofread.

If you have any further questions, do not hesitate to call me at (305) 995-7500. Please send a copy of the study abstract to the Research Review Committee when the study is complete. The reviewers rated your study highly; one of the reviewers (a senior high school principal) thought that the results may be even more "dramatic" in the senior high school. The Committee wishes you every success in your research activity.

Sincerely yours,

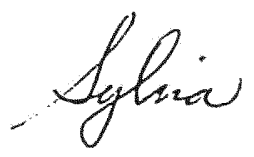

Dr. Sylvia H. Rothfarb

Chairperson

Research Review Committee

SHR/pw

cc: Ms. Terri Kanov

Or. Bill Renuart
YOUR RESEARCH REVIEW

APPROVAL NUMBER IS 312. 
Appendix B

Parent Letter and Permission

(English) 


\section{September 1993}

Dear Parent(s):

Another school year has begun and the exceptional student education staff is eager to provide your child with exciting learning experiences. 1 am sure your son/daughter is looking forward to another year of working with the teachers to reach their potential.

After reviewing the literature on writing and in expectation of assessment in writing, it has been decided that our students need more instruction and practice in the area of uriting. $A$ project that will focus on instruction in the area of writing and social skills will be implemented this school year. -

Your child will be given the opportunity to participate in this project. He/she will benefit greatly from a focused instruction in writing and social skills (the skills that enable students to work together). Your child will receive increased instruction in writing and social skills for a semester. This increased instruction will take place in your child's language arts class and will be taught by your child's regular classroom teacher.

I will be using the information obtained in the study for my doctoral dissertation at Florida International University. The information used will be: psychological report, standardized test scores and the Indiuidualized Educational Plan. of course, test scores and information obtained will be strictly confidential. Your child will only be identified by number.

Parent participation will be limited to the completion of a fifteen minute questionaire which will be done in September and again in February.

Your cooperation is appreciated. If you have any questions, please contact me at 235-1591 extension 219. I will be happy to meet with you to review this program and the benefits in it for your child. Please sign and return the attached form. Thank you.

Sincerely,

Margaret Fahringer

ESE Program Specialist 


\section{PARENT PERMISSION}

I have read the attached letter regarding the study on writing and social skills.

I understand that all test scores and information will be strictly confidential and my child will be identified only by number.

I give my child permision to participate.

I DO NOT give mY child permission to participate.

signature

date

Name of child 
Appendix C

Parent Letter and Permission

(Spanish) 
IFFICE OF EDUCATIONAL ACCOUNTABILITY • 1444 BISCAYNE BOULEVARD, SUITE $100 \bullet$ MIAMI, FLORIDA 33132

AVIO J. VISIEDO

UPERINTENOENT OF SCHOOLS

ERBERT F. WEINFELD

XECUTIVE DIRECTOR

IFFICE OF EDUCATIONAL ACCOUNTABILITY

105) $995-7501$
DADE COUNTY SCHOOL BOARD MS. JANET R. MCALILEY, CHAIRPERSON MS. BETSY H. KAPLAN, VICE-CHAIAPERSON MA. G. HOLMES BAADOOCK OA. ROSA CASTRO FEINGERG

DA. MICHAEL KROP MR. ROBERT AENICK April 27, 1993

Ms. Margaret Fahringer

Centennial Middle School

8601 S. W. 212 Street

Miami, Florida 33189

Dear Ms. Fahringer:

Enclosed please find the Spanish translation of the parent permission form approved/translated by the Division of Community Relations of DCPS. If you have any questions, please call me at (305) 995-7541.

- Sincerely yours,
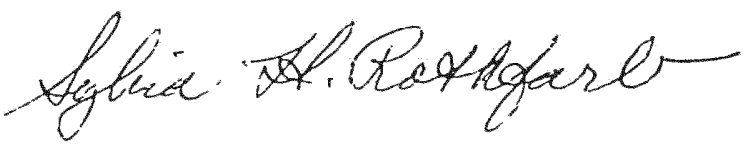

Or. SylviaH. Rothfarb

Chairperson

Research Review Committee

SHR:pw

Enclosure
RESEARCH REVIEW

APPROVAL NUMBER 312. 
Estimados padres:

Ha comenzado otro año escolar y nuestro personal especial está ansioso por proporcionar a su hijo(a) excitantes experiencias en su aprerdizaje. Estamos seguros de que su hijo(a) está deseoso(a) de iniciar otro año de trabajo con sus maestros en el desarrollo de su potencial.

Después de analizar la literatura sobre la redacción y las expectativas de las evaluaciones en cuanto a la misma, hemos decidido que nuestros estudiantes necesitan más instrucción y práctica en dicho campo. Un proyecto que se concentrará en la redacción y en las destrezas sociales será puesto en práctica en el presente curso escolar.

Su hijota) tendrá la oportunidad de participar en dicho proyecto. El(ella) podrá beneficiarse mucho al recibir instrucción concentrada en los campos de la redacción y de las destrezas sociales (o sea, las destrezas que permiten a los estudiantes trabajar juntos en armonía). Su hijo(a) recibirá dicho aprendizaje por espacio de un semestre (de septiembre a febrero). Dicha enseñanza será impartida por la(el) maestra(o) regular de su hijo(a) durante las clases de inglés.

Utilizaré la información y los resultados obtenidos en un estudio que es parte de mi tesis doctoral. Los datos que se utilizarán serán los siguientes: el informe psicológico, los resultados de las pruebas normadas y el plan individual de educación. Por supuesto, los resultados de las pruebas y los datos obtenidos serán considerados estrictamente confidenciales. Su hijo(a) solamente será identificado mediante un número.

Como padres, su participación se limitará a llenar un cuestionario por espacio de 15 minutos. Solamente tendrán que hacerlo dos veces, una en septiembre y otra en febrero.

Agrademos su cooperación. Si tuviesen alguna pregunta al respecto, por favor, pónganse en contacto conmigo, llamando al 235-1581, extensión 219. Para mi será un placer reunirme con ustedes para discutir los diferentes aspectos del programa y los beneficios que tiene para su hijo(a). Por favor, firmen y devuelvan la planilla adjunta. Muchas gracias.

Atentamente,

Margaret Fahringer

Especialista del Programa ESE 


\section{FORMULARIO DE AUTORIZACION PARA PADRES}

He leído la carta adjunta relacionada con el estudio sobre la redacción y las destrezas sociales.

Entiendo que todas las calificaciones de las pruebas y los demás datos obtenidos serán totalmente confidenciales y que mi hijo(a) solamente será identificado por un numero.

Doy mi permiso para que mi hijo(a) participe en el estudio.

NO doy mi permiso para que mi hijo(a) participe en el estudio.

Firma

Fecha

Nombre del estudiante 
Appendix D

Writing Prompts

(Towl-2) 
STORY

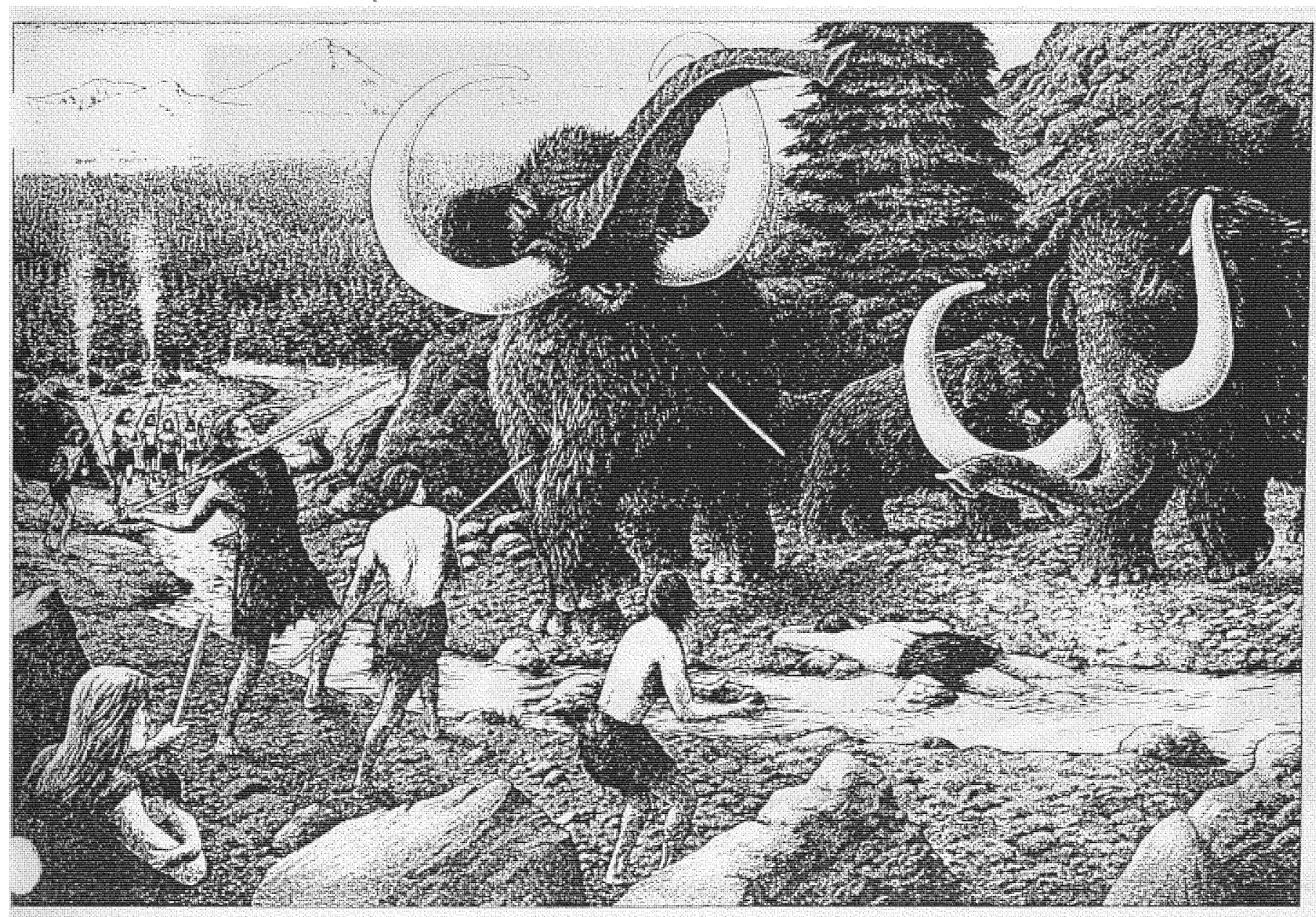




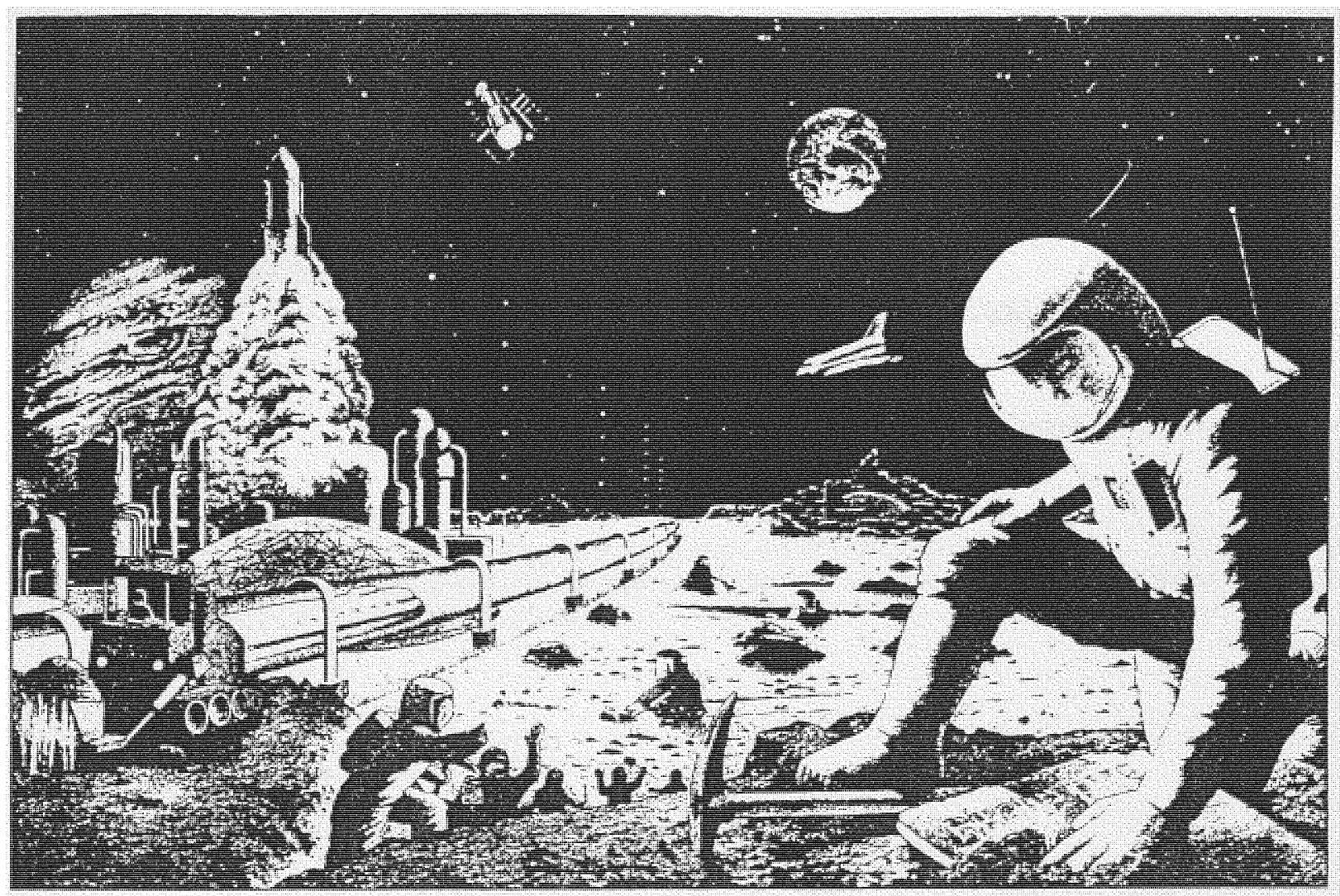


Appendix E

Social Skill Rating System 


\section{Directions}

This questionnaire is designed to measure how often your child exhibits certain social skills and how Important those skills are to your child's development. Ratings of problem behaviors are also requested. First, complete the information about your child and yourself.

\section{Student Information}

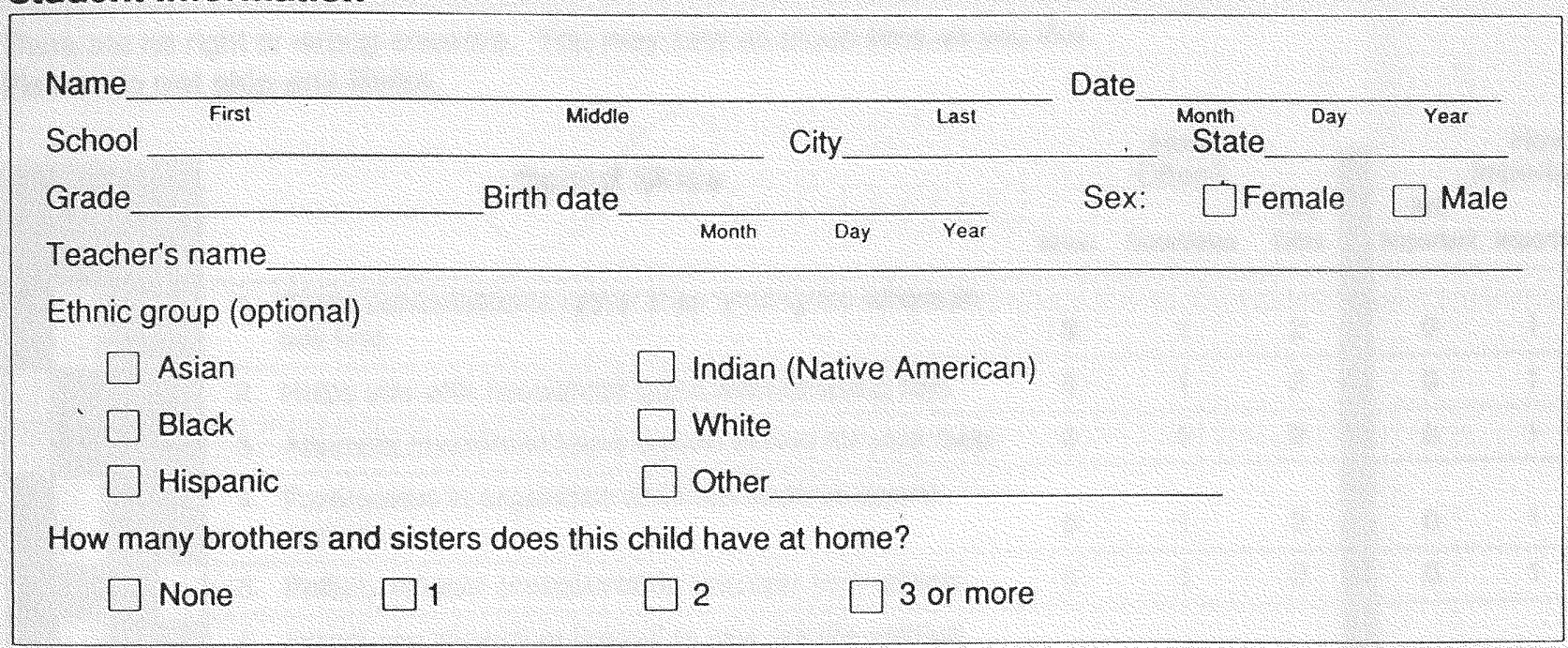

\section{Parent Information}

Name

Address

First

Niddle Telephone City State

Sex: $\square$ Female $\square$ Male

How are you related to this child?

$\square$ Mother

$\square$ Guardian

$\square$ Father

$\square$ Other 
Next, read each item on pages 2-4 (items 1-52) and think about your child's present behavior. Decide how often your child does the behavior described.

If your child never does this behavior, circle the 0 .

If your child sometimes does this behavior, circle the 1.

If your child very often does this behavior, circle the 2.

For items 1-40, you should also rate how important each of these behaviors is for your child's development.

If it is not important for your child's development, circle the 0.

If it is important for your child's development, circle the 1.

If it is critical for your child's development, circle the 2.

Here are two examples:

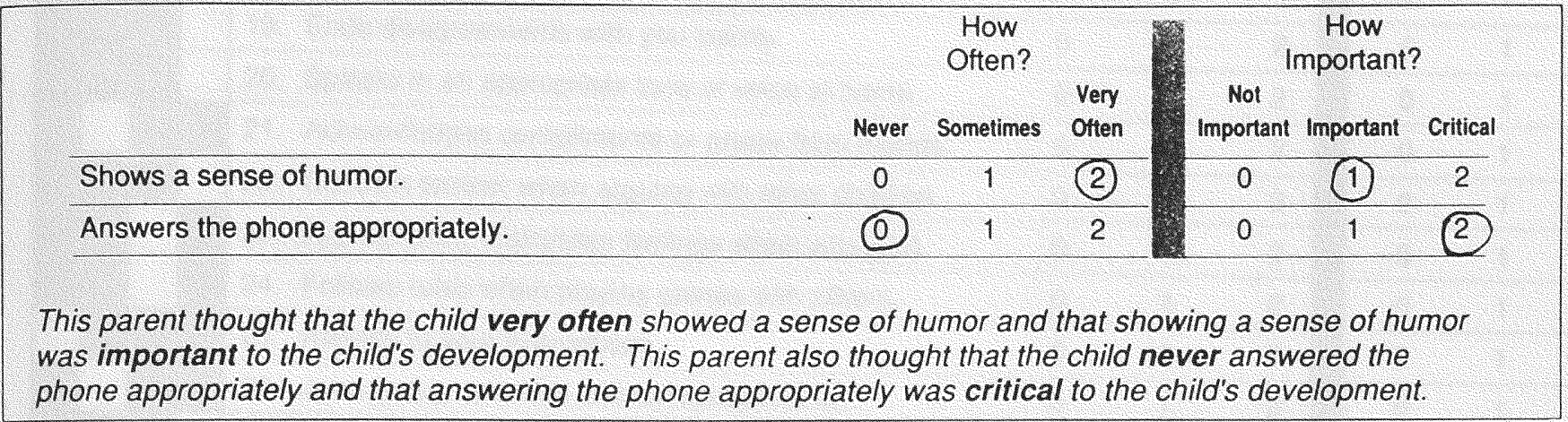

There are no right or wrong answers. You may take as much time as you like

Please do not skip any items.

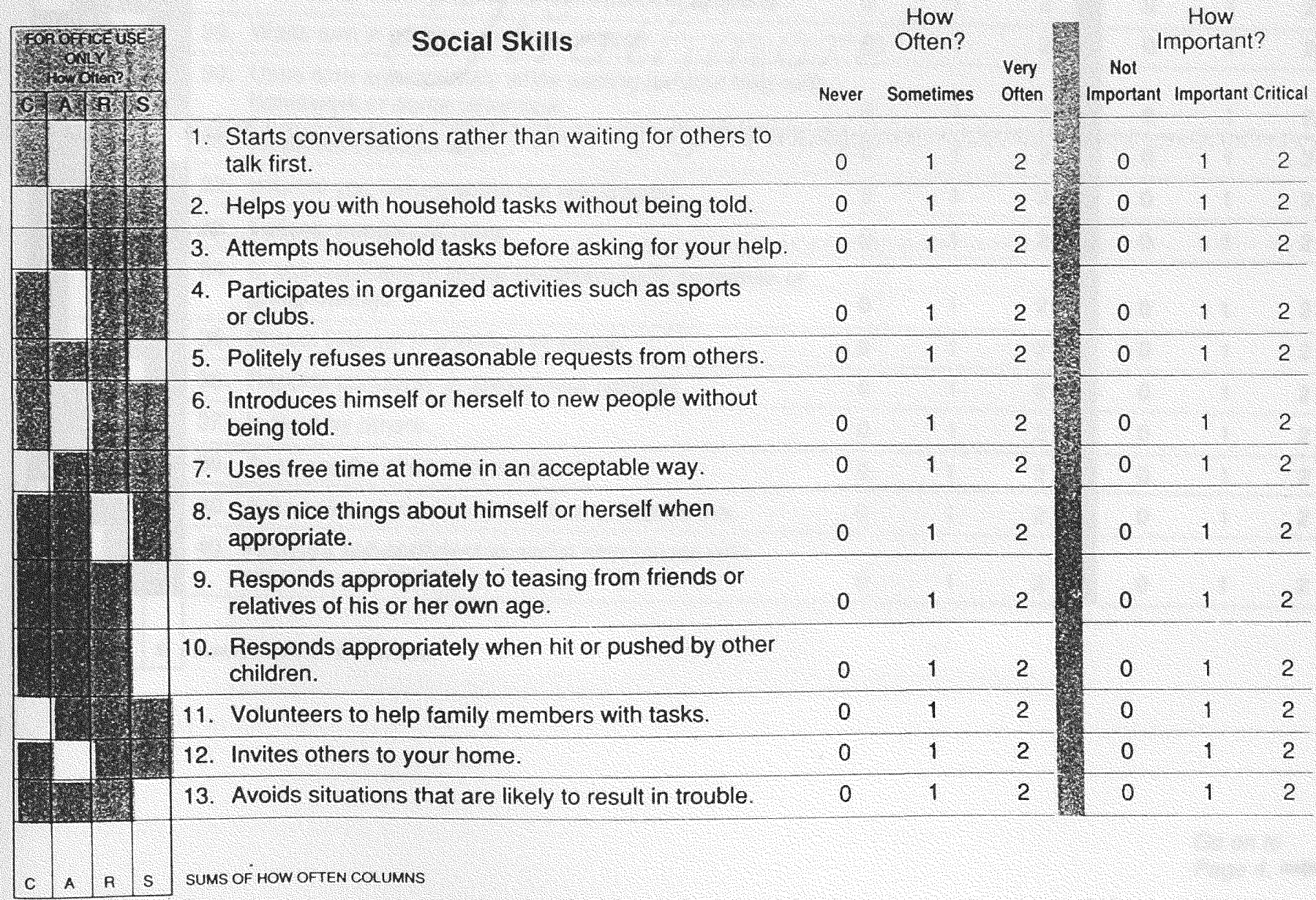




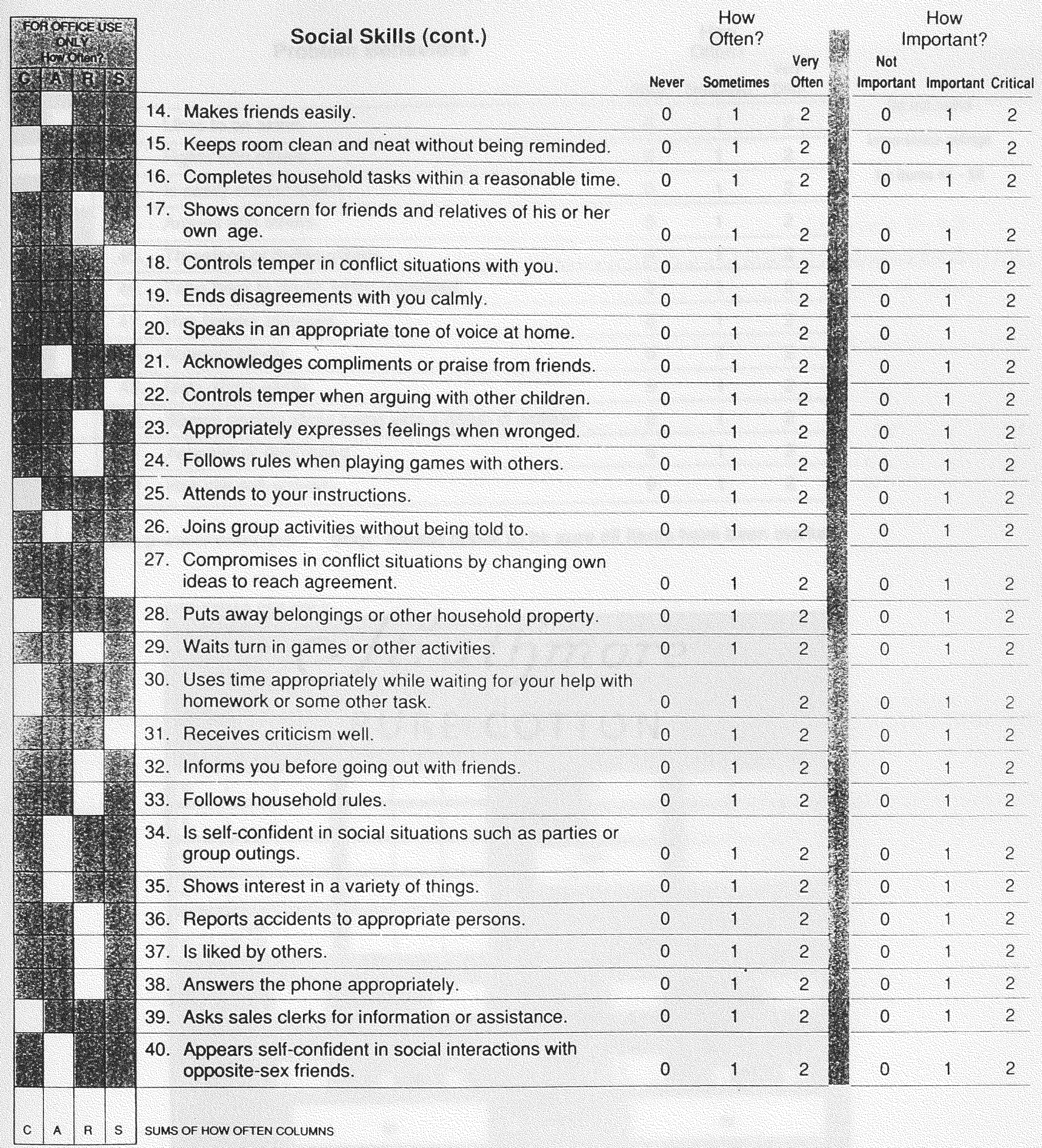




\begin{tabular}{|c|c|c|c|c|}
\hline 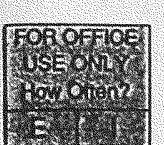 & Problem Behaviors & Never & $\begin{array}{l}\text { How } \\
\text { Often? } \\
\text { Sometimes }\end{array}$ & $\begin{array}{l}\text { Very } \\
\text { Often }\end{array}$ \\
\hline & 41. Likes to be alone. & 0 & 1 & 2 \\
\hline & 42. Fights with others. & 0 & 1 & 2 \\
\hline & 43. Is easily embarrassed. & 0 & 1 & 2 \\
\hline & 44. Argues with others. & 0 & 1 & 2 \\
\hline & 45. Threatens or bullies others. & 0 & 1 & 2 \\
\hline & 46. Talks back to adults when corrected. & 0 & 1 & 2 \\
\hline & 47. Has temper tantrums. & 0 & 1 & 2 \\
\hline & 48. Appears lonely. & 0 & 1 & 2 \\
\hline & 49. Gets angry easily. & 0 & 1 & 2 \\
\hline & 50. Shows anxiety about being with a group of children. & 0 & 1 & 2 \\
\hline & 51. Acts sad or depressed. & 0 & 1 & 2 \\
\hline & 52. Has low self-esteem. & 0 & 1 & 2 \\
\hline
\end{tabular}

SUMS OF HOW OFTEN COLUMNS Stop. Please check to be sure all items have been marked.

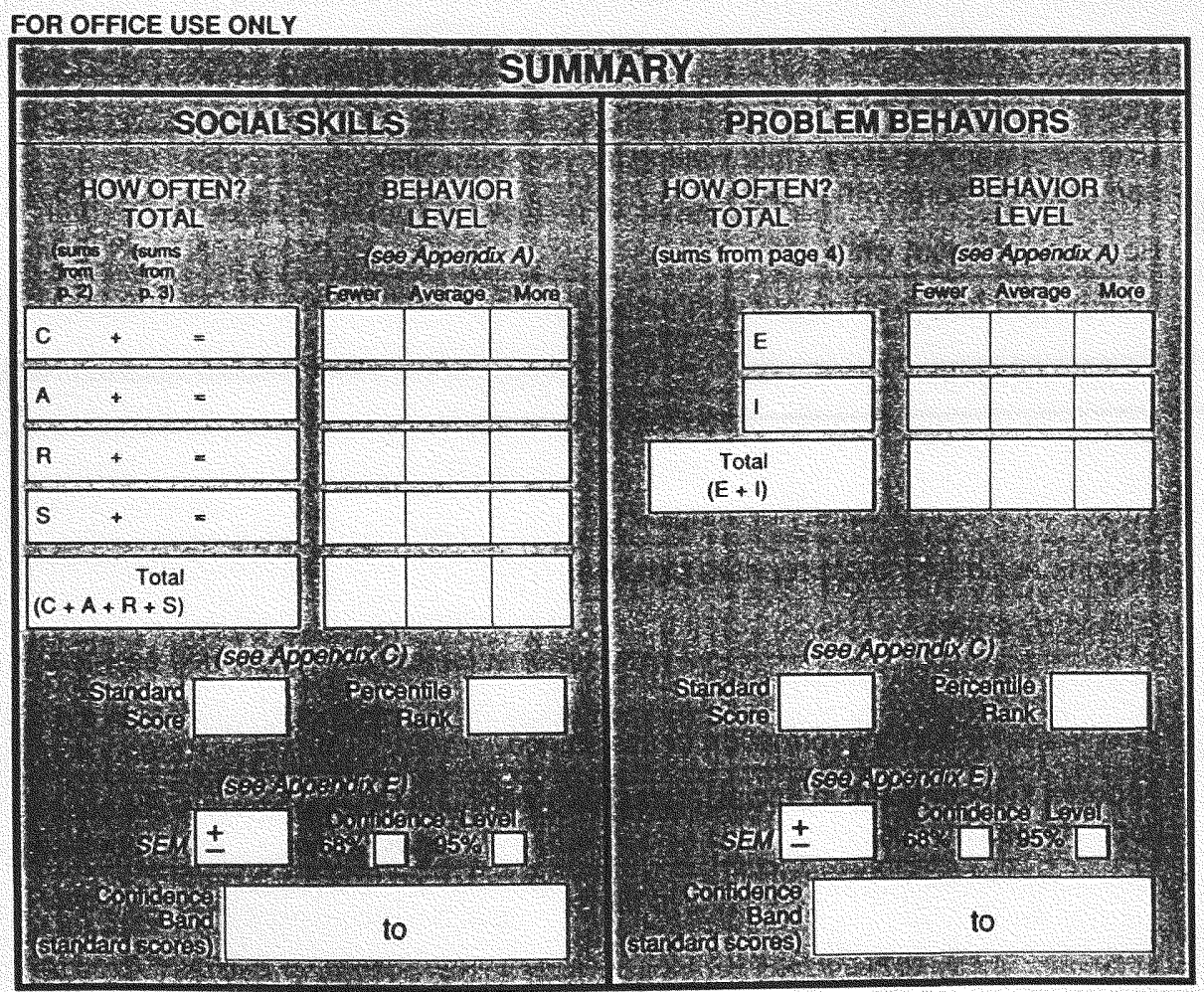


Directions

First write the information about yourself in the box below. Then turn to page 2 .

Stucient ate

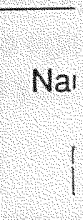

Grade

Age

Birth date

Month Day Year

School

Teacher's name 
This paper lists a lot of things that students your age may do. Please read each sentence and think about yourself. Decide how often you do the behavior described.

If you never do this behavior, circle the 0 .

If you sometimes do this behavior, circle the 1.

If you very often do this behavior, circle the 2 .

Then, decide how important the behavior is to your relationships with others.

If it is not important to your relationships, circle the 0 .

If it is important to your relationships, circle the 1 .

If it is critical to your relationships, circle the 2 .

Here are two examples:

\begin{tabular}{|c|c|c|c|c|c|c|}
\hline & \multicolumn{3}{|c|}{$\begin{array}{l}\text { How } \\
\text { Often? }\end{array}$} & \multicolumn{3}{|c|}{$\begin{array}{c}\text { How } \\
\text { Important? }\end{array}$} \\
\hline & Never & Sometimes & $\begin{array}{l}\text { Very } \\
\text { Otten }\end{array}$ & $\begin{array}{c}\text { Not } \\
\text { Important }\end{array}$ & Important & Critical \\
\hline I start conversations with classmates. & 0 & 1 & (2) & 0 & (1) & 2 \\
\hline I keep my desk clean and neat. & 0 & (1) & 2 & (0) & 1 & 2 \\
\hline
\end{tabular}

This student very often starts conversations with classmates, and starting conversations with classmates is important to this student. This student sometimes keeps his or her desk clean and neat but a clean and neat desk is not important to this student.

If you change an answer, be sure to erase completely. Please answer all questions. When you are finished, wait for further directions from your teacher. Be sure to ask questions if you do not know what to do. There are no right or wrong answers, just your feelings of how often you do these things and how important they are to you.

Bègin working when told to do so.

\begin{tabular}{|c|c|c|c|c|c|c|c|c|c|c|}
\hline \multicolumn{4}{|c|}{$\begin{array}{l}\text { JROFFICE USE } \\
\text { ONLY } \\
\text { How Otten? }\end{array}$} & \multirow[t]{2}{*}{$\therefore \therefore \therefore \cdots$} & \multirow{2}{*}{\multicolumn{2}{|c|}{$\begin{array}{l}\text { How } \\
\text { Often? } \\
\text { Sometimes }\end{array}$}} & \multirow[t]{2}{*}{$\begin{array}{l}\text { Very } \\
\text { Otten }\end{array}$} & \multicolumn{3}{|c|}{$\begin{array}{c}\text { How } \\
\text { Important? }\end{array}$} \\
\hline$c$ & $A$ & $E$ & S & & & & & & & \\
\hline & & & & 1. I make friends easily. & 0 & 1 & 2 & 0 & 1 & 2 \\
\hline & & & & $\begin{array}{l}\text { 2. I say nice things to others when they have done } \\
\text { something well. }\end{array}$ & 0 & 1 & 2 & 6 & $i$ & 2 \\
\hline & & & & $\begin{array}{l}\text { 3. I ask adults for help when other children try to hit me } \\
\text { or push me around. }\end{array}$ & 0 & 1 & 2 & 0 & 1 & 2 \\
\hline & & & & 4. I am confident on dates. & 0 & $\overrightarrow{1}$ & 2 & 0 & 1 & 2 \\
\hline & & & & $\begin{array}{l}\text { 5. I try to understand how my friends feel when they are } \\
\text { angry, upset, or sad. }\end{array}$ & 0 & 1 & 2 & 0 & 1 & 2 \\
\hline & & & & 6. I listen to adults when they are talking with me. & 0 & 1. & 2 & 0 & 1 & 2 \\
\hline & & & & $\begin{array}{l}\text { 7. I ignore other children when they tease me or call } \\
\text { me names. }\end{array}$ & 0 & 1 & 2 & 0 & 1 & 2 \\
\hline & & & & 8. I ask friends for help with my problems. & 0 & 1 & 2 & 0 & 1 & 2 \\
\hline & & & & 9. I ask before using other people's things. & 0 & 1 & 2 & 0 & 1 & 2 \\
\hline & & & & 10. I disagree with adults without fighting or arguing. & 0 & 1 & 2 & 0 & 1 & 2 \\
\hline & & & & $\begin{array}{l}\text { 11. I avoid doing things with others that may get me in } \\
\text { trouble with adults. }\end{array}$ & 0 & 1 & 2 & 0 & 1 & 2 \\
\hline & & & & 12. I feel sorry for others when bad things happen to them. & 0 & 1 & 2 & 0 & 1 & 2 \\
\hline
\end{tabular}




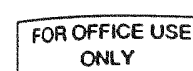

\begin{tabular}{|c|c|c|c|}
\hline \multicolumn{3}{|c|}{$\begin{array}{c}\text { ONLY } \\
\text { How Often? }\end{array}$} \\
\hline C & A & E & S \\
\hline & & & \\
\hline
\end{tabular}

\section{Social Skills (cont.)}

How

Often?

\section{How}

Nol

Important Important Critical

13. I do my homework on time.

Never Sometimes

Otten

\begin{tabular}{lll}
\hline 0 & 1 & 2 \\
\hline 0 & 1 & 2 \\
\hline
\end{tabular}

15. I do nice things for my parents like helping with household chores without being asked.

16. I am active in school activities such as sports or clubs.

17. I finish classroom work on time.

$\begin{array}{lll}0 & 1 & 2 \\ 0 & 1 & 2\end{array}$

18. I compromise with parents or teachers when we have disagreements.

$\begin{array}{lll}0 & 1 & 2 \\ 0 & 1 & 2 \\ 0 & 1 & 2\end{array}$

\begin{tabular}{lll}
0 & 1 & 2 \\
\hline 0 & 1 & 2 \\
\hline 0 & 1 & 2 \\
\hline
\end{tabular}

19. I ignore classmates who are clowning around in class. $\begin{array}{llll}0 & 1 & 2\end{array}$

20. I ask someone I like for a date.

0 1 2

21. I listen to my friends when they talk about problems they are having.

22. I end fights with my parents calmly.

23. I give compliments to members of the opposite sex.

24. I tell other people when they have done something well.

25. I smile, wave, or nod at others.

\begin{tabular}{lll}
0 & 1 & 2 \\
\hline
\end{tabular}

$\begin{array}{lll}0 & 1 & 2\end{array}$

0

$1 \quad 2$

26. I start conversations with opposite-sex friends without feeling uneasy or nervous.

27. I accept punishment from adults without getting mad.

0

28. I let friends know I like them by telling or showing them.

29. I stand up for my friends when they have been unfairly criticized.

30. I invite others to join in social activities.

31. I use my free time in a good way.

32. I control my temper when people are angry with me.

33. I get the attention of members of the opposite sex without feeling embarrassed.

\begin{tabular}{lll}
0 & 1 & 2 \\
\hline
\end{tabular}

34. I take criticism from my parents without getting angry.

35. I follow the teacher's directions.

\begin{tabular}{lll}
0 & 1 & 2 \\
\hline 0 & 1 & 2 \\
\hline 0 & 1 & 2 \\
\hline 0 & 1 & 2 \\
\hline 0 & 1 & 2 \\
\hline
\end{tabular}

38. I start talks with classroom members.

0 problem or an argument.

\begin{tabular}{lll}
0 & 1 & 2 \\
\hline 0 & 1 & 2 \\
\hline 0 & 1 & 2 \\
\hline 0 & 1 & 2 \\
\hline
\end{tabular}

\begin{tabular}{lll}
0 & 1 & 2 \\
\hline 0 & 1 & 2 \\
\hline 0 & 1 & 2 \\
\hline
\end{tabular}

\begin{tabular}{lll}
0 & 1 & 2 \\
\hline 0 & 1 & 2 \\
\hline 0 & 1 & 2 \\
\hline 0 & 1 & 2 \\
\hline 0 & 1 & 2 \\
\hline
\end{tabular}

\begin{tabular}{lll}
0 & 1 & 2 \\
\hline 0 & 1 & 2 \\
\hline 0 & 1 & 2 \\
\hline
\end{tabular}

\begin{tabular}{lll}
0 & 1 & 2 \\
\hline 0 & 1 & 2 \\
\hline 0 & 1 & 2 \\
\hline 0 & 1 & 2 \\
\hline
\end{tabular}

\begin{tabular}{lll}
0 & 1 & 2 \\
\hline 0 & 1 & 2 \\
\hline 0 & 1 & 2 \\
\hline 0 & 1 & 2 \\
\hline 0 & 1 & 2 \\
\hline 0 & 1 & 2 \\
\hline
\end{tabular}

39. I talk things over with classmates when there is a

Stop. Please check to be sure all items have been marked. 


\section{Rating System}

\section{Grades $7-12$ Social Skills Questionnaire}

Frank M. Gresham and Stephen N. Elliott

\section{Directions}

This questionnaire is designed to measure how often a student exhibits certain social skills and how important those skills are for success in your classroom. Ratings of problem behaviors and academic competence are also requested. First, complete the information about the student and yourself.

\section{Student Information}

Student's name

School

First

Middle

City

Date

Grade

Birth date

Month Day Year

Sex:

Month Day Year
State
State

Ethnic group (optional)

$\square$ Asian
$\square$ Black
$\square$ Hispanic
$\square$ Indian (Native American)
$\square$ White
Other

Is this student handicapped? $\square$ Yes $\square$ No

If handicapped, this student is classified as:

Learning-disabled

Behavior-disordered
Mentally handicapped

Other handicap (specify)

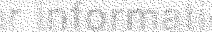

Teacher's name

First

Middle

Sex: $\square$ Female Male

What is your assignment?
[] Regular
Resource
Self-contained
Other (specify) 
Next, read each item on pages 2 and 3 (items 1 - 42) and think about this student's behavior during the past month or two. Decide how often the student does the behavior described.

If the student never does this behavior, circle the 0 .

If the student sometimes does this behavior, circle the 1 .

If the student very often does this behavior, circle the 2 .

For items 1-30, you should also rate how important each of these behaviors is for success in your classroom.

If the behavior is not important for success in your classroom, circle the 0 .

If the behavior is important for success in your classroom, circle the 1.

If the behavior is critical for success in your classroom, circle the 2.

Here are two examples:

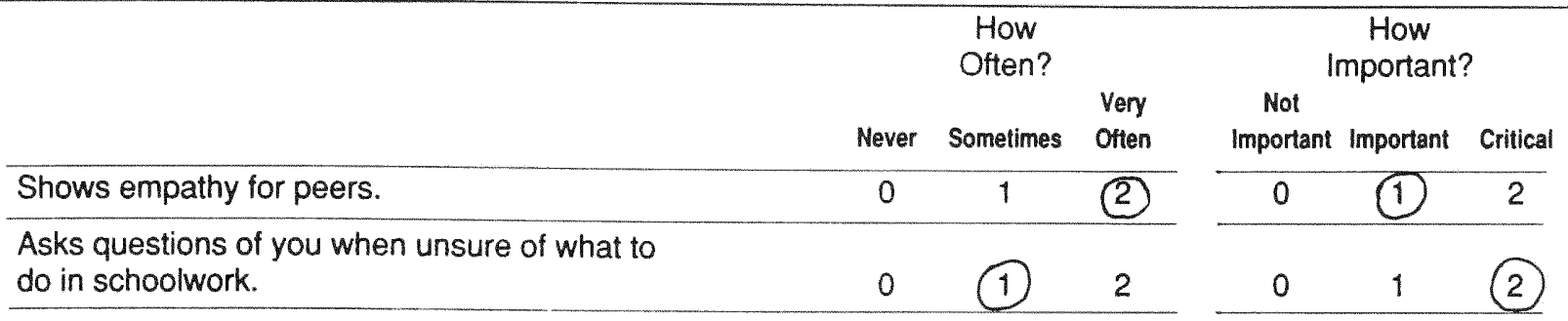

This student very often shows empathy for classmates. Also, this student sometimes asks questions when unsure of schoolwork. This teacher thinks that showing empathy is important for success in his or her classroom and that asking questions is critical for success.

Please do not skip any items. In some cases you may not have observed the student perform a particular behavior. Make an estimate of the degree to which you think the student would probably perform that behavior.

\begin{tabular}{|c|c|c|c|c|c|c|c|c|c|}
\hline \multicolumn{3}{|c|}{$\begin{array}{c}\text { FOR OFFICE USE } \\
\text { ONLY } \\
\text { How Otten? }\end{array}$} & & \multirow[b]{2}{*}{ Never } & \multirow[t]{2}{*}{$\begin{array}{c}\text { How } \\
\text { Often? } \\
\text { Sometimes }\end{array}$} & \multirow{2}{*}{$\begin{array}{l}\text { Very } \\
\text { Ofien }\end{array}$} & \multirow[t]{2}{*}{$\underset{\text { Not }}{\text { In }}$} & \multirow[t]{2}{*}{$\begin{array}{l}\text { How } \\
\text { mportant? } \\
\text { Important } \mathrm{C}\end{array}$} & \multirow[t]{2}{*}{ Critical } \\
\hline C & A & $\mathrm{S}$ & & & & & & & \\
\hline & & & 1. Produces correct schoolwork. & 0 & 1 & 2 & 0 & 1 & 2 \\
\hline & & & $\begin{array}{l}\text { 2. Keeps his or her work area clean without } \\
\text { being reminded. }\end{array}$ & 0 & 1 & 2 & 0 & 1 & 2 \\
\hline & & & $\begin{array}{l}\text { 3. Responds appropriately to physical aggression } \\
\text { from peers. }\end{array}$ & 0 & 1 & 2 & 0 & 1 & 2 \\
\hline & & & 4. Initiates conversations with peers. & 0 & 1 & 2 & 0 & 1 & 2 \\
\hline & & & 5. Volunteers to help peers on classroom tasks. & 0 & 1 & 2 & 0 & 1 & 2 \\
\hline & & & 6. Politely refuses unreasonable requests from others. & 0 & 1 & 2 & 0 & 1 & 2 \\
\hline & & & 7. Appropriately questions rules that may be unfair. & 0 & 1 & 2 & 0 & 1 & 2 \\
\hline & & & 8. Responds appropriately to teasing by peers. & 0 & 1 & 2 & 0 & 1 & 2 \\
\hline & & & 9. Accepts peers' ideas for group activities. & 0 & 1 & 2 & 0 & 1 & 2 \\
\hline & & & 10. Appropriately expresses feelings when wronged. & 0 & 1 & 2 & 0 & 1 & 2 \\
\hline & & & 11. Receives criticism well. & 0 & 1 & 2 & 0 & 1 & 2 \\
\hline & & & 12. Attends to your instructions. & 0 & 1 & 2 & 0 & 1 & 2 \\
\hline & & & 13. Uses time appropriately while waiting for your help. & 0 & 1 & 2 & 0 & 1 & 2 \\
\hline & & & $\begin{array}{l}\text { 14. Introduces himself or herself to new people without } \\
\text { being told to. }\end{array}$ & 0 & 1 & 2 & 0 & 1 & 2 \\
\hline & & & $\begin{array}{l}\text { 15. Compromises in conflict situations by changing } \\
\text { own ideas to reach agreement. }\end{array}$ & 0 & 1 & 2 & 0 & 1 & 2 \\
\hline
\end{tabular}




\begin{tabular}{|c|c|c|c|c|c|c|c|c|c|}
\hline \multicolumn{3}{|c|}{$\begin{array}{c}\text { FOR OFFICE USE } \\
\text { ONLY } \\
\text { How OHen? }\end{array}$} & \multirow[t]{2}{*}{ Social Skills (cont.) } & \multirow{2}{*}{\multicolumn{2}{|c|}{$\begin{array}{c}\text { How } \\
\text { Often? } \\
\text { Never Sometimes }\end{array}$}} & \multirow{2}{*}{$\begin{array}{l}\text { Very } \\
\text { Otten }\end{array}$} & \multirow{2}{*}{$\begin{array}{c}\text { Not } \\
\text { Important } \\
\end{array}$} & \multirow{2}{*}{$\begin{array}{l}\text { How } \\
\text { mportant? } \\
\text { Important }\end{array}$} & \multirow[b]{2}{*}{ Critical } \\
\hline $\mathrm{C}$ & A & S & & & & & & & \\
\hline & & & 16. Acknowledges compliments or praise from peers. & 0 & 1 & 2 & 0 & 1 & 2 \\
\hline & & & $\begin{array}{l}\text { 17. Easily makes transition from one classroom } \\
\text { activity to another. }\end{array}$ & 0 & 1 & 2 & 0 & 1 & 2 \\
\hline & & & 18. Controls temper in conflict situations with peers. & 0 & 1 & 2 & 0 & 1. & 2 \\
\hline & & & 19. Finishes class assignments within time limits. & 0 & 1 & 2 & 0 & 1 & 2 \\
\hline & & & $\begin{array}{l}\text { 20. Listens to classmates when they present their } \\
\text { work or ideas. }\end{array}$ & 0 & 1. & 2 & 0 & 1. & 2 \\
\hline & & & $\begin{array}{l}\text { 21. Appears confident in social interactions with } \\
\text { opposite-sex peers. }\end{array}$ & 0 & 1. & 2 & 0 & 1 & 2 \\
\hline & & & 22. Invites others to join in activities. & 0 & 1 & 2 & 0 & 1 & 2 \\
\hline & & & 23. Controls temper in conflict situations with adults. & 0 & 1 & 2 & 0 & 1 & 2 \\
\hline & & & 24. Ignores peer distractions when doing class work. & 0 & 1 & 2 & 0 & 1. & 2 \\
\hline & & & $\begin{array}{l}\text { 25. Stands up for peers when they have been } \\
\text { unfairly criticized. }\end{array}$ & 0 & 1 & 2 & 0 & 1 & 2 \\
\hline & & & 26. Puts work materials or school property away. & 0 & 1 & 2 & 0 & 1 & 2 \\
\hline & & & $\begin{array}{l}\text { 27. Appropriately tells you when he or she thinks you } \\
\text { have treated him or her unfairly. }\end{array}$ & 0 & 1 & 2 & 0 & 1 & 2 \\
\hline & & & 28. Gives compliments to members of the opposite sex. & 0 & 1 & 2 & 0 & 1 & 2 \\
\hline & & & 29. Complies with your directions. & 0 & 1 & 2 & 0 & 1 & 2 \\
\hline & & & 30. Responds appropriately to peer pressure. & 0 & 1 & 2 & 0 & 1 & 2 \\
\hline
\end{tabular}

\begin{tabular}{|c|c|c|c|c|c|}
\hline \multicolumn{2}{|c|}{$\begin{array}{l}\text { FOR OFFICE } \\
\text { USE ONLY } \\
\text { How Often? }\end{array}$} & \multirow[t]{2}{*}{ Problem Behaviors } & \multirow{2}{*}{\multicolumn{2}{|c|}{$\begin{array}{c}\text { How } \\
\text { Often? } \\
\text { Sometimes }\end{array}$}} & \multirow{2}{*}{$\begin{array}{l}\text { Very } \\
\text { Ofter }\end{array}$} \\
\hline$E$ & 1 & & & & \\
\hline & & 31. Likes to be alone. & 0 & 1 & 2 \\
\hline & & 32. Fights with others. & 0 & 1 & 2 \\
\hline & & 33. Is easily embarrassed. & 0 & 1 & 2 \\
\hline & & 34. Argues with others. & 0 & 1 & 2 \\
\hline & & 35. Threatens or bullies others. & 0 & 1 & 2 \\
\hline & & 36. Talks back to adults when corrected. & 0 & 1 & 2 \\
\hline & & 37. Has temper tantrums. & 0 & 1 & 2 \\
\hline & & 38. Appears lonely. & 0 & 1 & 2 \\
\hline & & 39. Gets angry easily. & 0 & 1 & 2 \\
\hline & & 40. Shows anxiety about being with a group of children. & 0 & 1 & 2 \\
\hline & & 41. Acts sad or depressed. & 0 & 1 & 2 \\
\hline & & 42. Has low self-esteem. & 0 & 1 & 2 \\
\hline
\end{tabular}


Appendix F

Data Entry Sheet 


\section{Data entry sheet \\ name ( not to be entered)}

ID number

group 1= Experimental $2=$ control

grade

age

sex $1=$ male $2=$ female

ethnicity $1=$ white $2=$ hispanic $3=$ black $4=$ other

primary language $1=$ English $2=$ Spanish $3=$ other

reading level

reading percentile

spelling level

IQ score FS

IQ score (verbal)

SS teacher score

SS teacher score (post)

SS parent score

SS parent score (post)

SS student score

SS student score (post)

SS competency score

SS competency score (post)

Word fluency score (WJPB)

Word fluency score (post)

Word samples score (WJPB)

Word samples score (post)

Thematic maturity (TOWL)

Thematic maturity (post)

Syntactic maturity (TOWL) Syntactic maturity (post) 
Appendix G

Process Writing Approach \&

Lesson Plan Topics 
Writing Process

I. Prewriting

a. create context for writing

1. function

2. model

3. content, pattern \& style

b. get ready to write

1. establish purpose and audience

2. review selection

3. brainstorm writing ideas

4. organize \& categorize ideas

II. Composing

a. write first draft : focus on getting ideas down on paper

b. conference: either with teacher, with a peer or a group

III. Post writing

a. edit \& revise

1. re-read

2. re-think

3. conference with teacher/peer/group

4. improve story elements (plot, setting, characters, theme)

5. improve mechanics (vocabulary, grammar, sentence structure)

b. share \& publish

1. publish to read

2. display

3. present writing by reading it aloud to others

4. talk with others

5. obtain reactions to writing 
Appendix $\mathrm{H}$

Scope and Sequence of

Writing Topics 
I. Sharing Experiences

- 1. Biographies

2. Autobiographies

3. journals and logs

4. poetry anthology

II. Giving Directions

1. cookbooks

2. rules in a game

3. posters

III. Playing with words

1. jokes and riddle

- 2. slogans

3. codes and ciphers

4. telegrams

5. vocabulary games

IV. Stating Opinions
1. essay
2. advertisements
3. advice columns
4. poetry
5. book reviews
6. proverbs
7. panel discussions

V. Patterning stories

1. picture book

2. fantasy

3. character studies

4. comic books (super heroes)

5. sounds

VI. Giving Information

1. magazine articles

2. reference materials

3. encyclopedia

4. maps and atlases 


\section{Appendix I}

Sample of Student Tests 
STORY

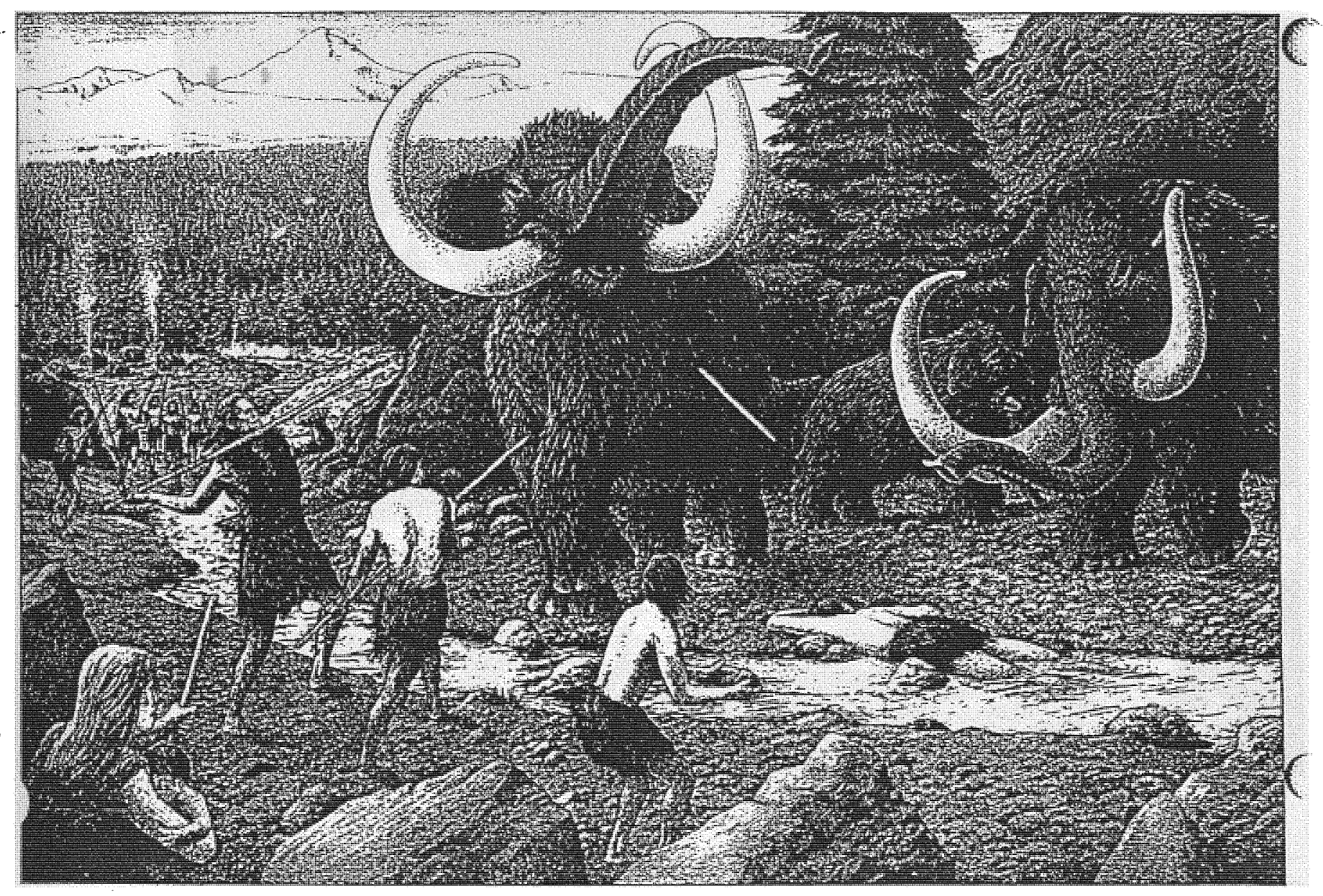

The men are hunting a animal.

118 
Story

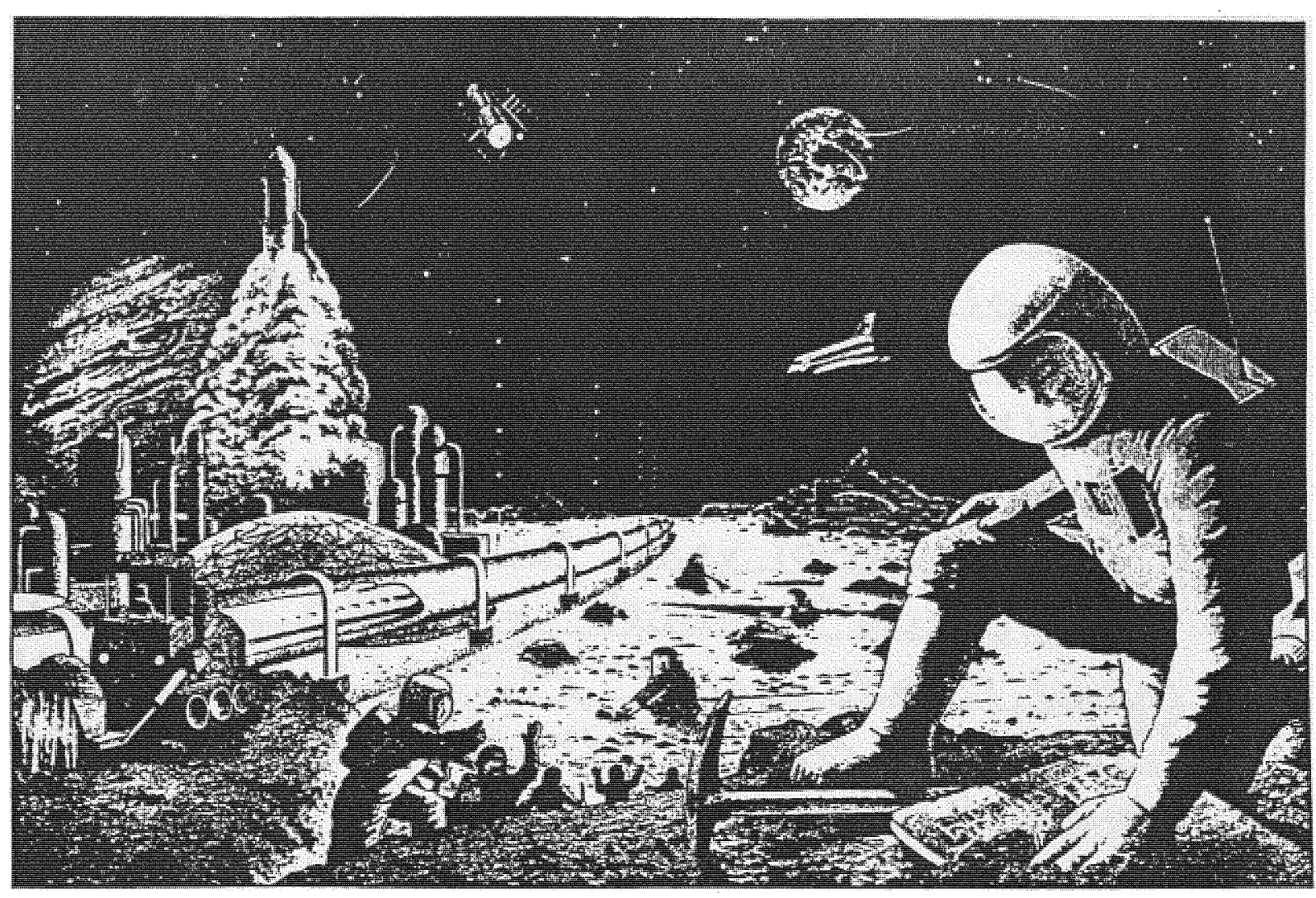

Hi! Mynane s John.

I live in the time 2096 AD said John. We ard billing a city on the moon. said John.

This is, my friend. Jim. said John Jim in the commuter of the city, the reason we are building a city on the moon w that the est th going to eire two years ag there was a nuclear wa between North korea and south Bared, North Korea was winning the war, but then the North 1 morea's misicmized the ty of sean

119 
Korea they hit Togo, and 3 million oceich dire that day and at least a more million oops sill diefrum the unclear reaction and Japan didu't take that if vas a mistake they launched 122 their mise les at North Fired then the Unific sties demanded they stay the of t' but the North Korea knew

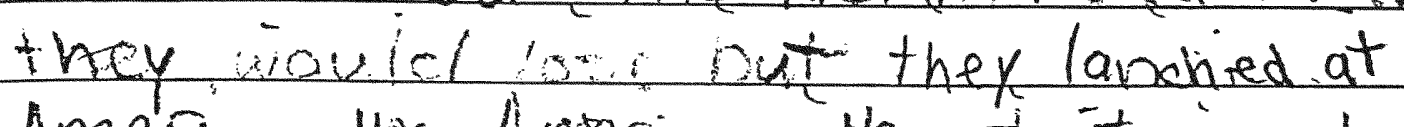
America the Arteries thai it was fanon

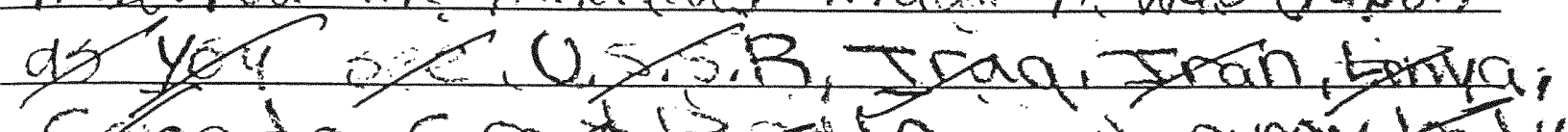
Grenada, Great isatin, every body

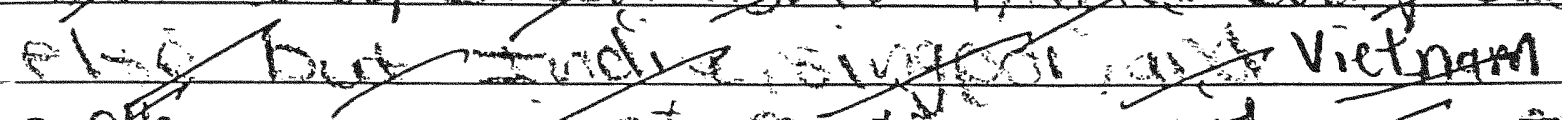
earth was a giant reaction night the are the las y pops less angst John

(If more space is needed, ask for another sheet of paper.)

120 


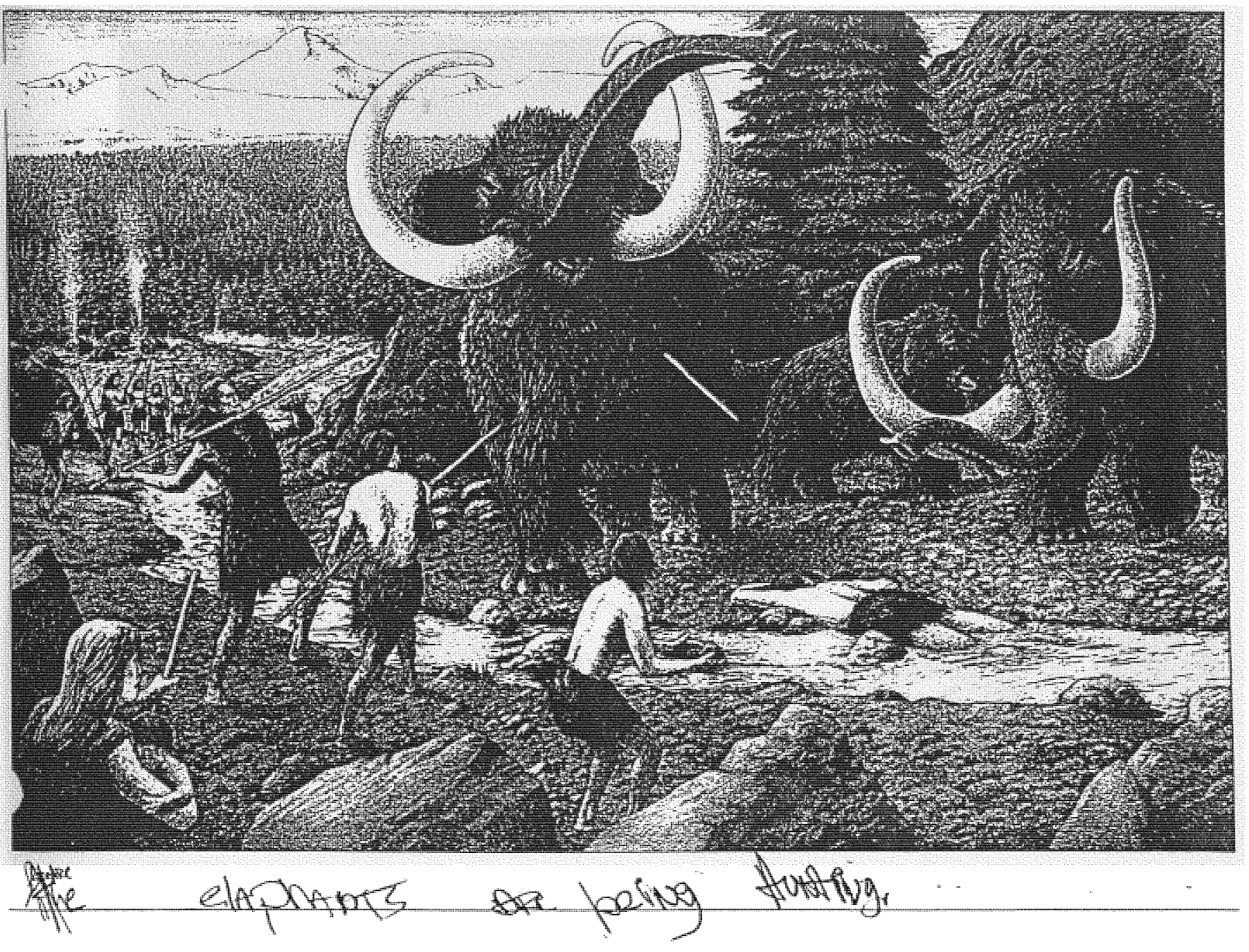


Story

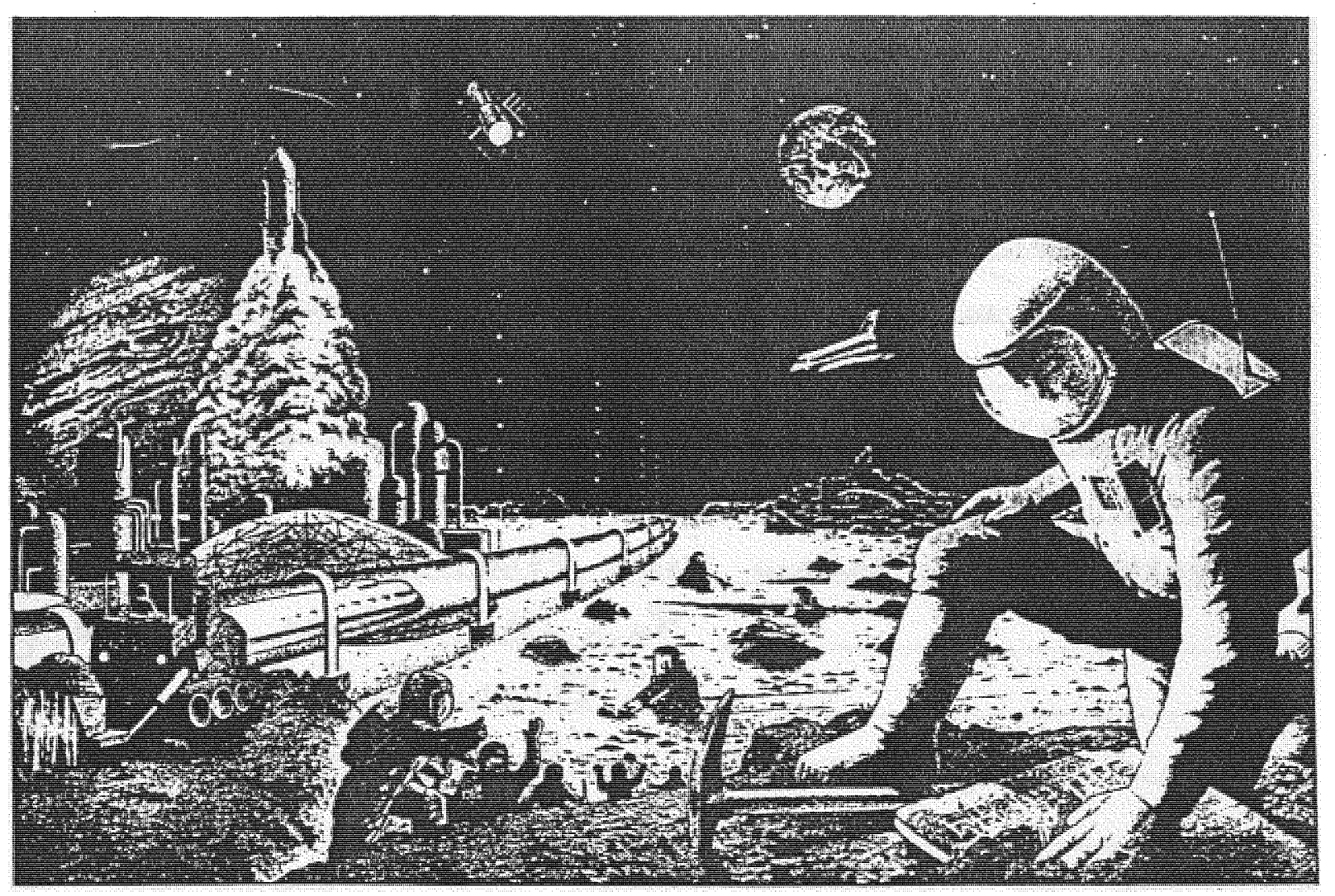

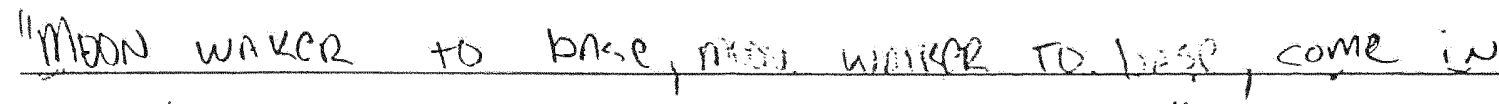
Dace"." We here you more wo usp, what is it". I Just found. A tabes wi al out of steel" What's it say?" I DON't know it. whiten in some forked language" Bring it into base imoinitly moon usaiveri"yes sir:" 47

MOON walker got up, AND, tURNeD GRCUND. He Sow About 5 people in. black uniforms slolwy oaring toward) him.

All of $A$ sunder A. Radio transmision came on the 76 rico it saida. "Give me the steel tablet."

"No"

"NO SOS"

"Or else what"? 8 r

122 
"Then will have to use force."

Mod n walker looked row n at his laser in his elf. 105 There was only 1 charge left. H cOuld only take one out A no The pt surely kill him.

Moor walker to base come in base" "It's NO use", SAiD A voice, wive got a TRANSmiter signal blocking your RADIO."

"Why do yo" want the tablet." MOON walker AskeD on easy. "Why do you want it, hub, bines"? "I DON waNt it base wants it."

Well ain that a pity solider, huh, You ReADy to biC for base i" 1 OO copt

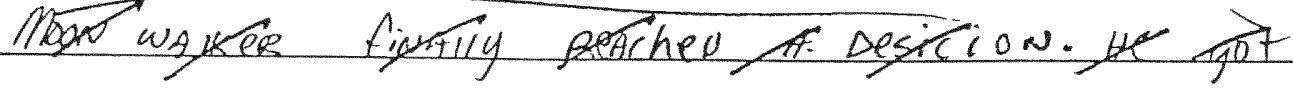
up tubed of his bet pack sw i flem the opposite digestion aus modem was meg has faster Tetpers. but they Dion' follow they. Just let nim flo All of a super his tet pack, went hay wire, it shot strait wp it was heADing fOR The Atmosphere. It WAS gINA Erie him like toAst. "If we cant have it coloring can solder."

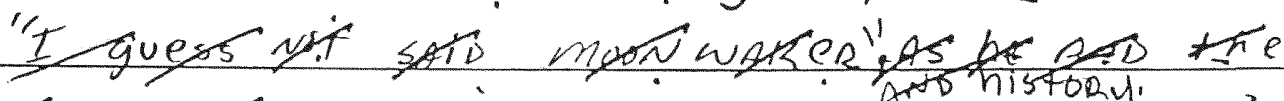
toltec that contpinco the wame of the planet

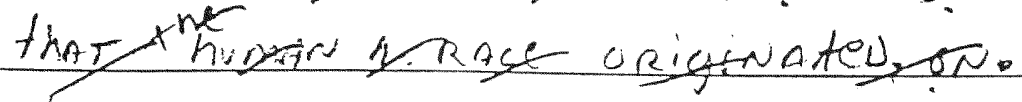

(If more space is needed, ask for another sheet of paper.)

123 
Appendix J

Instructional Model for

Social Skill Instruction

and Lesson Topics 


\begin{tabular}{ll} 
Lesson \# & \multicolumn{1}{c}{ Skill } \\
\hline 1 & Making transitions \\
2 & Paying attention \\
3 & Making transitions \\
4 & Paying attention \\
5 & Making positive self-statements \\
6 & Paying attention \\
7 & Giving a compliment to peer \\
8 & Making transitions \\
9 & Giving a compliment to a peer \\
10 & Making positive self-statements \\
11 & Volunteering to help peers with classroom tasks \\
12 & Paying attention to a speaker \\
13 & Making positive self-statements \\
14 & Volunteering to help pers \\
15 & Paying attention to a speaker \\
16 & Making positive self-statements \\
17 & Volunteering to help peers \\
18 & Paying attention to a speaker \\
19 & Responding to a compliment from a peer \\
20 & Accepting peer's suggestion for group activities \\
21 & Receiving criticism well \\
22 & Responding to a compliment from a peer \\
23 & Accepting peer's suggestion for group activities \\
24 & Receiving criticism well \\
25 & Accepting peer's suggestion for group activities \\
26 & Responding to a compliment from a peer \\
27 & Cooperating with others without prompting \\
28 & Receiving criticism well \\
29 & Compromising in situations with peers and adults to reach agreement \\
30 &
\end{tabular}


Joining ingoing groups without prompting

Compromising in situations

Making positive self-statements

Joining ongoing activities

Saying nice things

Giving a compliment to a peer

Saying nice things

Joining ongoing groups

Volunteering to help peers

Paying attention to a speaker

Saying nice things

Giving a compliment to a peer

Volunteering to help peers

Making positive self-statements

Paying attention to a speaker

- Giving a compliment to a peer

Saying nice things

Volunteering to help peers

Compromising in situations

Joining ongoing activities

Volunteering to help peers

Making positive self statements

Saying nice things

Giving a compliment

Paying attention to a speaker

Joining ongoing activities

Making positive self-statements

Compromising in situations

Volunteering to help 
Social skill

Domains and Subdomains

and Behavioral objectives

Main goal: to provide students with social skills training which will assist them in relating to othors, supporting others, encouraging others, and helping others in group activities related to writing.

\section{Cooperation}

working and classroom interaction skills

1. makes transition from classroom activity to another without wasting time or interrupting others

2. finishes classroom assignment within time limits

3. produces correct school work

4. puts materials in their proper place

-5. pays attention to and follows teacher directions

6. uses time appropriately while waiting for assistance

7. listens to feedback from peers regarding suggestions for revisions

8. accepts role in group activity

\section{Assertion}

conversation and joining skills

1. gives a compliment to a peer

2. gives feedback in editing activities

3. makes positive self-statements about own work and ideas

4. joins and participates in group activities

5. volunteers for individual task in a group activity

6. invites others to join in an activity

7. convinces others to see point of view

8. expresses feelings about one's idea in a group 


\section{Responsibility}

1. asks teacher or group member for assistance

2. pays attention to speaker in a group

3. responds to feedback from group member

4. responds to a compliment from a peer

5. completes tasks of given role and supports other group members in their roles

6.

7.

\section{Empathy}

1. tells adult or group member when they do something for student that he or she likes or appreciates

2. says nice things to others when they do something nice

3. gives non-verbal greeting or acknowledges others

4. listens to adults/group members when instructions are given

5. responds appropriately to persuasion

6. responds appropriately to the feelings and ideas of others

\section{Self- control}

1. accepts peer suggestions for group activities

2. responds to peer pressure appropriately

3. cooperates with peers in a group activity

4. compromises in conflict situations with peers or adults by changing ideas to reach agreement

5. responds to teasing from peers appropriately

6. controls temper in conflict situations

7. receives criticism well 


\section{Instructional Model for Social Skill Units}

from Social Skill Intervention Guide

(F.M. Gresham, 1992). American Guidance Service

1. Greet students and introduce session objective.

2. Define featured social skill.

3. Initiate Tell Phase.

4. Initiate Show Phase.

5. Initiate Do Phase with role play.

6. Review skill and assign homework.

7. Provide feedback about group performance and specify date and time of next performance.

\section{TELL PHASE}

1. Introduce the skill by asking questions listed in the specific skill unit. With these questions you will establish the following:

a. students understand what is meant by the skill.

b. students understand the words used to describe the skill.

c. students have some ideas about ways they might use the skill.

d. students are aware of the feelings related to use or non-use of skill.

e. students can recall times when they've needed this skill.

2. Read and discuss the skill definition. Emphasize the key terms in the skill unit.

3. Establish the rationale for the importance of the skill. Do this by using the rationale statements in the skill unit and by asking questions that focus on the benefits of using the skill correctly and appropriately. Prompt students as needed to elicit the reasons/rationale listed in the skill unit.

4. Identify the skill steps. Note that these steps, specific to each skill unit, are the ones the students need to master to perform the skill correctly and appropriately. Be sure that the students understand each skill step and the sequence of steps. Discuss each skill step. Ask the students to repeat the steps in the proper sequence. If possible, write the skill steps on the board so that the students may use the written steps as a reminder. 


\section{SHOW PHASE}

1. Model the skill by using one of the situations specific to the skill unit. Since most skills involve a dialogue or situation between two people, you may wish to enact the skill with an aide, another teacher, or a student. Begin by explaining the situation. As you enact the situation, demonstrate each skill step in its proper sequence. Enact the skill a second time. This time, however, use the suggestions for negative modeling as given in the specific skill unit to enact the skill incorrectly.

2. Model the skill again. This time, explain and comment on each skill step as you perform it.

3. Role play a situation with a student. Role play at least twice, showing different ways the skill steps might be performed.

4. Discuss alternative ways of communicating in the presentations. If necessary, refine the students' understanding of the skill by enacting additional role plays.

5. Repeat the role plays by using situations appropriate to your students' lives. Ask students to suggest situations for which they would find this skill useful.

Do Phase

1. Ask the students to define the skill. Prompt students, as necessary, to repeat the skill definition that you presented in the Tell Phase. Ask for the definition that until at least half of the students have repeated it.

2. Ask the students who did not define the skill in the preceding activity to tell why this skill is important. As needed, prompt students to give the rationale/reasons that were mentioned in the Tell Phase. Discuss the reasons, clarifying any ideas that are unique or inappropriate.

3. Ask students to identify the skill steps. List them in the proper order on a chalkboard or flip chart. When the students have identified all the skill steps, read out loud together in their proper sequence. As appropriate, ask students to think of words, abbreviated phrases, or images they can use to remind them of each step.

4. Have students practice the skill. Invite pairs of students to enact the situations specific to the skill unit. After each enactment, provide feedback to the students who performed the skill. For example, ask all the observers whether the performers used all the skill steps. 
Encourage students to comment first on steps the performers did well. Then invite students to comment on what the performers might have done differently.

Provide your own informative feedback to students involved in the role plays.

5. Continue by role playing additional situations suggested by the students. Provide information feedback and invite student feedback.

\section{Follow Through and Practice Phase}

Note that each skill unit provides specific follow-through and practice activities. You will want to review periodically. Do this review in the next session and plan a review at the end of a longer period of time.

\section{Generalization Phase}

Note that each skill unit provides specific generalization activities that help students internalize the skill by relating it to their own lives and experiences. Use or more generalization activities to help students maintain the skill you have taught during the training session. 
Appendix $\mathrm{K}$

Strategies for Social Skill Training 


\section{Table 3.1}

\section{Guidelines for Using Modeling}

\section{Establish the Need to Learn the Skill}

To sell a social skill to students, consider doing the following:

a. Ask students why the skill might be important to them.

b. Point out potential consequences of using or not using the skill.

c. Use examples from books, television, movies, etc., in which characters use the skill.

d. Identify situations in which the skill could come in handy for students.

\section{Identify Skill Components}

To help students know what steps and in what order they must perform the behavior in question, analyze the steps of the social skill by doing the following:

a. Present a social skill (e.g., starting a conversation).

b. Brainstorm what the students would have to do to start a conversation with someone else.

c. Write all the students' euggestions on a chalkboard or flip chart.

d. Discuss with the group the relevance of each suggestion. With the group, decide what behaviors would be important and unimportant and why.

e. Decide with the group the list of behaviors that would be most important in performing the skill in question.

f. Decide with the group the order in which they should perform the behaviors. Identify potential problems that might occur in performing the skill (e.g., the other person ignores the one trying to initiate a conversation.).

3. Present the Modeling Display

a. Decide if you or a student will model the skill.

b. Point out the chalkboard or flip chart list of skills that are necessary for performing the skill.

c. Before presenting the modeling display, review the steps to be performed.

d. Instruct students to watch and see if each step is performed in the proper sequence.

e. Model the skill for the group or have a student model the skill.

f. After modeling, invite the students to evaluate the modeling sequence. Discuss their comments.

4. Rehearse the Skill

To help the students remember the steps of the behavior, invite different students to model the skill for the group.

\section{Provide Specific Feedback}

a. Point out the correct things students did in performing the skill.

b. Offer suggestions for how the students might improve their performance. If necessary, remodel the skill and have students rehearse once again.

\section{Program for Generalization}

a. Role-play a number of different situations in which the skill would be appropriate. Vary these situations as much as possible in terms of who, what, when, and where the skill will be performed.

b. Teach a number of different ways in which the students could perform the skill. Since an infinite number of ways exist in which people can have a conversation, teach a sufficient number so that the students can generalize the skill. 


\section{Table 3.2}

\section{Guidelines for Using Behavior Rehearsal}

A. Conert Rehearsal

1. Have students close their eyes. Then present a scene involving social interaction.

2. Have students imagine themselves engaging in a particular social skill in the scene.

3. Have students imagine how the other people in the scene will respond to their behavior.

4. Have students imagine alternative acceptable behaviors they could perform in the same social situation and the consequences associated with each behavior.

B. Verbal Rehearsal

1. Present a social situation involving social interaction.

2. Have students specify each step involved in performing a social skill.

3. Have students orally arrange these steps in proper sequence.

4. Have students describe situations in which the social skill would be appropriate.

5. Have students describe the potential consequences of performing the social skill.

6. For each situation, have students describe alternative social behaviors and the consequences associated with each behavior.

\section{Overt Rehearsal}

1. Describe a role-play situation, select participants, and designate roles for each participant.

2. Have participants role-play the social situation; instruct observers to watch the performances of each participant closely

3. Discuss and evaluate the performances in the role-play and provide suggestions for improved performance.

4. Ask the participants to incorporate the feedback suggestions a they replay the scene.

5. Select new participants to role-play the same social situation.

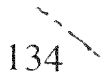




\section{Table 3.3}

\section{Guidelines for Using Coaching}

1. Present a social concept. For example, ask the group what is meant by cooperation.

2. Ask for definitions of the given social concept.

3. Provide clarification for the group's definition of a social concept. For example, say, "Cooperation could also mean . . as well as ...."

4. Ask for specific behavioral examples of the concept. For example, say, "What are some things people might do to show they are cooperating?"

5. Ask for specific behavioral nonexamples of the concept. For example, say, "What are some things people might do to show they were not cooperating?"

6. Elicit potential outcomes for performing the skill and for not performing the skill.

7. Generate situations and settings in which the skill would be appropriate; generate situations and settings in which the skill - would be inappropriate.

8. Use behavior rehearsal to practice the skill.

9. Use specific informative feedback about behavior rehearsal.

10. Based on feedback of the initial behavior rehearsal, have students replay the skill.

Step 8 requires behavioral enactment of the social skill. At this point, the students translate the description and their comprehension of the concept into an actual behavioral sequence. Behavioral rehearsal takes place in the context of a role-play situation based on the situations and settings generated in Step 7. Following behavioral rehearsal, you will provide specific informative feedback regarding skill performance.

Social Problem-Solving. Through the use of social problem-solving, children can process how to solve interpersonal problems. This pragmatic approach teaches alternative adaptive solutions (Goldfried \& D'Zurilla, 1969). You can use social problem-solving with individual children, with small groups, or within entire classrooms (Spivack \& Shure, 1982). However, this approach does not focus upon discrete social skills training and is most useful with highly motivated students who have relatively well-developed cognitive and verbal skills. Social problem-solving involves many of the procedures and processes encompassed in modeling, coaching, and behavoral rehearsal.

Table 3.4 presents some general guidelines for using social problem-solving in a small group format. 


\section{Table 3.4 \\ Guidelines for Social Problem-Solving}

1. Provide a general orientation to the problem. Indicate that many ways exist to solve problems with others in a socially appropriate manner. Explain that just as students can solve math problems, so too can they solve social problems. Stress that they can always find an answer.

2. Define and formulate the problem by asking the students questions like the following: What exactly is the problem? What are the facts concerning the problem? Are you just being angry or upset instead of trying to find out what is really going on in this situation?

3. Generate alternative solutions to the problem by brainstorming as many solutions as possible. Stress that the students need not be concerned about how good these solutions are. Make a list of all the solutions brainstormed by the students.

4. Specify consequences of each alternative solution identified in the brainstorming.

5. Based on the consequences the students discussed, invite the students to choose the solution they consider best.

6. Specify the requirements necessary to implement the solution. That is, identify who, what, when, where, and how.

7. Verify the outcomes of the solution. To do this, ask the students questions like the following: Did the solution work? Could you have achieved a better outcome by performing the solution in a different or better way? How could you achieve a better outcome by modifying what you did?

As shown in Table 3.4 , in social problem-solving you first teach students how to define a social problem. For example, a child may want to play a game with others at recess but is excluded from the group. A child might offer the following definition of this problem: "I want to play and others won't let me. This makes me feel bad."

Step 2 in social problem-solving is to help children formulate a goal statement that identifies what they want from is particular social interaction (e.g., to get to know someone better, to have fun, to win a game, and so on). In Step 3 , the students brainstorm alternative solutions. The intent of this step is to teach children to offer numerous solutions to the problem without considering the feasibility of each solution.

In Step 4 of social problem-solving, students consider the consequences of each solution they brainstormed. In Step 5 , they choose the best solution to the problem based on 930 sideration of the consequences. In Step 6 , the stu- 